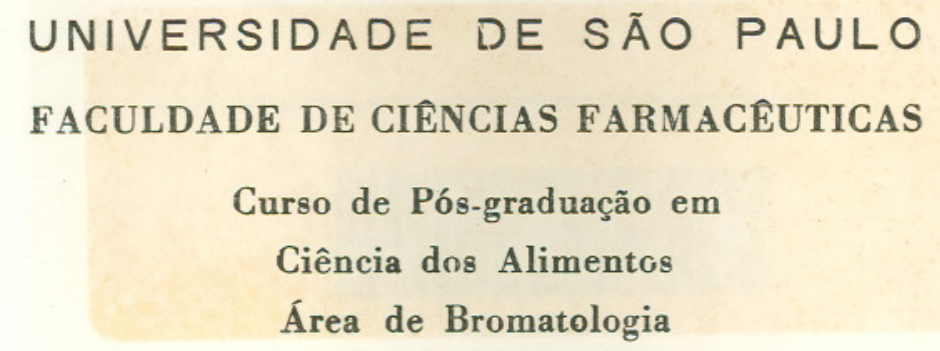

\title{
DESENVOLVIMENTO DE BASES GORDUROSAS PARA MARGARINAS CREMOSAS POR INTERESTERIFICAÇÃO
}

LUIZ ANTONIO GIOIELLI

Tese para obtenção do grau de DOUTOR

Orientador:

Prof. Dr. RENATO BARUFFALDI

$$
\begin{aligned}
& 10963 \\
& \text { São Paulo }
\end{aligned}
$$


A minha esposa

Maria Lücia.

Aos meus filhos

Maria Fernanda e

Luiz Henrique. 


\section{AGRADECIMENTOS}

Ao Prof.or. Renato Baruffaldi, pela orientação e incentivo.

Ao Prof.or. Eugênio Aquarone, pelo convite para o ingresso na carreira universitāria.

Aos colegas Prof. Dr. Michele Vitolo, Prof. Ricardo Schuch e Prof. Ronaldo Nogueira de Moraes Pitombo, pelo auxilio e sugestões.

A Farmacêutica-bioquimica Etsuka Otaki pela valiosa colaboração na parte experimental.

A Anderson Clayton S.A., na pessoa do Farmacêu tico Deodato Rodrigues Alves, pelo auxilio e informações pres tadas.

A SANBRA, Sociedade Algodoeira do Nordeste Bra sileiro S.A., pela possibilidade de acesso à sua biblioteca.

A Maria Amélia Rocha Costa, pela revisão das referências bibliogräficas.

A todos aqueles que, direta ou indiretamente, contribuiram para a realização deste trabalho. 
Pāg.

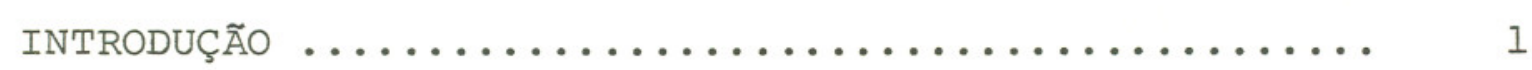

1. Métodos de modificação .................... 3

1.1 - Fracionamento ................... 3

1.2 - Hidrogenação $\ldots \ldots \ldots \ldots \ldots \ldots \ldots \ldots \ldots \ldots$

1.3 - Interesterificação ............... 6

1.3.1 - Mudanças de composição ........ 7

1.3 .2 - Métodos de detecção ........... 10

1.3 .3 - Processo industrial ........... 11

1.3 .4 - Aplicações ............... 12

1.3 .5 - Interesterificação dirigida ..... 13

1.3.6 - Interesterificação catalisada por enzimas ............... 14

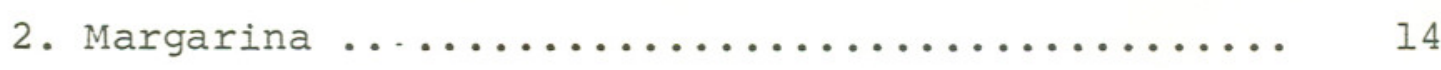

2.1 - Fabricação de margarina $\ldots \ldots \ldots \ldots \ldots \ldots 18$

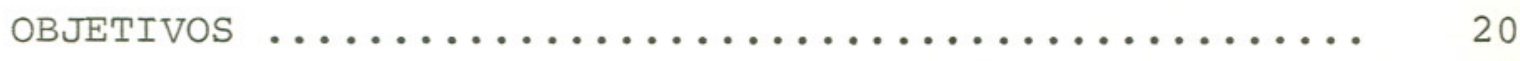

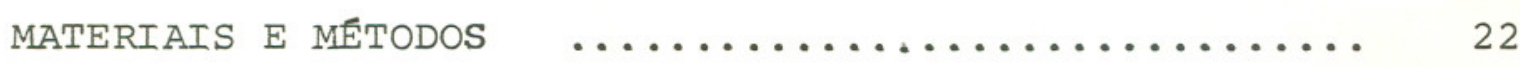

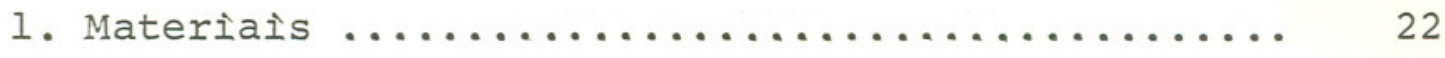

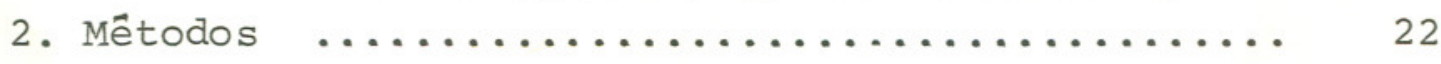

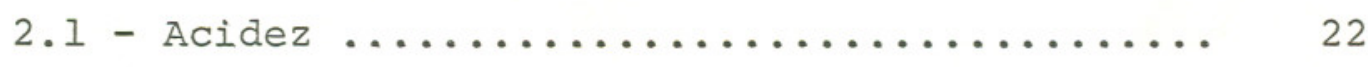

2.2 - Indice de peróxido ................ 22

2.3 - Ponto de fusão e ponto de amolecimento ... 22

2.4 - Matēria insaponificāvel ............. 23

2.5 - Indice de saponificação ............. 23 
Pāg.

2.6 - Indice de iodo .................... 23

2.7 - Indice de gordura sölida $\ldots \ldots \ldots \ldots \ldots \ldots . \ldots 23$

2.8 - Esterificação de ácidos graxos .......... 23

2.9 - Composição em ácidos graxos .............. 23

2.10 - Composição em triglicérides ............ 25

2.11 - Hidrólise enzimätica ................ 26

2.12 - Estabilidade à oxidação ............... 26

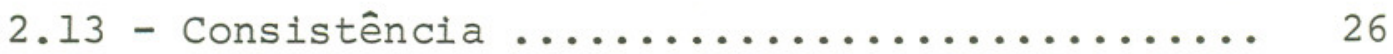

2.14 - Cálculo da composição gliceríaica ....... 26

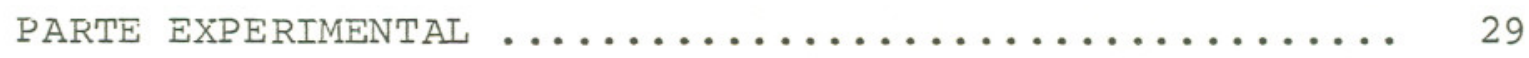

1. Caracterização das matērias-primas ........... 29

2. Reações de interesterificação $\ldots \ldots \ldots \ldots . . . . .30$

3. Mistura de gorduras rearranjadas isoladamente... 32

4. Aåição do óleo de soja ..................... 32

5. Preparação de margarinas $\ldots \ldots \ldots \ldots \ldots \ldots \ldots \ldots \ldots \ldots$

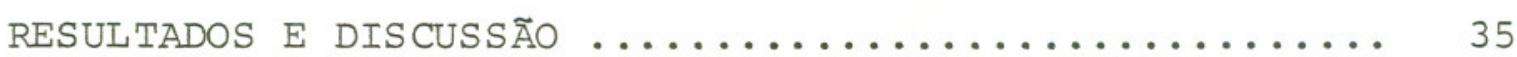

1. Matërias-primas ........................ 35

2. Reações de interesterificação ............... 39

2.1 - Pontos de fusão e de amolecimento ........ 39

2.2 - Indice de gordura sölida ............ 50

2.3 - Composição em âcidos graxos ............. 62

2.4 - Composição em triglicērides ........... 82

2.5 - Estabilidade à oxidação ............... 104

3. Mistura de gorduras rearranjadas e adição do

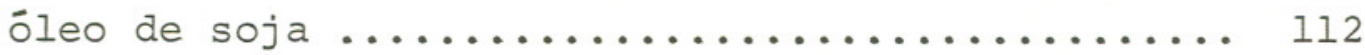

4. Preparação de margarinas ................ 130 
Pāg .

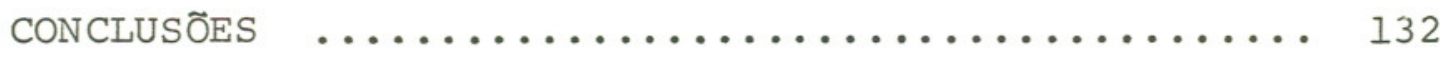

REFERENCIAS BIBLIOGRĂFICAS $\ldots \ldots \ldots \ldots \ldots \ldots \ldots \ldots \ldots \ldots \ldots \ldots$ 


\section{INTRODUÇÃO}

Os óleos e gorduras desempenham importan te papel na alimentação humana. Suas principais funções são relacionadas a seguir $(22,39)$ :

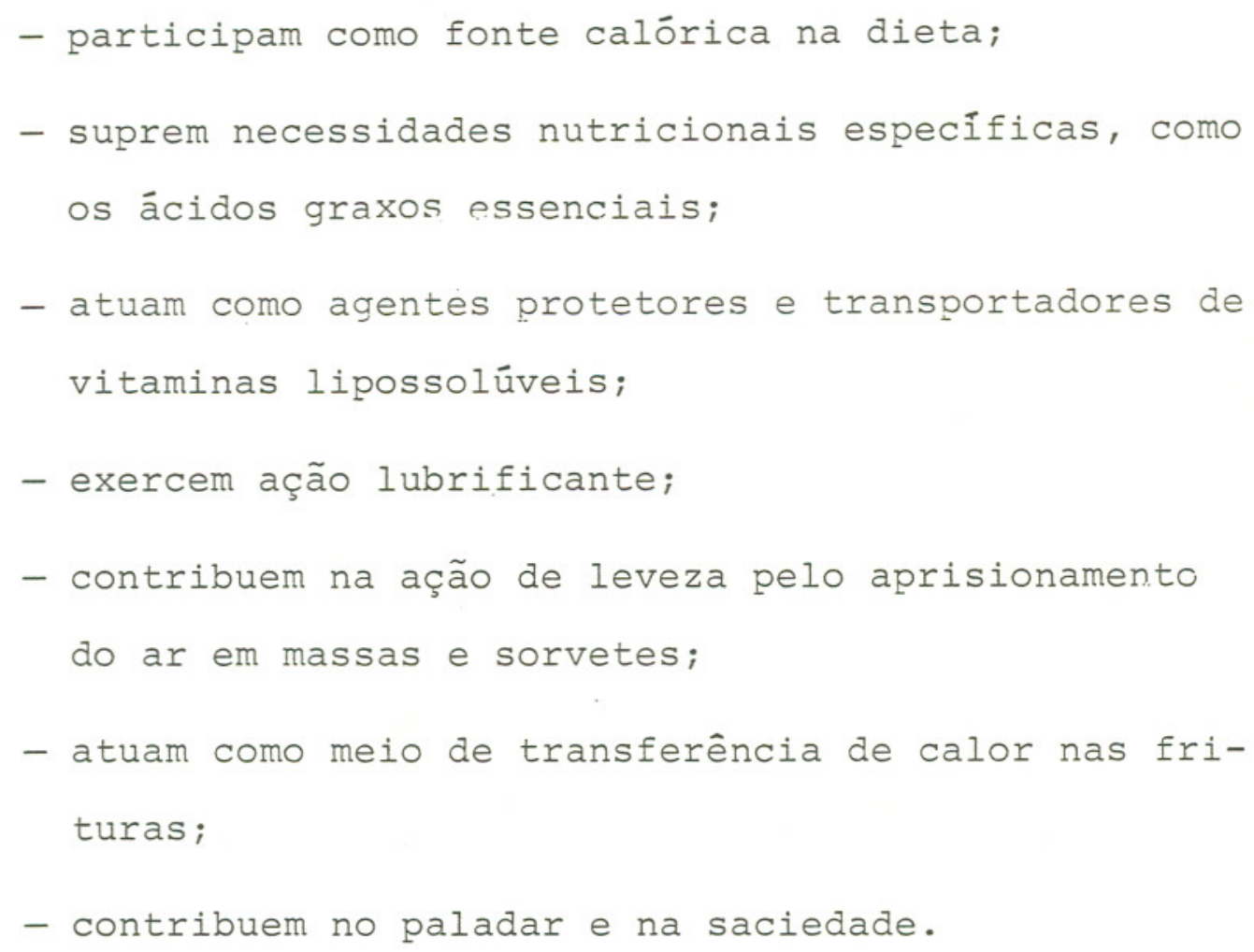

Comercialmente são apresentados nas formas de óleos de mesa para tempero, óleos e gorduras para fritura, manteiga, margarina e gordura vegetal hidrogenada. Alēm destes, são incorporados na confecção de numerosos ou tros produtos, como pães, bolos, biscoitos, chocolates, sor vetes e maioneses.

A produção mundial de óleos e gorduras comestiveis encontra-se atualmente na casa dos 60 milhões de 
toneladas anuais $(16,92)$. Aproximadamente $2 / 3$ desse total são representados por produtos de origem vegetal. Entre estes, os de maior produção são os óleos de soja, palma, girassol, colza, algodão, amendoim, coco e oliva (16, $31,48,92)$.

A produção total brasileira de óleos vegetais para 1984 é estimada em 2,6 milhões de toneladas, compreendida por 2,4 milhões de toneladas de óleo de soja, 140.000 toneladas de óleo de algodão, 46.000 t de óleo de amendoim e 21.000 t de azeite de dendê (31). A produção de gordura de babaçu nos últimos anos tem se situado na faixa de $100.000-150.000 t$ anuais $(39,71,94)$.

Para atender às diferentes aplicações mencionadas, os óleos e gorduras devem respeitar exigências especificas para cada caso. Estas, nem sempre podem ser satisfeitas por produtos obtidos da natureza ou por aqueles cujas fontes naturais existem em pequena quantidade, sendo exemplos típicos a gordura de cacau e a manteiga.

Para suprir essas necessidades do merca do e para fornecer produtos uniformes a partir de matérias-primas variáveis, tēcnicas de modificação de óleos e gorduras permitem maior flexibilidade de escolha da matéria-prima e ajudam a equilibrar as tendências entre disponi bilidade local. e demanda.

No estágio atual, esses métodos estão tão firmemente estabelecidos e são aplicados em escala tão grande que seria praticamente impossivel atender aos pa- 
drões de mercado sem o uso de técnicas de modificação (22) .

\section{MÉTODOS DE MODIFICAÇÃO}

Os métodos de modificação de óleos e gorduras podem ser divididos em três níveis (22).

No primeiro nivel, representado pelo fracionamento, tanto os ácidos graxos como os triglicérides permanecem inalterados. E simplesmente uma separação física dos triglicérides.

No nível intermediārio, representado pela interesterificação, os ácidos graxos permanecem inalterados, mas são redistribuídos, criando novas estruturas.

No terceiro nivel, representado pela hidrogenação, as ligações éster nos triglicérides não se alteram, mas os ácidos graxos são modificados por satura ção, isomerização espacial ou de posição.

Em muitos casos, aplicam-se combinações de técnicas, a fim de conseguir resultado específico desejado.

\section{1 - Fracionamento}

A operação de fracionamento é basicamente a separação de óleos e gorduras em duas ou mais frações com diferentes pontos de fusão.

O fracionamento, nas operações de larga escala, é obtido através de cristalização parcial. E 
aplicado geralmente para eliminar, de uma gordura ou óleo, uma fração que è responsável por propriedades indesejāveis ou para se obter uma fração que apresente características convenientes $(22)$.

Essa técnica de modificação tem grande aplicação na tecnologia de óleos e gorduras comestiveis. Por exemplo, no processo de desmargarinização de óleos vegetais, visando à eliminação de triglicérides de maior ponto de fusão para evitar a turvação em dias mais frios. Também é utilizâ da na produção de sucedâneos da manteiga de cacau a partir de óleos de palma e de caroço de palma ou de öleos de soja e algodão hidrogenados (46).

\section{2 - Hidrogenação}

Esse processo é empregado em larga escą la no campo dos óleos e gorduras comestíveis.

A hidrogenação visa eliminar parte das duplas ligações dos ácidos graxos, uma vez que a completa saturação resulta em produtos com pontos de fusão muito altos, inadequados para uso alimenticio. Uma proporção significati va das duplas restantes é isomerizada por conversão cis-trans e mudança de posição na cadeia dos ácidos graxos. A quantidade de isômeros trans encontrada em produtos comerciais hidrogenados varia entre 5 e $45 \%$ (62).

LASZLO et al. (49) analisaram amostras de margarina e gordura vegetal hidrogenada produzidas no Brasil. Verificaram que o teor de ácidos graxos trans variou de 
6 a $45 \%$ nas gorduras hidrogenadas, ao passo que para as mar garinas a variação foi de 3 a $30 \%$

Como resultado dessas transformações químicas, ocorre alteração em importantes aspectos de quali dade: a faixa de fusão se desloca para temperaturas mais al tas e melhora a estabilidade à oxidação e à mudança do aroma (23).

o processo é normalmente realizado de modo descontínuo, em reatores onde são introduzidos óleo, hidrogênio e catalisador. A reação é controlada por fatores como agitação, temperatura e pressão, que permitem alterar a seletividade de hidrogenação $(22,23)$.

A aplicação principal da hidrogenação é a conversão de óleos como os de algodão, soja e outros em gorduras plásticas, semi-sólidas. Estas são adequadas para a manufatura de margarinas ou gorduras vegetais, substitutos de gorduras animais, originalmente mais caras e menos abundantes (63).

O efeito nutricional do consumo de gor duras hidrogenadas não está claro, apesar das numerosas pes quisas conduzidas nesta área (53).

APPLEWHITE (8) concluiu que não hã evidências que isòmeros trans possuam qualidades biológicas negativas em homens ou animais quando niveis adequados de ácidos graxos essenciais estão presentes na dieta.

Entretanto, outros autores consideram que ácidos graxos trans alteram funções enzimáticas, dimi- 
nuem a formação de prostaglandina, diminuem o tamanho do rim, prejudicam o crescimento, agravam a deficiência de àcidos graxos essenciais e podem estar envolvidos na carcinogênese por influenciar a permeabilidade da membrana. Além disso, podem apresentar efeitos sobre os níveis de colesterol e triglicérides e em doenças coronárias $(53,55,62)$.

$$
\text { Evidentemente, o metabolismo dos isôme }
$$

ros trans deverá ser elucidado. Se forem comprovados efei tos adversos para a saúde, alternativas para a hidrogenação parcial adequadas para a produção de gorduras plásticas deverão estar disponiveis.

\section{3 - Interesterificação}

A interesterificação compreende três processos $(42,81)$ :

- Acidólise: intercâmbio entre uma gordura e ácidos graxos livres. Como exemplo, a introdução de ācị dos graxos de baixo peso molecular em gordura com ácidos graxos maiores.

- Alcoólise: intercâmbio entre uma gordura e um álcool. Uma aplicação importante é a reação com glicerol, para produzir mono e diglicérides que são utilizados como emulsificantes. Outro exemplo é a reação com metanol, formando ésteres metí licos, como combustivel alternativo ao óleo diesel. 
- Transesterificação: rearranjo dos ácidos graxos em triglicérides, ao acaso, até a obtenção do equilíbrio (randomização), alterando as proprie dades físicas e químicas dos óleos e gorduras.

Desde 1950 a importância do processo de interesterificação tem aumentado continuamente. A transes terificação, principalmente nos últimos anos, vem assumindo a mesma importância da hidrogenação ou fracionamento (42).

Apesar da transesterificação ser um capitulo dentro da interesterificação, na literatura estes termos são utilizados indistintamente.

SEHER (78) estimou que no início dos anos 70 a produção mundial de gorduras hidrogenadas era de 4 milhões de toneladas ao ano, enquanto que gorduras e óleos interesterificados representavam 1 milhão de toneladas. Para a Alemanha, mais de $40 \%$ do total de gorduras usa das na produção de margarina eram interesterificadas.

Fontes industriais estimam que gorduras interesterificadas representam de 17 a $22 \%$ daquelas usadas na fabricação de margarina na Europa (56).

\section{3 .1 - Mudanças de composição}

Em óleos e gorduras naturais, normalmen te os ācidos graxos não estão esterificados ao acaso entre as hidroxilas do glicerol, mas sim obedecem certas ten- 
dências de distribuição entre aquelas posições (17). Por exemplo, em óleos e gorduras vegetais há preferência dos ácidos insaturados pela posição central do glicerol. Já para a banha, gordura do leite de vaca e gordura de Ucuuba o ácido palmítico, saturado, ocupa preferencialmente aquela posição $(10,17)$. Para todas as gorduras, de modo geral, a posição 3 do glicerol é ocupada por ácidos graxos "incomuns", ou seja, aqueles fora da faixa de 12 a 22 átomos de carbono (17).

A interesterificação pode ser entendị da como a quebra de um glicerídeo específico com remoção de um ácido graxo ao acaso. Este é então embaralhado com - restante dos ácidos graxos e substituído ao acaso por outro ácido. Pode ser intra ou inter-moléculas de triglicê rides.

No estudo do rearranjo de triglicérides monoinsaturados simētricos, foi observado que a intraesterificação ocorria à velocidade superior que a interesterificação. Contudo, no final do processo era obtida a rando mização total (21).

A interesterificação pode ocorrer a al tas temperaturas $\left(300^{\circ} \mathrm{C}\right.$ ou mais), mais é muito demorada e normalmente acompanhada de decomposição e polimerização. o uso de catalisadores acelera a reação e permite diminuir a temperatura do processo. Os mais usados são os alquila tos metálicos (metóxido de sódio, etóxido de sódio), seguidos dos metais sódio, liga sódio-potássio e dos hidróxidos de sódio ou potássio em combinação com glicerol(80). 
Os alquilatos de sódio são usados como pó fino, em proporção média de 0,2 a $0,4 \%$. Tem as vantagens de fácil manuseio, baixo preço e de iniciar a reação em temperaturas baixas como 50 a $70^{\circ} \mathrm{C}$. Podem ser usados mes mo em niveis de $0,1 \%$ se a matéria-prima é seca e bem refina da (teor de água inferior a 0,01\%, ácidos graxos livres inferiores a $0,05 \%$ e indice de peróxido menor que 1,0 meq $\left.\mathrm{O}_{2} / \mathrm{kg}\right)$. Podem ser facilmente removidos após a reação por lavagem com água $(32,42,80)$.

A tendência à oxidação de óleos e gorduras é dependente não somente dos ácidos graxos componentes mas também de sua distribuição na molécula glicerídica. A concentração de ácidos graxos insaturados na posição 2 do glicerol aumenta a estabilidade em relação à oxidação.

\section{Como o processo de interesterificação} modifica a distribuição dos ācidos graxos, altera a estabilidade à oxidação, podendo aumentā-la ou diminuí-la $(50,69$, 88).

Quanto à utilização de gorduras interesterificadas na alimentação, ALFIN-SLATER et al. concluiram que elas são nutricionalmente iguais a outras gorduras similares com teores equivalentes de ácidos graxos essenciais. O único problema previsivel seria o das impurezas ou sub-produtos que o catalisador pudesse originar (74). 


\section{3 .2 - Métodos de detecção}

São utilizados alguns métodos para com provar a ocorrência da reação e detectar o ponto final (28, $80)$.

A mudança visual que ocorre é o desenvolvimento de coloração marrom que se intensifica com o progresso da reação. Normalmente a reação é processada por período de tempo fixo (30 ou $60 \mathrm{~min}$ ) após o aparecimento da cor escura.

o ponto de fusão é uma das mais rápidas e simples técnicas. Entretanto, em alguns casos, as mu danças são tão pequenas que podem estar na faixa do erro ex perimental.

o Indice de gordura sólida exprime a relação sólido/líquido da gordura a diversas temperaturas. As mudanças nos triglicérides dos tipos trissaturados e dissaturados provocadas pela interesterificação são refletidas nas curvas de sólidos antes e após a reação.

As alterações básicas que ocorrem no processo de interesterificação são na composição gliceríli ca. Portanto, seu conhecimento é fundamental.

A técnica de cromatografia em camada delgada sobre nitrato de prata separa os glicerídeos de acordo com suas insaturações.

A cromatografia em fase gasosa promove separação baseada no número de átomos de carbono dos 
triglicérides. Este método dá bons resultados com gorduras ou misturas contendo ácidos graxos de cadeias carbônicas com comprimentos diferentes.

A lipase pancreática hidrolisa preferencialmente os ácidos graxos ligados às posições 1 e 3 do glicerol e portanto produz 2-monoglicérides. Se a gordura tem distribuição ao acaso dos ácidos graxos, então a composição da posição 2 será a mesma da gordura total.

Além destes, outros métodos como espec trometria de massa, curvas de resfriamento, calorimetria di ferencial e difração de raios $\mathrm{X}$ podem ser usados para detectar mudanças provocadas pela interesterificação.

\section{3 .3 - Processo industrial}

A interesterificação envolve três etapas importantes:pré-tratamento do óleo, reação com o catali sador e destruição do catalisador. Pode ser realizada em lotes ou de modo contínuo.

Basicamente, consiste de secagem sob vácuo à temperatura de $120-150^{\circ} \mathrm{C}$, resfriamento à temperatụ ra de processo e introdução do catalisador. Após o período de reação, o catalisador é destruído por adição de água ou ácido no sistema. O restante do tratamento é simi lar a uma refinação normal (21, 22, 80). 


\section{$1.3 .4-\underline{\text { Aplicações }}$}

Como Como a interesterificação altera as características de fusão e cristalização, ela encontra aplicações no campo das gorduras plásticas, margarinas e substitutos da manteiga de cacau, onde estas propriedades são importantes.

Margarinas de alto teor de ácidos graxos poli-insaturados e baixos níveis de isômeros trans são obtidas por interesterificação.

LIST et al. (54) obtiveram gordura adequada para produção de margarina cremosa interesterificando 80 partes de óleo de soja e 20 partes de óleo de soja totalmente hidrogenado. Esta base gordurosa continha 51,5\% de ácidos graxos poli-insaturados e 1,6\% de isômeros trans.

LO \& HANDEL (55) produziram gordura com caracteristicas físicas similares às de margarinas cremosas comerciais pela interesterificação de $60 \%$ de óleo de soja e 40\% de sebo comestível. O produto final continha 3,0\% de ácidos graxos trans, que estavam presentes origi nalmente no sebo.

YARON et al. (95) concluíram que a interesterificação possibilita a obtenção de bases gorduro sas para margarinas comuns a partir de óleo de soja parcialmente hidrogenado e óleo de soja.

Devido o alto preço da manteiga de cacau, tem sido desenvolvidos substitutos usando interesterificação de gorduras do grupo do ácido läurico. 
exemplo, óleo de caroço de palma hidrogenado e posteriormente rearranjado tem ponto de fusão igual a $35^{\circ} \mathrm{C}$ e curva de sólidos semelhante à da manteiga de cacau (80).

No Brasil, a gordura de babaçu é utilizada para esta finalidade (9).

\subsection{5 - Interesterificação dirigida}

A interesterificação tende a produzir uma composição de equilíbrio de triglicérides. Se a mistura de reação for resfriada abaixo de seu ponto de fusão, os glicerídeos trissaturados começarão a cristalizar, saindo da reação. Esta cristalização seletiva desloca o equilibrio e a reação começará novamente a produzir mais glicerídeos trissaturados para restabelecer o equilíbrio. Como - processo é direcionado no sentido de produzir um tipo particular de glicerídeo, é chamado de interesterificação di rigida.

Como a velocidade da reação é lenta devido a baixa temperatura, o tempo de processo é maior. sistema, consequentemente, é mais caro, visto que o equipa mento necessário è muito maior $(22,42,80)$. 


\subsection{6 - Interesterificação catalisada por enzimas}

Lipases microbianas extracelulares podem ser usadas como catalisadores para interesterificação de óleos e gorduras.

O uso de lipases especificas propicia a formação de produtos que não podem ser obtidos pelos métodos de rearranjo químico.

Os catalisadores para o processo enzimá tico são preparados recobrindo materiais inorgânicos (suportes) com as lipases. As partículas de catalisador são ativadas por adição de pequena quantidade de água.

Podem ser utilizados sistemas de reação em lotes ou contínuos, estes últimos empregando leito de catalisador ativo imobilizado (58, 68, 70).

2. MARGARINA

A margarina foi inventada em 1869 pelo francês Hippolyte Mège Mouriès como um substituto da manteiga (2).

Atualmente, entretanto, é um produto de alta tecnologia, com características próprias e muitas variações.

A produção mundial de margarina em 1978 correspondeu a 6,8 milhões de toneladas (56). No período en tre outubro de 1983 e setembro de 1984 a produção mundial 
projetada se eleva a 8,2 milhões de toneladas (60).

No Brasil, as margarinas foram lançadas em nível de consumo de massa, no início da década de 60. Em principios dos anos 70 surgiram as primeiras marcas cremosas. Posicionadas como substitutos econômicos da manteiga, as mar garinas conquistaram o mercado (79).

A produção brasileira de margarinas em 1983 foi de 272.000 toneladas, sendo que as de uso doméstico representaram praticamente $97 \%$ do total.

A margarina é uma emulsão do tipo água em óleo. A fase continua é uma mistura de gorduras vegetais e/ou animais. A fase aquosa è constituída por leite desnatado ou água. São incorporados ao produto uma série de aditivos, tais como sal, acidulantes, antioxidantes, aromatizantes, conservadores, corantes, estabilizantes e vitaminas.

São encontrados no mercado diversos tipos de margarinas com aplicações específicas.

Há margarinas de uso doméstico e as de aplicação industrial.

As margarinas industriais são destinadas à confeitaria e à cozinha profissional.

Entre as de uso doméstico, há margarinas comuns, mais duras, mais adequadas para fritura e cozimento e as cremosas ou "soft", que apresentam alto poder de espalhabilidade mesmo à temperatura de refrigeração. Ou, ainda, as chamadas chamadas margarinas nutricionais ou dietẹ 
ticas, com elevado teor de ácidos graxos poli-insaturados.

Em 1983, foi lançado no Brasil um tipo especial de margarina com 65\% de gordura, chamado de creme vegetal (79). Estes produtos de baixo valor calórico devido seu reduzido conteúdo gorduroso $(40-65 \%)(33,61)$ não podem receber a denominação de margarina porque não contēm 0 minimo de $82 \%$ de gordura estabelecido pela legislação.

Existem, em outros países, margarinas ljquidas, acondicionadas em frascos ou tambores. Há também margarinas aeradas, com volume 50\% maior. Como a densidade é menor diminui a quantidade de calorias recebidas em cada porção (61).

As principais propriedades das margarinas, como consistência e plasticidade, dependem basicamen te de alguns fatores (7): Indice de gordura sólida, método de resfriamento, tratamento térmico após o resfriamento, tem po e grau de trabalho mecânico, tamanho e forma dos cristais e estado de emulsão.

Portanto, a composição da fase gorduro sa assim como as condições de processamento são igualmen te importantes na determinação das propriedades físicas da margarina $(37,91)$. A sua consistência é pouco influenciada pelos métodos de emulsificação do produto ou por variações nas proporções relativas de leite e gordura (37).

Uma margarina ideal seria aquela cuja fase gordurosa não apresentasse variações em seu indice de gordura sólida até aproximadamente $35-38^{\circ} \mathrm{C}$, quando então fundiria imediatamente (7). 
Um aspecto fundamental nas técnicas de processamento de gorduras é a sua tendência à cristalização. As gorduras são polimórficas, podendo existir em três diferentes formas cristalinas, $\alpha, \beta$ ' ou $\beta$-prima e $\beta$. A forma $\beta$ é a mais estável e implica em maiores consis tência e ponto de fusão (67). Como a forma $\alpha$ é muito instável, os óleos e gorduras são divididos em apenas duas categorias, de adordo com seus estados de cristalização: B' $\beta$.

Estão incluidos na categoria $\beta$ os óleos de soja, açafroa, girassol, gergelim, amendoim, milho, oliva, as gorduras de coco e caroço de palma, a banha e a man teiga de cacau. Na categoria $\beta$ ' estão os óleos de algodão, colza, palma e baleia, as gorduras de arenque e do leite, - sebo e a banha rearranjada (91).

Após o processo de interesterificação, todas as gorduras apresentam tendência de se cristalizarem na forma $\beta$. As exceções são o óleo de palma, que não altera a sua caracteristica e a banha, que passa para a forma B-prima (91).

A característica desejável de cristali zação de margarinas è na forma s-prima. Contudo, é possível obter produtos adequados mesmo usando gorduras com alta propensão à forma $\beta$, como o óleo de soja hidrogenado. Isto é conseguido através o uso de múltiplos componentes de consistências variāveis na formulação da base gordurosa. (91) 
Do ponto de vista nutricional, a"American Medical Association" e a "American Heart Association" recomendam que margarinas contenham um minimo de $25 \%$ de ácidos graxos poli-insaturados, um máximo de 25\% de ácidos saturados e uma relação mínima poli-insaturados/saturados de $1,2(54,90)$.

MASSIELO (61) apontou as tendências futuras para margarinas. Segundo o autor, haverá aumento considerável na produção de cremes vegetais. As margarinas altamente poli-insaturadas continuarão crescendo, não somente por fatores de saúde mas também por considerações energêe ticas. Haverá demanda maior por produtos feitos com ingredi entes considerados de origem natural, como óleos não hidro genados, aromas naturais e sem conservantes. Finalmente, aumentará a participação de margarinas com teores reduzi dos de isômeros trans, o que poderá ser conseguido pelo pro cesso de interesterificação.

\section{1 - Fabricação de margarina}

$\mathrm{Na}$ produção de margarinas, as fases oleo sa e aquosa são preparadas separadamente.

\footnotetext{
$\bar{A}$ fase oleosa são adicionados os elemen tos lipossolúveis, como antioxidantes (BHA, BHT), aromati zantes (fosfolípides, mono e diglicérides) e vitaminas (A, D, E).

Ao leite desnatado, que forma a fase aquosa, são incluídos o sal, acidulantes (ácido lático e
} 
ácido cítrico) e conservadores (sorbato de sódio, benzoato de sódio).

As duas fases são misturadas, em tanques agitados ou em sistemas contínuos. Neste estágio, a emulsão água em óleo, finamente dividida, ainda não está formada (67).

Esta mistura è transferida, por meio de bomba de alta pressão, a um trocador de calor tubular de superficie raspada, chamado votator (unidade A). Neste, ocorre rápido resfriamento do material, ao mesmo tempo em que se forma a emulsão final. O abaixamento de temperatura, muito rápido resulta em super-resfriamento da gordu ra, ou seja, ela permanece líquida mesmo abaixo de seu ponto de fusão. o produto passa então a um tubo de cristalização (unidade B) onde a gordura solidifica, podendo sofrer ou não trabalho mecânico $(67,91)$.

Finalmente, após a embalagem, a margarina pode receber tratamento de temperagem ou maturação(38). 
OBJETIVOS

Para a realização do trabalho foram escolhidos três óleos ou gorduras não hidrogenados produzidos no Brasil: soja, dendê e babaçu.

o óleo de soja foi selecionado por ser o óleo de maior produção brasileira e mundial, além de ser rico em ácidos graxos poli-insaturados.

O azeite de dendê, embora seja produzido no Brasil em pequena escala, é o segundo óleo vegetal em volume de produção no mundo e largamente empregado na Europa. Além disso, é a oleaginosa de maior produtividade, com $4.000 \mathrm{~kg}$ de óleo por hectare ao ano. As demais oleaginosas, como colza, girassol, amendoim, soja, algodão e babaçu apresentam produtividades que variam de 480 a $130 \mathrm{~kg}$ óleo/ha ano (19, 71).

A gordura de babaçu apresenta produção considerável no Brasil quando comparado aos demais óleos vegetais, excluindo o de soja. Sua potencialidade foi reconhecida nos dois últimos encontros da Conferência Mundial sobre o Processamento de Sementes Oleaginosas e Oleos Comes tíveis $(13,48)$.

Os objetivos do trabalho são os seguintes: 
- efetuar reações de interesterificação entre os óleos e gorduras mencionados com a finalidade de obter bases para margarina, como alternati va ao processo de hidrogenação;

- realizar acompanhamento das reações com a re tirada periódica de amostras, a fim de verificar as alterações químicas e físicas que estão ocorrendo;

- emulsificar as bases gordurosas selecionadas com fases aquosas adequadas procurando obter margarinas de mesa do tipo cremoso e preferencialmente com alto teor de ácidos graxos poliinsaturados. 
22 .

MATERIAIS E METODOS

\section{MATERIAis}

Foram utilizados como matérias-primas a gordura de babaçu, o azeite de dendê e o óleo de soja, adqui ridos no comércio.

2. METODOS

\subsection{Acidez}

A acidez foi determinada por via titulo mētrica, utilizando solução de hidróxido de sódio 0,1N, segundo o Instituto Adolfo Lutz (43).

\subsection{Indice de peróxido}

o indice de peróxido foi determinado se gundo a "American Oil Chemists' Society" (3).

\subsection{Ponto de fusão e ponto de amolecimento}

o ponto de fusão (tubo capilar fechado) e o ponto de amolecimento (tubo capilar aberto) foram determinados segundo a "American Oil Chemists' Society" (4). 


\title{
2.4 Matēria insaponificável
}

\author{
o teor de insaponificáveis foi determi \\ nado segundo a Farmacopéia Brasileira (30).
}

\subsection{Indice de saponificação}

o indice de saponificação foi determinado segundo o Instituto Adolfo Lutz (44).

\subsection{Indice de iodo}

o indice de iodo foi calculado a partir da composição em ácidos graxos das amostras (7).

\subsection{Indice de gordura sólida}

o indice de gordura sólida foi determinado por dilatometria, segundo a "American Oil Chemists' Society" (5), utilizando dilatômetro descrito por WILLIANS (93) .

\subsection{Esterificação de ácidos graxos}

Os äcidos graxos foram transformados em ésteres metillicos, segundo HARTMAN \& LAGO (40), visando a análise por cromatografia em fase gasosa.

\subsection{Composição em ácidos graxos}

A análise de ácidos graxos foi realizada em cromatógrafo de gás CG, modelo 37-D, equipado com detetor de ionização de chama. 
As condições de análise foram as seguin tes $(34,77)$ :

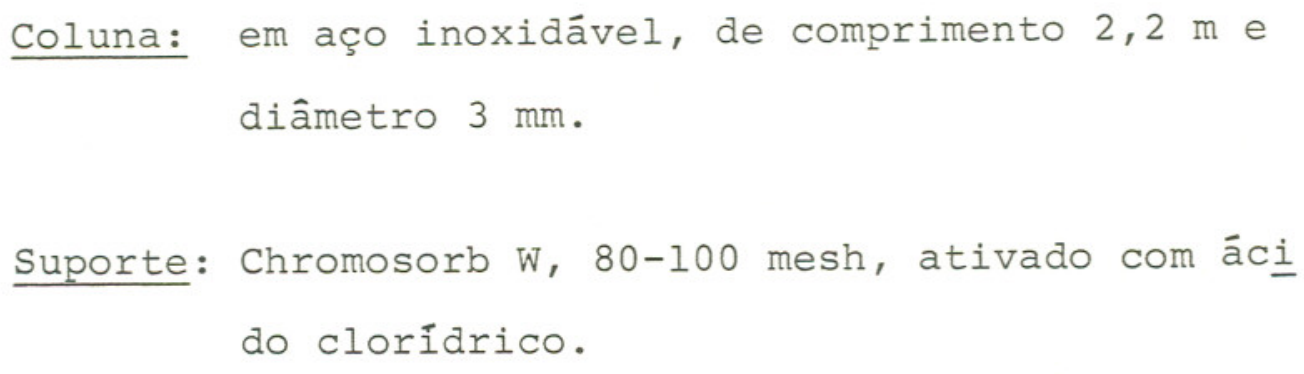

Suporte: Chromosorb W, 80-100 mesh, ativado com ácí do cloridrico.

Fase estacionária: DEGS (succinato de dietilenogli col) a $17 \%$

Fluxo de nitrogênio: $30 \mathrm{ml} / \mathrm{min}$.

Fluxo de hidrogênio: $30 \mathrm{ml} / \mathrm{min}$.

Fluxo de ar sintético: $210 \mathrm{ml} / \mathrm{min}$.

Temperatura do detetor: $280^{\circ} \mathrm{C}$

Temperatura do vaporizador: $280^{\circ} \mathrm{C}$

Temperatura da coluna: $192^{\circ} \mathrm{C}$

Velocidade do papel: $0,25 \mathrm{pol} / \mathrm{min}$.

A composição qualitativa foi determinada por comparação das distâncias de retenção dos picos com as dos respectivos padrões de ácidos graxos.

A composição quantitativa foi determiną da por triangulação, multiplicando a altura do pico por sua largura na base, relacionando a área de cada pico com a área total e expressando como porcentagem em massa. 


\subsection{Composição em triglicérides}

A análise de triglicérides foi realizą da em cromatógrafo de gás CG, modelo 37-D, equipaco com detetor de ionização de chama e programador linear de tempe ratura.

As condições de análise foram as seguin tes $(35)$ :

Coluna: em aço inoxidável, de comprimento $60 \mathrm{~cm} \mathrm{e}$ diâmetro $3 \mathrm{~mm}$.

Suporte: Gascrom Q, 100-120 mesh.

Fase estacionária: JXR (polímero de metil-siloxano)

a $3 \%$

Fluxo de nitrogênio: $120 \mathrm{ml} / \mathrm{min}$.

Fluxo de hidrogênio: $120 \mathrm{ml} / \mathrm{min}$.

Fluxo de ar sintético: $840 \mathrm{ml} / \mathrm{min}$.

Temperatura do detetor: $340^{\circ} \mathrm{C}$

Temperatura do vaporizador: $330^{\circ} \mathrm{C}$

Temperatura da coluna: programada, de 228 a $330^{\circ} \mathrm{C}$, com variação de $3^{\circ} \mathrm{C} / \mathrm{min}$.

Velocidade do papel: 0,25 pol/min.

A separação dos triglicérides é baseada no número de átomos de carbono de cada molécula, não importando o grau de insaturação dos ácidos graxos componen tes. 
A composição quantitativa foi determina da por triangulação, relacionando a área de cada pico com a área total e expressando como porcentagem em massa, após - emprego de fatores de correção determinados experimentalmente (15).

\subsection{Hidrólise enzimática}

A hidrólise enzimática de triglicérides, visando a obtenção dos 2-monoglicérides, foi realizada por incubação a $40^{\circ} \mathrm{C}$ com lipase pancreática de porco, segundo MATTSON \& VOLPENHEIN (64).

\subsection{Estabilidade à oxidação}

O teste de estabilidade à oxidação foi realizado em estufa a $60^{\circ} \mathrm{C}$, conforme o procedimento de BARUFFALDI et al. $(11,12)$.

\subsection{Consistência}

A determinação da consistência foi feita segundo a American Oil Chemists' Society, pelo emprego do penetrômetro de cone (6).

\subsection{Cálculo da composição glicerídica}

A composição em termos de triglicéri des para óleos e gorduras pode ser calculada por considerações estatisticas, conhecendo-se os ácidos graxos e totais e os da posição 2 . 
Para gorduras naturais foi utilizada a teoria chamada de 1,3-random-2-random desenvolvida por VANDERWAL (86) e COLEMAN (24). Para gorduras interesterificadas utilizou-se a distribuição totalmente ao acaso conhecida por 1,2,3-random $(47,81)$.

o número de triglicérides de uma gordura, levando-se em conta todos os isômeros, é igual à terceira potência do número de ácidos graxos presentes $(47,65)$. Desse modo, para auxiliar a análise dos dados, foi usado - programa de computação para este fim apresentado por MANI \& LAKSHMINARAYANA (59), em linguagem FORTRAN, que é descrí to a seguir. Utilizou-se computador Burroughs B-6700. 


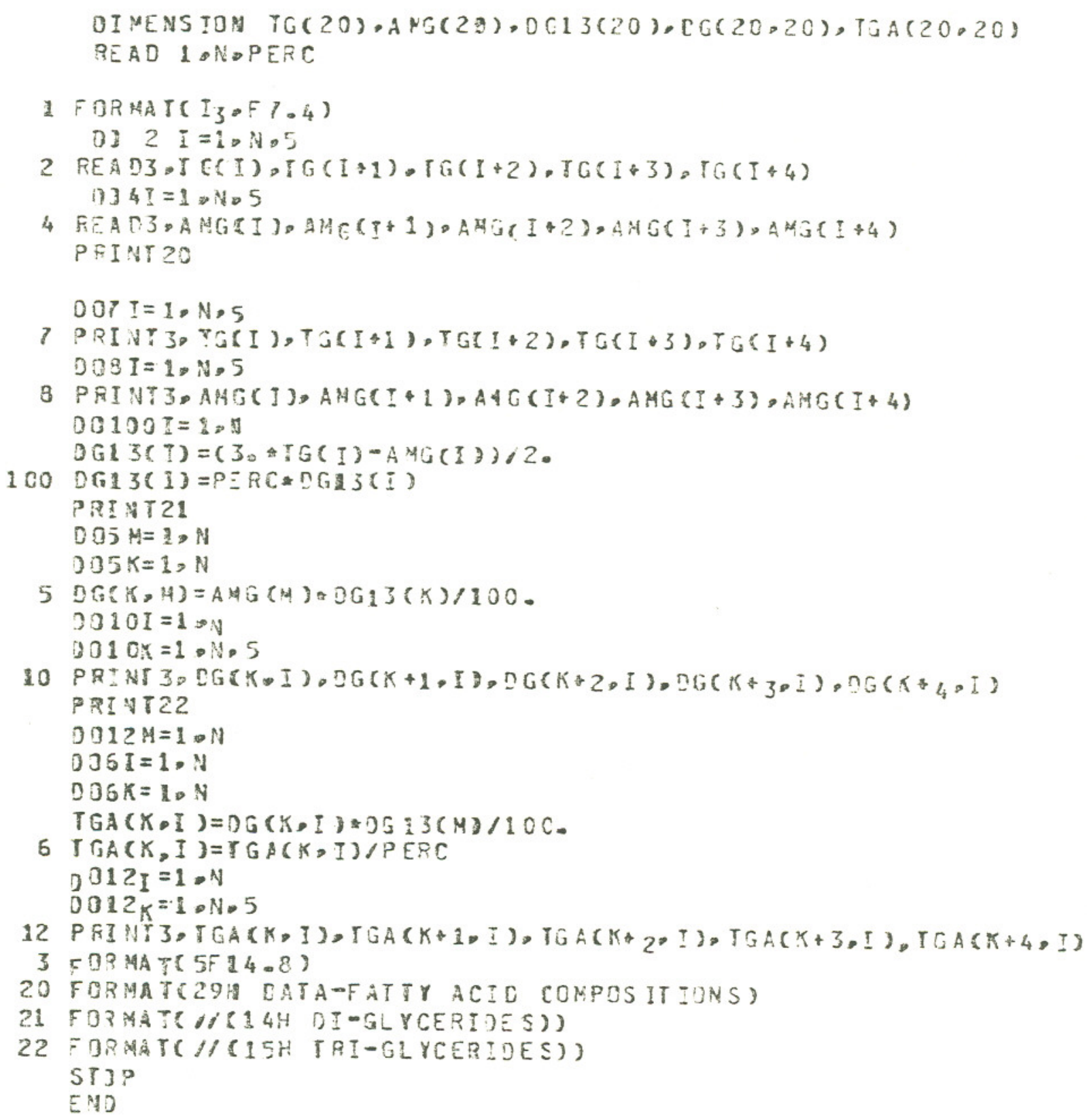




\section{PARTE EXPERIMENTAL}

\section{CARACTERIZAÇÃO DAS MATERIAS-PRIMAS}

As matérias-primas foram inicialmente caracterizadas quanto à sua composição e propriedades fisico-quimicas.

A qualidade e identidade da gordura de babaçu, do azeite de dendê e do óleo de soja foram testadas em função de dados de literatura, bem como da legislação vigente (25).

Em virtude do azeite de dendê não se en contrar na forma refinada, tornou-se necessária a etapa prẹ via de neutralização. Esta foi realizada com o emprego de hidróxido de sódio a $20^{\circ}$ Bé, segundo o procedimento descrito por TANGo et al. (85), adaptado para pequenas quantidades.

Devido a alta acidez do dendê bruto e as condições de laboratório em que foi efetuada a neutralização, o rendimento em óleo neutralizado foi baixo, situando-se ao redor de $40 \%$. 


\section{REAÇÕES DE INTERESTERIFICAÇÃO}

As reações de interesterificação foram realizadas em balão de três bocas de $250 \mathrm{ml}$. Posteriormente, foi feita ampliação de escala, com a utilização de balões análogos de 500 e $1000 \mathrm{ml}$.

Inicialmente, era feito aquecimento a 90-95 ${ }^{\circ} \mathrm{C}$ durante 1 hora, sob pressão reduzida proporcionada por trompa d'água e sob agitação produzida por barra magné tica, para remoção de traços de umidade do material.

Após esta etapa, o sistema era resfriado a $60^{\circ} \mathrm{C}$, quando se fazia a adição do catalisador, na pro porção de $0,5 \%$, mantendo-se a pressão reduzida e a agita ção. Imediatamente antes da adição do catalisador retirava-se uma amostra inicial, correspondendo como controle.

Em intervalos regulares de $5 \mathrm{~min}$ eram retiradas amostras intermediárias para o acompanhamento da reação, admitindo-se momentaneamente a entrada de ar no sistema. As amostras eram imediatamente agitadas na presen ça de água destilada para interrupção da reação.

Após o período de 30 a $45 \mathrm{~min}$ era adi cionada água destilada para inativar o catalisador, mantendo-se a agitação por mais $3 \mathrm{~min}$. A gordura rearranjada era então filtrada a quente, sob vácuo, sobre sulfato de sódio e kieselgur. A filtração tinha como finalidades a retenção de umidade e a remoção de sabões e compostos escuros formados, uma vez que se observava ligeiro escureci mento nos primeiros minutos e que se acentuava com o pro- 
gresso da reação.

o catalisador utilizado foi metóxido de sódio, preparado pela reação entre sódio metálico e metanol anidro, na véspera de cada reação. o excesso de metá nol era evaporado sob vácuo e o produto seco triturado em graal de vidro. Para facilitar a dispersão do catalisador, este era pré-misturado a uma porção da gordura a ser rearranjada, sendo então adicionado ao restante, sob agitação.

As reações de interesterificação foram realizadas com misturas binărias de gordura de babaçu e azeite de dendê neutralizado, nas proporções de 80:20, 60:40, 40:60 e 20:80, respectivamente. Além destas, ambos foram rearranjados isoladamente.

Para cada produto de reação foram realizadas as seguintes análises: pontos de fusão e de amole cimento (amostras inicial, intermediárias e final); indice de gordura sólida, composição em ácidos graxos e teste de estabilidade à oxidação (amostras inicial e final); composi ção em triglicérides e hidrólise enzimática (amostras inicial e final, alēm de intermediārias selecionadas em função da variação dos pontos de fusão e de amolecimento). 
3. MISTURA DE GORDURAS REARRANJADAS ISOLADAMENTE

A gordura de babaçu e o azeite de dendê neutralizado interesterificados separadamente foram misturados nas mesmas proporções em que sofreram o processo de rearranjo em conjunto.

Portanto, foram feitas misturas nas relações de $80: 20,60: 40,40: 60$ e 20:80, respectivamente. Estas foram analisadas quanto aos pontos de fusão e de amolecimento e indice de gordura sólida.

\section{ADIÇÃO DO OLEO DE SOJA}

As gorduras rearranjadas com caracteristicas fisicas adequadas como componentes de bases gordu rosas para margarinas sofreram a adição de óleo de soja. Estas misturas foram analisadas quanto aos pontos de fusão e de amolecimento e indice de gordura sólida.

Esta adição teve por finalidade diminuir a consistência das gorduras bem como elevar o teor de ácidos graxos poli-insaturados.

A inclusão do óleo de soja foi feita nas proporções de $20,40,60$ e $80 \%$, procurando-se obter bases gordurosas de plasticidade adequada para produção de margarinas do tipo cremoso. Tomou-se como referência a análise de doze margarinas comerciais brasileiras realizada por GIOIELLI et al. (36). 
Foram selecionadas duas bases gordurosas para preparação experimental de margarinas. Estas gorduras foram analisadas quanto à composição em ácidos graxos.

\section{PREPARAÇÃO DE MARGARINAS}

Visto que as bases gordurosas selecionadas continham elevado teor de azeite de dendê, que mantem sua coloração característica após os processos de neutraliza ção e interesterificação, tornou-se necessária a etapa de clarificação.

Como o caroteno, principal pigmento do dendê, não è eficientemente removido pela utilização de adsor ventes (85), a redução na coloração é conseguida na etapa de desodorização. Esta foi realizada pela injeção de vapor na gordura, sob alta temperatura e vácuo intenso (20). Nesta fase tambēm consegue-se a eliminação de possíveis ésteres metílicos formados pela ação do catalisador de interesterifí cação.

As margarinas foram formuladas com

de fase gordurosa e 18\% de fase aquosa (leite desnatado), com a inclusão dos seguintes aditivos:

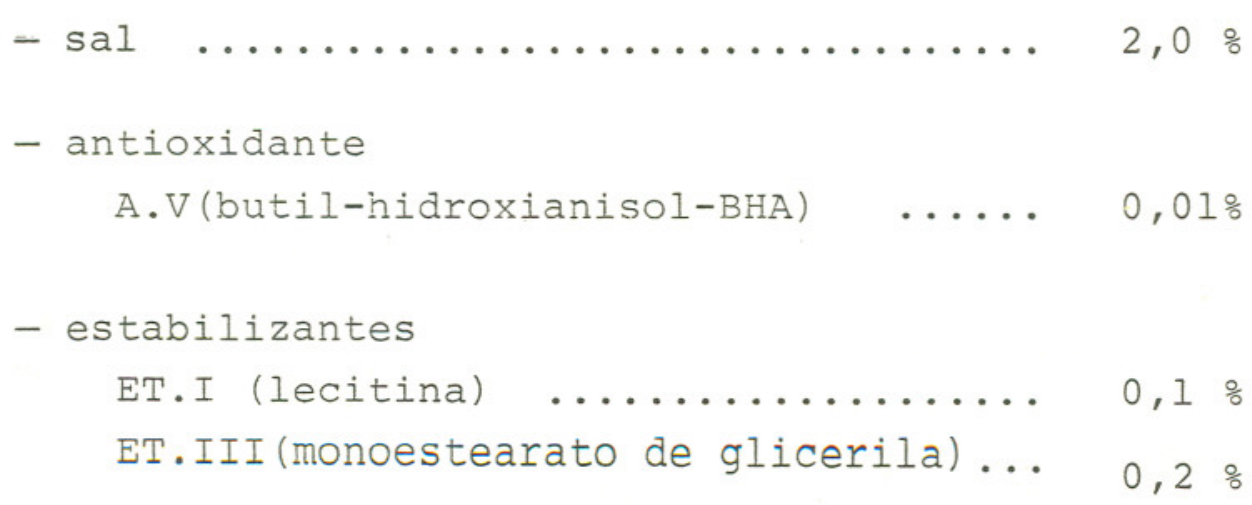


- acidulante

$$
\text { H.VII (ácido lático) } \ldots \ldots \ldots \ldots \ldots, 0,05 \%
$$

- conservante

$$
\text { P.IV (ácido sōrbico) } \quad \ldots \ldots \ldots \ldots \ldots, 0,05 \%
$$

- corante

C. I (beta-caroteno) (........... q.s.

- aromatizante

F.IV (idêntico ao natural) ....... q.s.

- vitamina

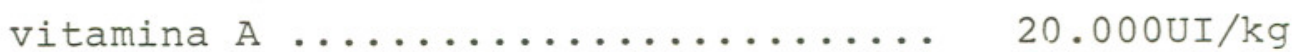

A fase aquosa, incluindo os aditivos hi drossolúveis, foi resfriada a $10^{\circ} \mathrm{C}$. As bases gordurosas, contendo os componentes lipossolúveis, foram aquecidas a $40^{\circ} \mathrm{C}$.

A preparação das margarinas foi feita pe la adição da fase aquosa às bases gordurosas, lentamente e sob agitação.

Após a emulsificação, durante cerca de 5 min, foi feito o resfriamento sob agitação em banho de ge10. As margarinas foram então acondicionadas em embalagens plásticas e mantidas sob refrigeração.

Posteriormente foram analisadas quanto à consistência a $10^{\circ} \mathrm{C}$ através a utilização de penetrômetro de cone. 
RESULTADOS E DISCUSSÃO

\section{MATERIAS-PRIMAS}

As tabelas 1 e 2 apresentam as caracteristicas físico-quimicas e a composição em ácidos graxos das matērias-primas utilizadas.

A gordura de babaçu se enquadra dentro dos limites fixados pela legislação quanto às caracteristiticas de identidades (25) com exceção ao indice de iodo, que mostrou-se superior.

Com relação à composição em ácidos graxos, o ácido láurico é o principal componente. Contudo, foi observado em percentual inferior em relação aos citados na literatura $(41,82,83)$. Estes resultados mostram considerāveis variações nos teores dos diversos ácidos graxos da gordura de babaçu. Portanto, são cabỉveis novos estudos que procurem avaliar os motivos destas variações.

O azeite de dendê obedece as características de identidade (25) e a composição apresentada por TANGO et al. (85). Entretanto, os pontos de fusão e de amolecimento relativamente baixos fazem supor tratar-se de fração líquida (oleina) obtida no fracionamento por cristalização do material $(57,85)$.

Em função do processo de neutralização realizado, verificou-se ligeira elevação nos pontos de fu- 
são e de amolecimento. Isto ocorre porque os ácidos graxos livres e glicerideos parciais abaixam a faixa destes pontos (85) .

Da mesma forma, glicerídeos parciais e ācidos graxos livres diminuem o Indice de gordura sólida por formação eutētica (45). Em geral, óleos de palma brutos apresentam consistência minima para teores de ácidos graxos livres ao redor de 7\%. Este fenômeno persiste mesmo após a neutralização, visto ser devido à formação eutética entre di e triglicērides (26).

Enquanto que para o dendê bruto o teor de gordura sólida a 10, 15 e $20^{\circ} \mathrm{C}$ é de 20,5, 12,1 e 6,7\%, respectivamente, para o dendê neutralizado estes valores são 30,6, 16,1 e 6,7\%, respectivamente (Tabela 4). Portan to, a neutralização aumentou a consistência do azeite de dendê, visto que há relação direta entre indice de gordura sólida e consistência (51, 52).

o óleo de soja utilizado se encontra nos limites fixados para as caracteristicas de identidade (25). Apenas o Indice de saponificação apresentou-se acima. A composição em àcidos graxos é comparävel àquela citada por ERICKSON (29). 
TABELA 1. Caracteristicas físico-químicas das gorduras utilizadas como matérias-primas.

\begin{tabular}{|c|c|c|c|c|}
\hline Determinação & Babaçu & $\begin{array}{l}\text { Dendê } \\
\text { bruto }\end{array}$ & $\begin{array}{l}\text { Dendê } \\
\text { neutro }\end{array}$ & soja \\
\hline Acidez ( & 0,1 & 12,0 & 0,1 & 0,1 \\
\hline $\begin{array}{l}\text { Indice de peróxido } \\
\text { (meq } \mathrm{O}_{2} / 1000 \mathrm{~g} \text { ) }\end{array}$ & 0,3 & 0,7 & 1,7 & 4,6 \\
\hline Ponto de fusão $\left({ }^{\circ} \mathrm{C}\right)$ & 25,0 & 22,2 & 22,8 & - \\
\hline Ponto de amolecimento $\left({ }^{\circ} \mathrm{C}\right)$ & 24,0 & 21,2 & 22,0 & - \\
\hline Insaponificāvel $\left(\frac{\%}{\partial}\right)$ & 0,4 & - & 0,6 & 1,0 \\
\hline $\begin{array}{l}\text { Indice de saponificação } \\
(\mathrm{mg} \mathrm{KOH} / \mathrm{g})\end{array}$ & 256 & - & 206 & 202 \\
\hline $\begin{array}{l}\text { Indice de iodo calculado } \\
(\mathrm{g} \text { iodo/100 g) }\end{array}$ & 22 & 61 & 59 & 137 \\
\hline
\end{tabular}


TABELA 2. Composição em ácidos graxos das matērias-primas

\begin{tabular}{|c|c|c|c|c|c|}
\hline \multirow{2}{*}{ Ácido } & \multirow{2}{*}{ graxo } & \multicolumn{4}{|c|}{$\%$ em massa } \\
\hline & & babaçu & $\begin{array}{l}\text { dendê } \\
\text { bruto }\end{array}$ & $\begin{array}{l}\text { dendê } \\
\text { neutro }\end{array}$ & soja \\
\hline $\mathrm{C}_{6}$ & - capróico & $\mathrm{TR}^{\mathrm{a}}$ & - & - & - \\
\hline $\mathrm{c}_{8}$ & - caprïlico & 7,9 & - & - & - \\
\hline $\mathrm{C}_{10}$ & - cáprico & 7,7 & - & - & - \\
\hline $\mathrm{C}_{12}$ & - läurico & 27,4 & 0,2 & 0,2 & $\mathrm{TR}$ \\
\hline $\mathrm{C}_{14}$ & - mirístico & 18,5 & 1,0 & 1,2 & $\mathrm{TR}$ \\
\hline $\mathrm{C}_{16}$ & - palmítico & 11,1 & 35,7 & 38,0 & 11,4 \\
\hline$c_{16: 1}$ & - palmitoléico & - & $\mathrm{TR}$ & - & - \\
\hline$c_{18}$ & - esteārico & 4,4 & 5,5 & 4,6 & 3,2 \\
\hline $\mathrm{C}_{18: 1}$ & - oléico & 19,6 & 44,6 & 43,6 & 21,3 \\
\hline $\mathrm{C}_{18: 2}$ & - linoléico & 3,4 & 12,6 & 12,4 & 55,4 \\
\hline$C_{18: 3}-$ & - linolênico & - & 0,4 & $\mathrm{TR}$ & 8,7 \\
\hline
\end{tabular}

$$
a_{T R}=\text { traços }
$$




\section{REAÇÕES DE INTERESTERIFICAÇÃO}

\section{1 - Pontos de fusão e de amolecimento}

A tabela 3 e as figuras de 1 a 6 representam a variação nos pontos de fusão e de amolecimento durante as reações de interesterificação com proporções variā veis de gordura de babaçu e azeite de dendê neutralizado.

$$
\text { Observa-se que em todas as reações }
$$

rearranjo promoveu aumento nos pontos de fusão e de amolecí mento, sendo que esta elevação se acentuou à medida em que a proporção do azeite de dendê aumentava. Dessa forma, enquanto que para a gordura de babaçu a variação é de $1-2^{\circ} \mathrm{C}$, para o azeite de dendê é da ordem de $18-20^{\circ} \mathrm{C}$.

Outro ponto a ser salientado é que o equilíbrio da reação, ou seja, quando praticamente não há mais alteração nos pontos de fusão e de amolecimento, foi alcançado rapidamente. Em alguns casos, em apenas 5-10 mi nutos após a introdução do catalisador. Em outros, mo máxi mo de 20-25 minutos. Isto vem confirmar que com o emprego de alquilatos metálicos como o metóxido de sódio o tempo de reação pode ser da ordem de alguns minutos (21, 80$)$.

Apesar de ter sido efetuado o acompanha mento da reação com a retirada periódica de amostras, o estudo cinētico do processo não é recomendado. COENEN (21) justifica atravēs das seguintes razões:

- os óleos contēm traços de impurezas que envenenam uma proporção importante do catalisador; 
- a concentração real do catalisador ativo não é muito definida;

- a reação é extremamente rāpida;

- os mētodos de análise de triglicérides não estão suficientemente desenvolvidos.

Como consequência destas considerações é praticamente impossível efetuar uma interesterificação parcial controlada, de modo que o processo sempre é conduzido ao equilíbrio.

As figuras 7 e 8 representam diagramas das misturas de gordura de babaçu e azeite de dendê neutralizado em função dos pontos de fusão e de amolecimento.

Verifica-se que para a maioria das compo sições de babaçu:dendê antes do rearranjo os pontos de fusão e de amolecimento são inferiores daqueles das gorduras isoladamente. Isso mostra que a inter-solubilidade destas gorduras não é completa, levando à formação de um sistema eutētico $(72,73,87)$. A composição eutētica se situa na faixa de $40 \%$ de babaçu para $60 \%$ de dendê até $20 \%$ de babaçu para $80 \%$ de dendê. 
TABELA 3. Pontos de fusão e de amolecimento durante as reações de interesterificação com proporções variāveis de gordura de babaçu e azeite de dendê neutralizado.

\begin{tabular}{|c|c|c|c|c|c|c|c|c|c|c|c|c|}
\hline \multirow{3}{*}{$\begin{array}{l}\text { Tempo } \\
\text { (min) }\end{array}$} & \multicolumn{12}{|c|}{ Proporção (babaçu: dendê) } \\
\hline & \multicolumn{2}{|c|}{$100: 0$} & \multicolumn{2}{|c|}{$80: 20$} & \multicolumn{2}{|c|}{$60: 40$} & \multicolumn{2}{|c|}{$40: 60$} & \multicolumn{2}{|c|}{$20: 80$} & \multicolumn{2}{|c|}{$0: \perp 00$} \\
\hline & $\begin{array}{l}\mathrm{a} \\
\operatorname{PF}\left({ }^{\circ} \mathrm{C}\right)\end{array}$ & $\stackrel{\mathrm{b}}{\mathrm{PA}\left({ }^{\circ} \mathrm{C}\right)}$ & $\mathrm{PF}\left({ }^{\circ} \mathrm{C}\right)$ & $\mathrm{PA}\left({ }^{\circ} \mathrm{C}\right)$ & $\mathrm{PF}\left({ }^{\mathrm{O}} \mathrm{C}\right)$ & $P A\left({ }^{\circ} \mathrm{C}\right)$ & $\mathrm{PF}\left({ }^{\mathrm{O}} \mathrm{C}\right)$ & $\mathrm{PA}\left({ }^{\mathrm{O}} \mathrm{C}\right)$ & $\mathrm{PF}\left({ }^{\mathrm{O}} \mathrm{C}\right)$ & $\mathrm{PA}\left({ }^{\mathrm{O}} \mathrm{C}\right)$ & $\mathrm{PF}\left({ }^{\mathrm{O}} \mathrm{C}\right)$ & $\mathrm{PA}\left({ }^{\circ} \mathrm{C}\right)$ \\
\hline 0 & 25,0 & 24,0 & 23,0 & 22,6 & 21,0 & 20,4 & 20,8 & 17.8 & 20,8 & 17.6 & 23.4 & 21.6 \\
\hline 5 & 26,4 & 25,2 & 24.6 & 23,6 & 22,2 & $2 \mathrm{I}, 4$ & 24,2 & 23,0 & 22,2 & 20.0 & 26,6 & 23.8 \\
\hline 10 & 26.6 & 25,4 & 27,2 & 25,8 & 24,8 & 23,6 & 29,8 & 28,0 & 34,0 & 23.4 & 35.0 & 28.6 \\
\hline 15 & $26 \cdot 8$ & 25.2 & 27.6 & 26,0 & 27.6 & 25,8 & 31,6 & 29.0 & 34.4 & 28.8 & 38,8 & 35.8 \\
\hline 20 & 26.8 & 25.2 & 27,6 & 26,2 & 28.8 & 26,4 & 32,0 & 29,2 & 36.8 & 29.6 & 43,2 & 36,6 \\
\hline 25 & 26,6 & 25.2 & 27,6 & 26,0 & 29,2 & 27.2 & 32.2 & 29,2 & 39.6 & 31,0 & 43.8 & 36,2 \\
\hline 30 & 26,8 & 25,0 & 27,8 & 26.0 & 29,4 & 27.6 & 32,4 & 29,0 & 40.4 & 32,2 & 43,8 & 39,0 \\
\hline 35 & - & - & - & - & - & - & 32,2 & 29,6 & 40,0 & 32,0 & 44,0 & 37,6 \\
\hline 40 & - & - & - & - & - & - & 32,2 & 30,0 & 40,8 & 31,0 & 43,8 & 38,4 \\
\hline 45 & - & - & - & - & - & - & 32,4 & 29,8 & 40,6 & 31,2 & 44,0 & 40,0 \\
\hline
\end{tabular}


42.

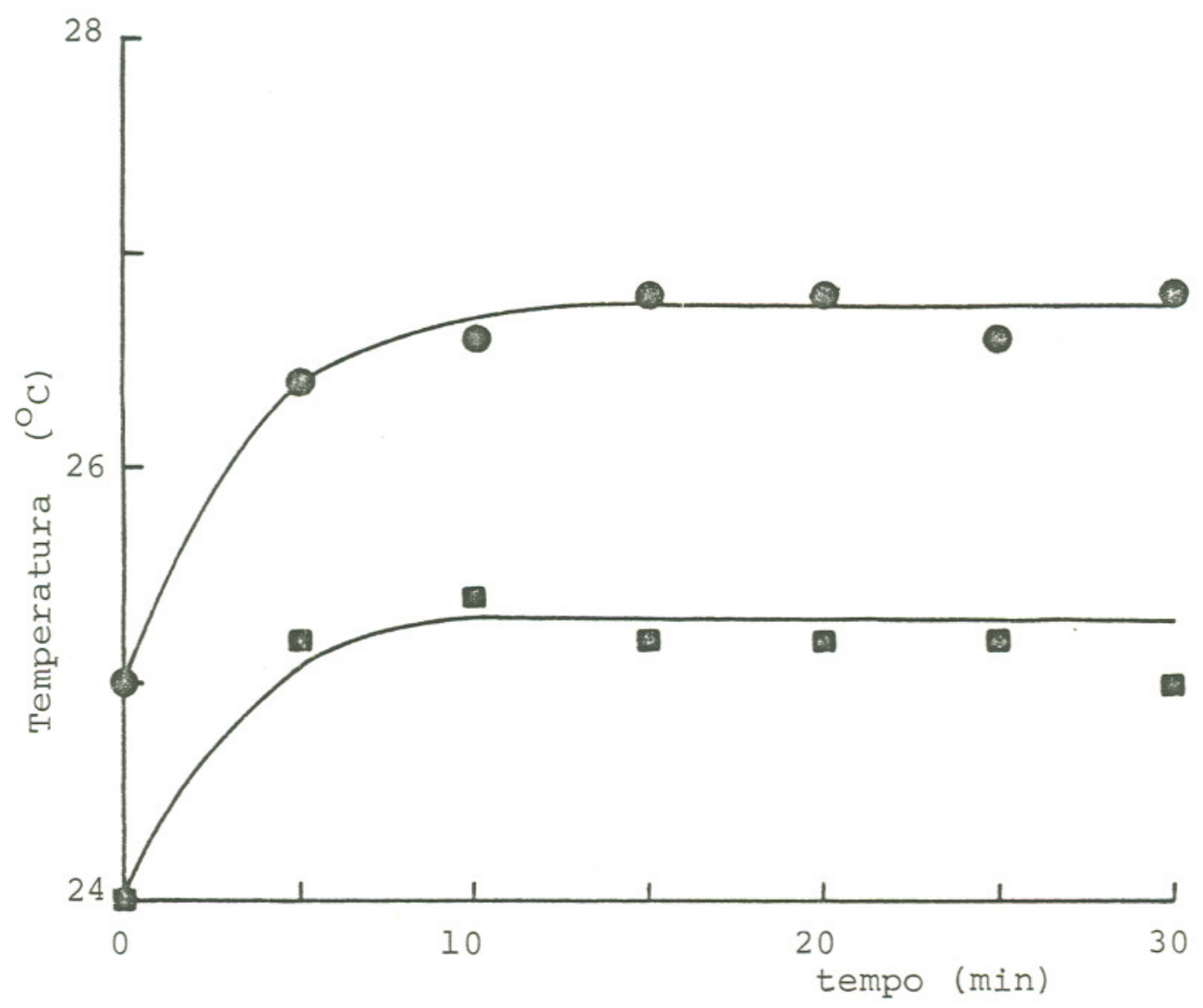

FIGURA 1. Temperatura em função do tempo para a reação de interesterificação de gordura de babaçu. ( ) , ponto de fusão (घ), ponto de amoleci mento. 
43.

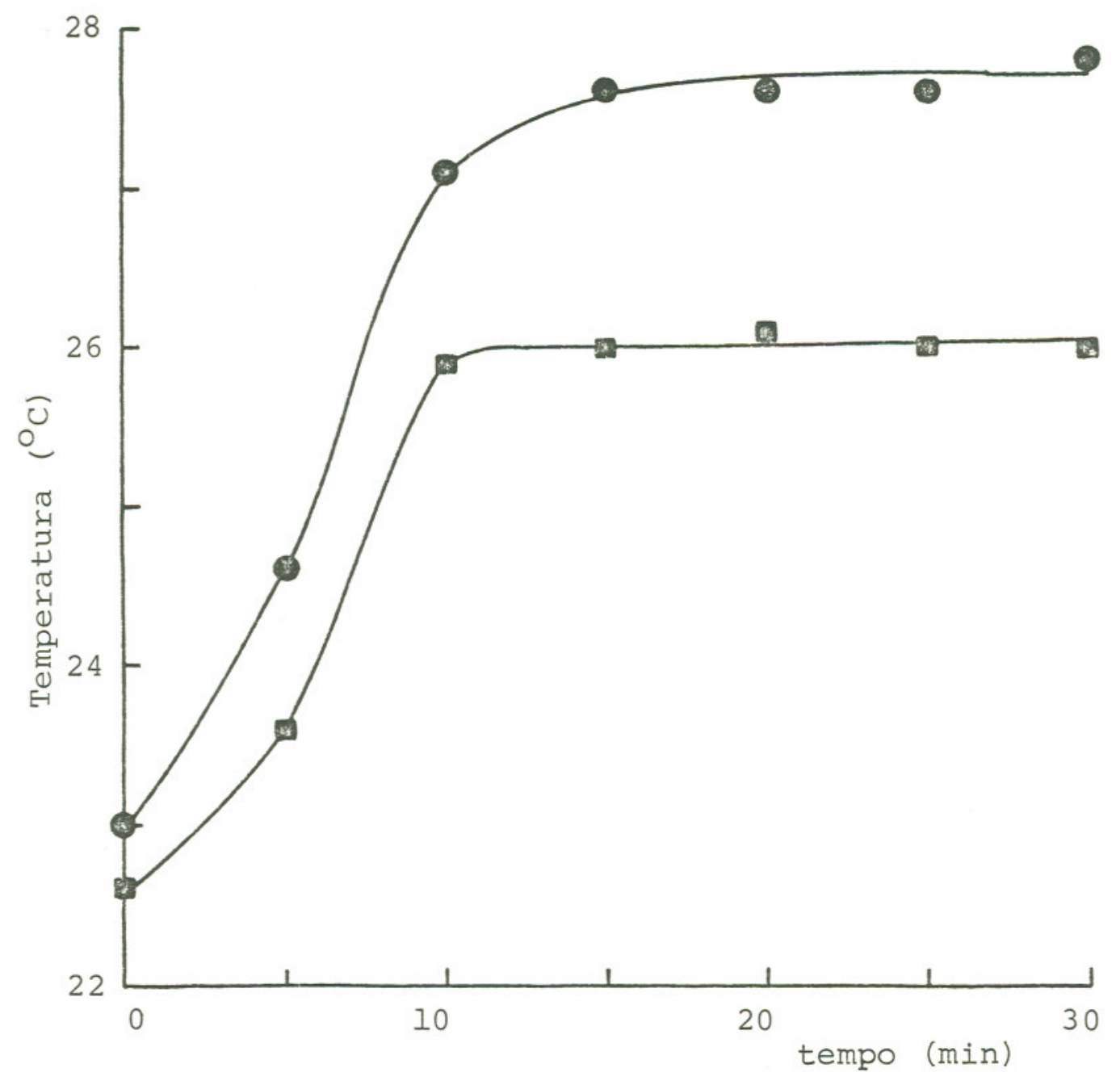

FIGURA 2. Temperatura em função do tempo para a reação de interesterificação de babaçu e dendê neutralizado na proporção respectiva de 80:20.

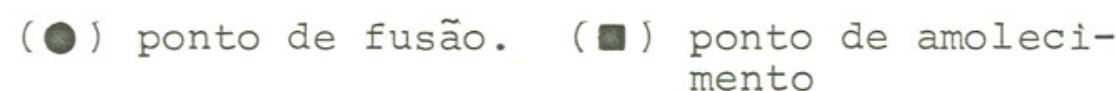




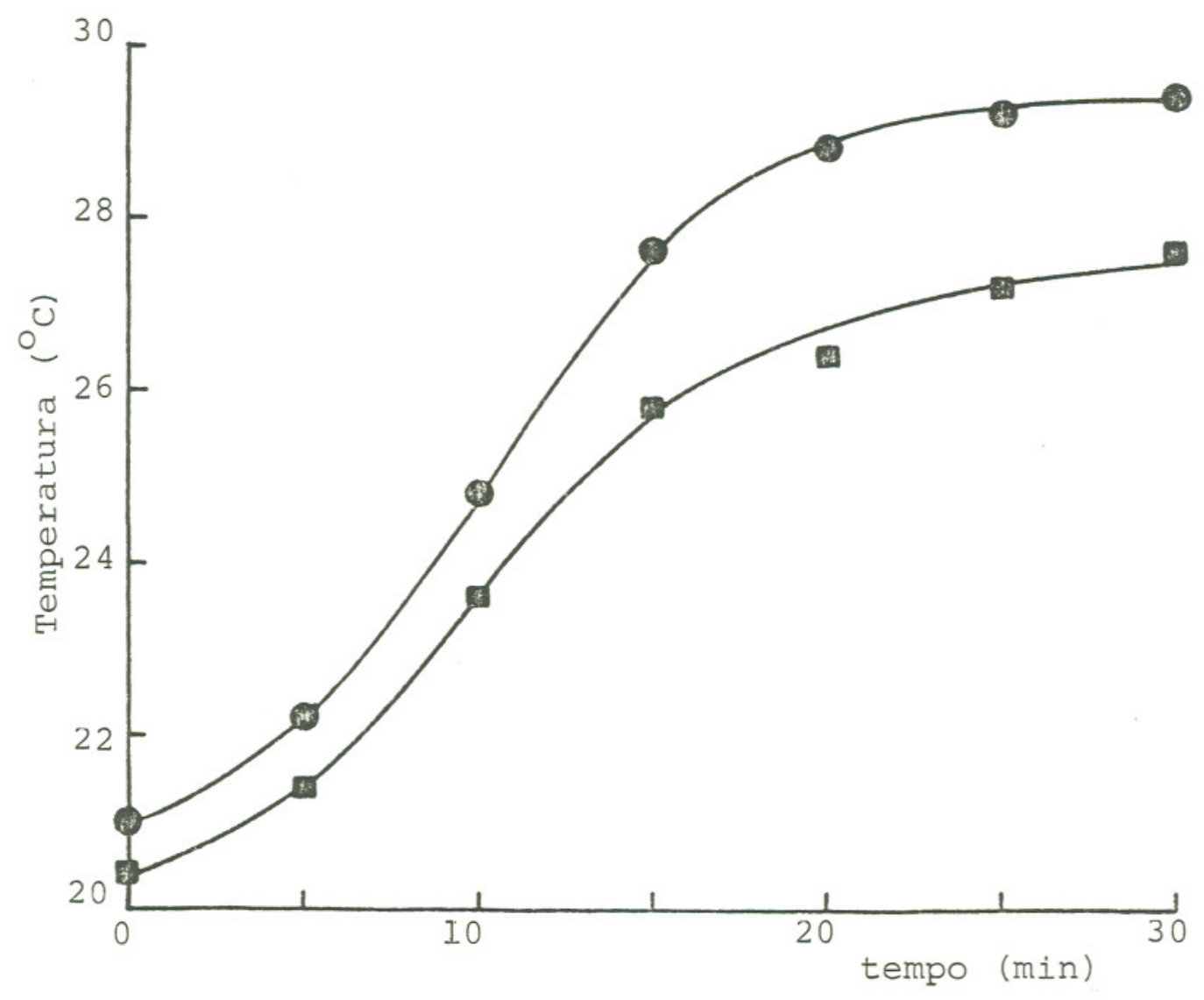

FIGURA 3. Temperatura em função do tempo para a reação de interesterificação de babaçu e dendê neutralizado na proporção respectiva de 60:40.

(O) ponto de fusão

(a) ponto de amolecimento 


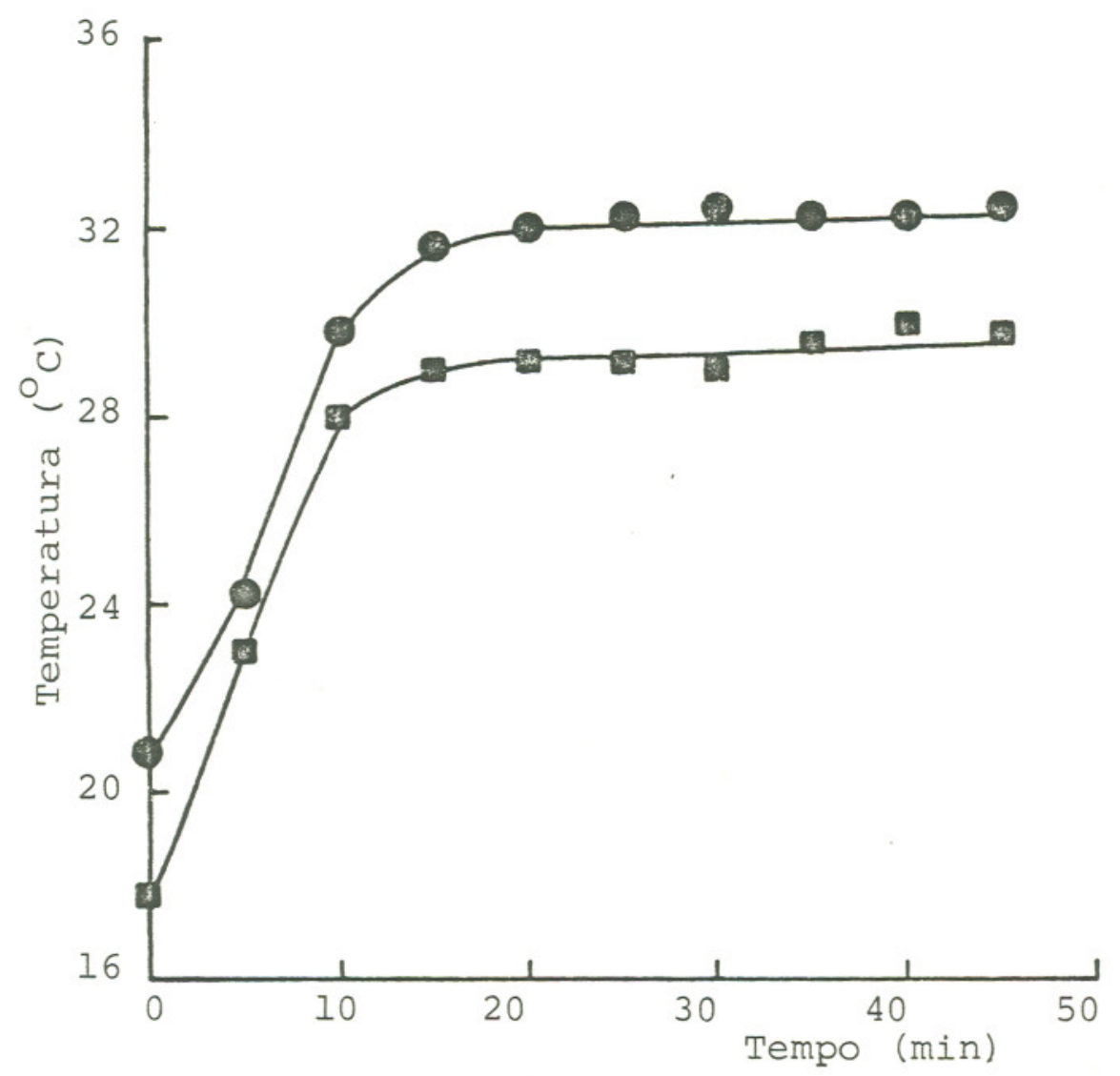

FIGURA 4. Temperatura em função do tempo para a reação de interesterificação de babaçu e dendê neutralizado na proporção respectiva de 40:60.

(O) ponto de fusão

(घ) ponto de amolecimento 
46.

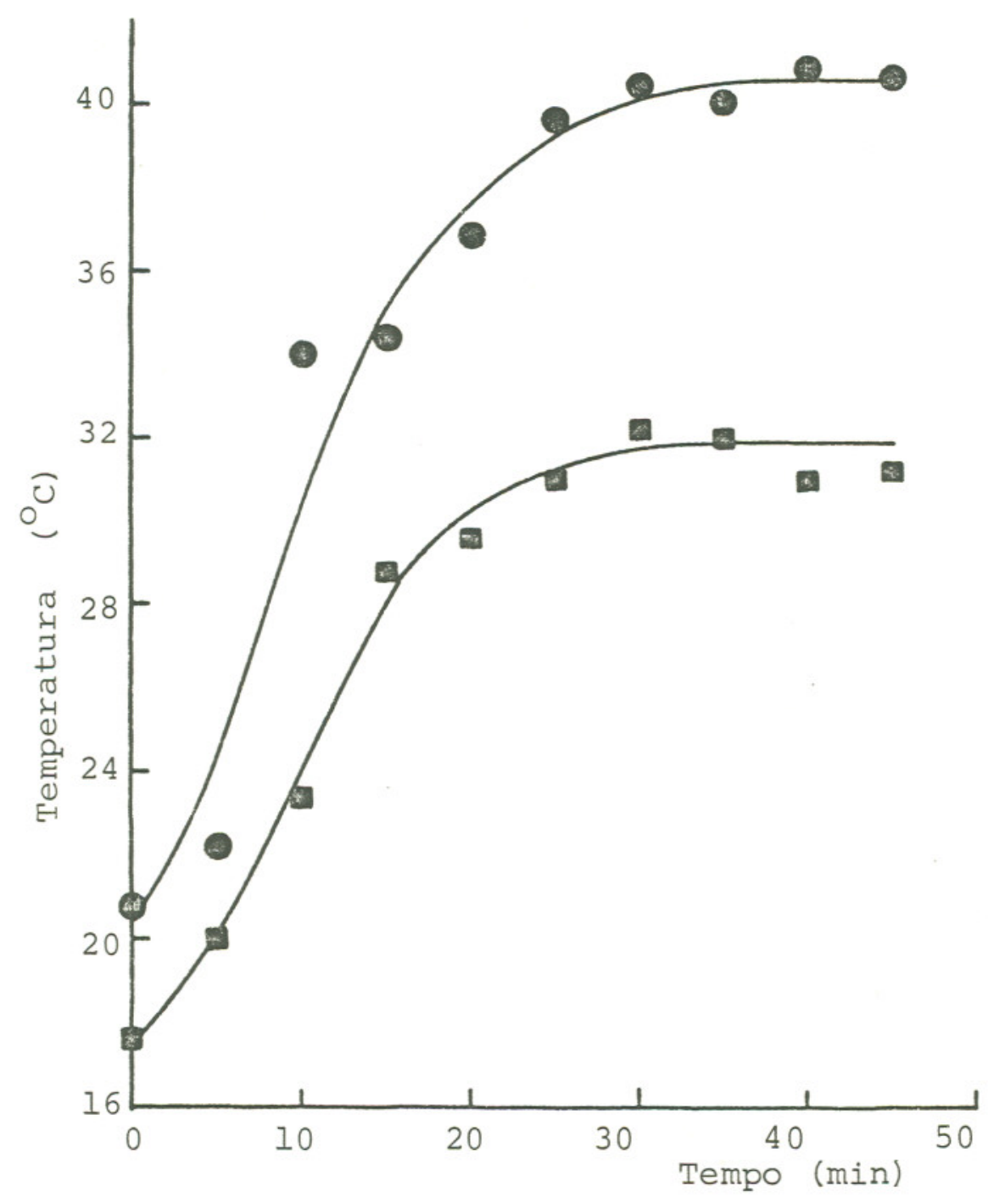

FIGURA 5. Temperatura em função do tempo para a reação de interesterificação de babaçu e dendê neutralizado na proporção respectiva de 20:80.

(-) ponto de fusão

(a) ponto de amolecimento 


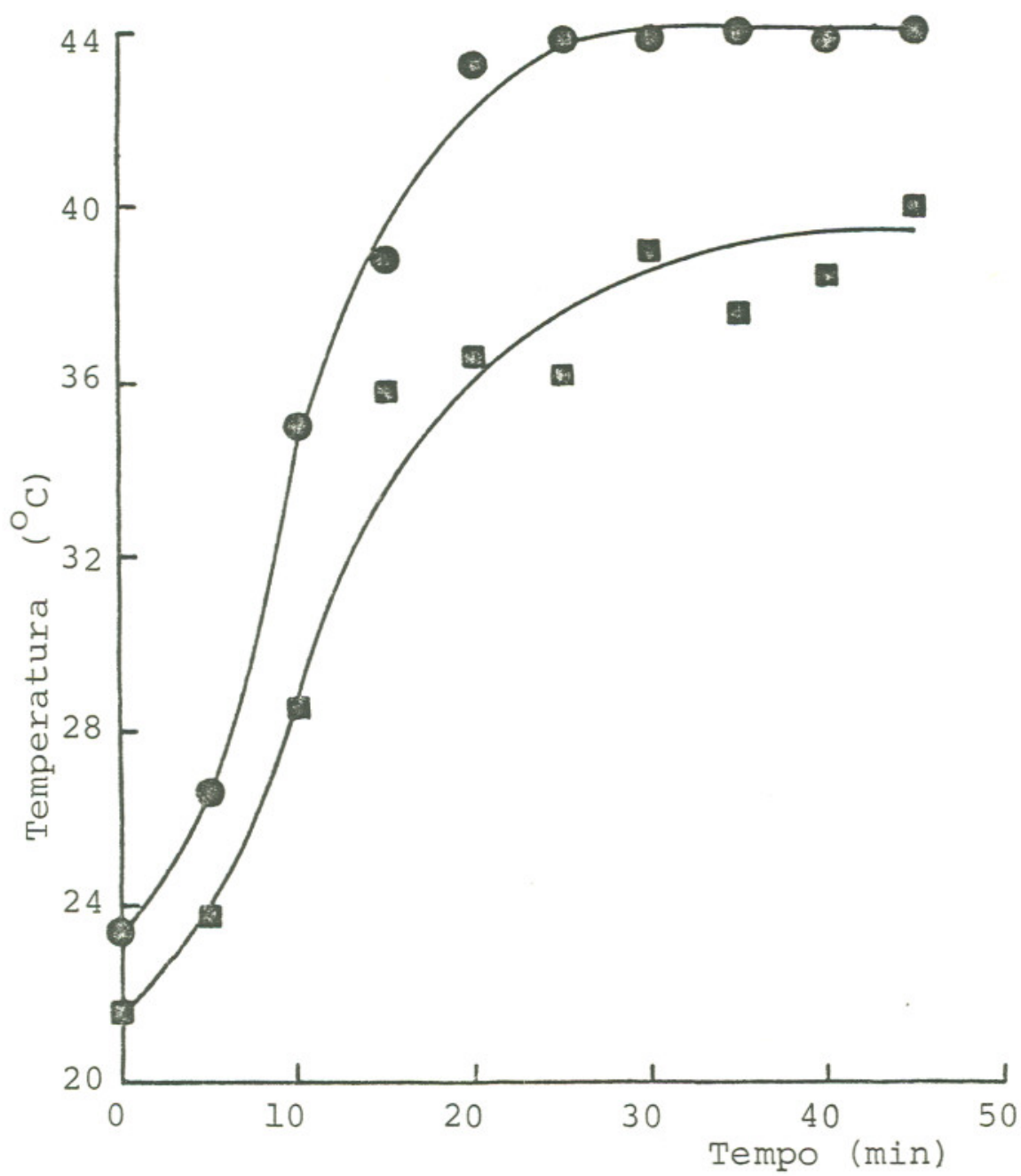

FIGURA 6. Temperatura em função do tempo para a reação de interesterificação de azeite de dendê neu tralizado.

(O) ponto de fusão

( $)$ ponto de amolecimento 
48.

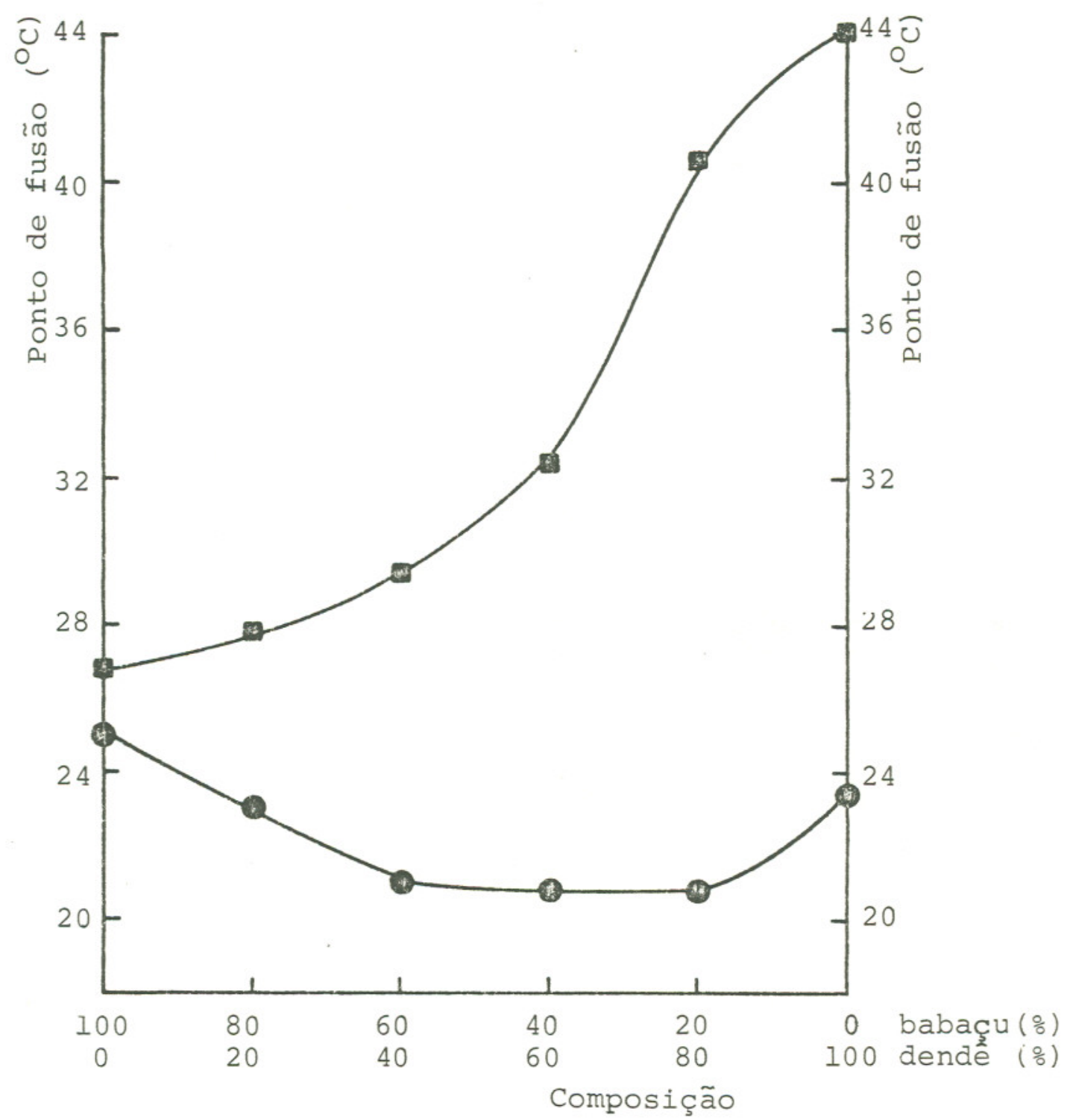

FIGURA 7. Diagrama da mistura de babaçu e dendê neutralizado em função do ponto de fusão.

(O) antes

(घ) após 
49.

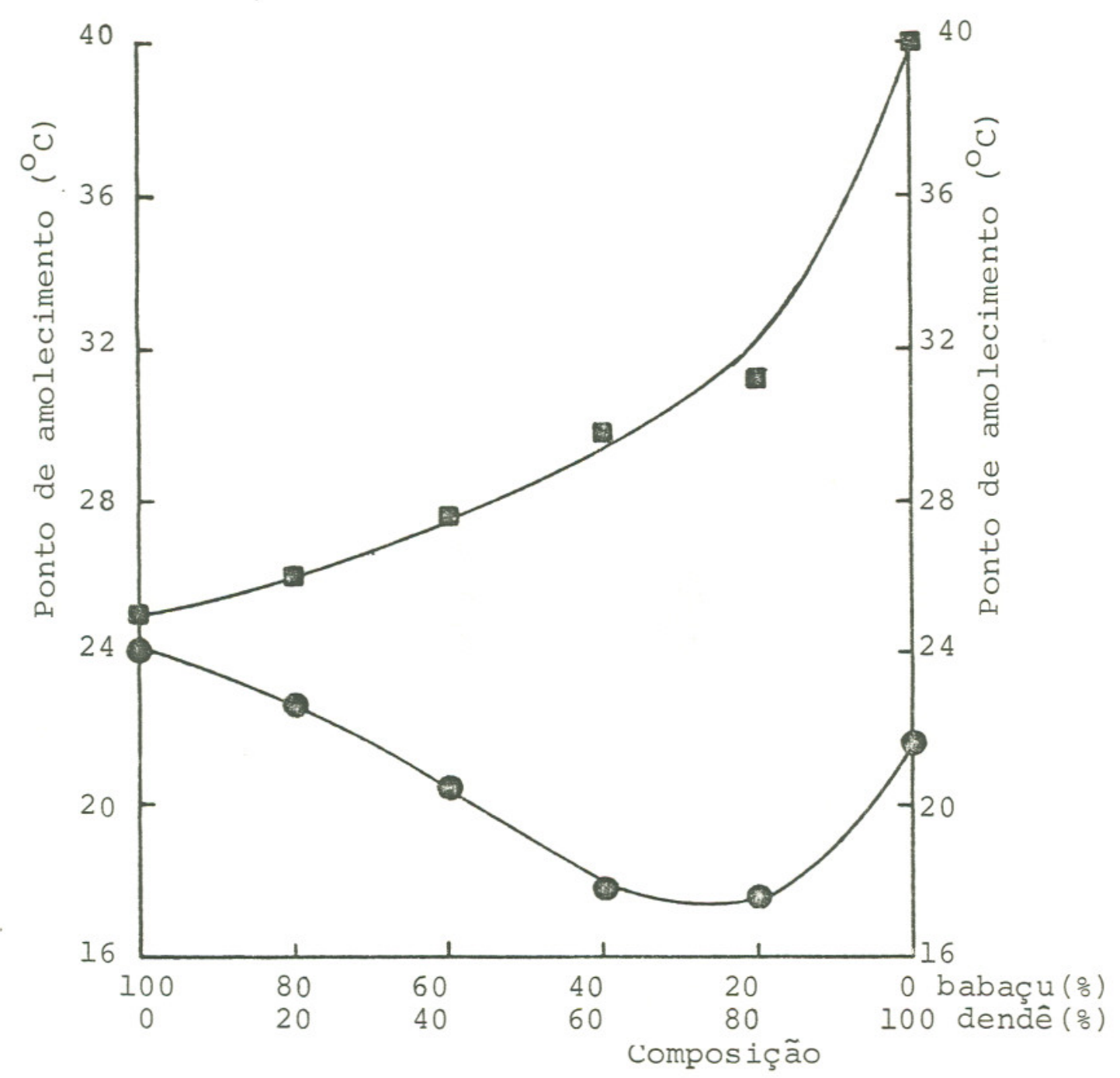

FIGURA 8. Dìagrama da mistura de babaçu e dendê neutralizado em função do ponto de amolecimen to.

(O) antes

(घ) apōs 


\section{2 - Indice de gordura sólida}

A tabela 4 e as figuras de 9 a 14 representam os indices de gordura sólida antes e após a reações de interesterificação com proporções variáveis de gordura de babaçu e azeite de dendê neutralizado.

O efeito provocado pelo rearranjo foi, de modo geral, pequena diminuição no teor de gordura sólida em temperaturas mais baixas e o seu aumento em temperaturas maiores, mais pronunciado à medida que aumenta a proporção do azeite de dendê. Portanto, o rearranjo induziu à diminuição da inclinação das curvas de sólidos, indicando que as gorduras aumentaram suas faixas de plasticidade.

Uma maneira de se verificar as interações entre triglicérides é através da construção de diagra mas de curvas iso-sólidas $(51,52)$, semelhantes aos diagramas de isodilatação introduzidos por ROSSELL (73). Estes dados são apresentados nas tabelas 5 e 6 e representados gra ficamente nas figuras 15 e 16 .

Na mistura de babaçu e dendê antes do rearranjo (Fig. 15) observa-se a formação de um sistema eutētico, cuja composição estā na proporção de $20 \%$ de babaçu para $80 \%$ de dendê. A incompatibilidade destas gorduras nesta faixa de mistura provoca considerável amolecimento. Este mesmo efeito ocorre em composições de óleo de palma e óleo de caroço de palma (96) ou de óleo de palma é́leo de coco (51).

Após o rearranjo (Fig. 16), entretanto, diminui a incompatibilidade, visto que a variação é mínima. 
TABELA 4. Indices de gordura sólida antes e após as reações de interesterificação com proporções variáveis de gordura de babaçu e azeite de dendê neutralizado

\begin{tabular}{|c|c|c|c|c|c|c|c|c|c|c|c|c|c|}
\hline \multirow{3}{*}{$\begin{array}{c}\text { Proporção } \\
\text { (babaçu: dendê) }\end{array}$} & \multicolumn{13}{|c|}{ Indice de gordura sólida (을 a } \\
\hline & \multicolumn{5}{|c|}{ Antes } & \multicolumn{8}{|c|}{ Após } \\
\hline & $10^{\circ} \mathrm{C}$ & $15^{\circ} \mathrm{C}$ & $20^{\circ} \mathrm{C}$ & $25^{\circ} \mathrm{C}$ & $30^{\circ} \mathrm{C}$ & $10^{\circ} \mathrm{C}$ & $15^{\circ} \mathrm{C}$ & $20^{\circ} \mathrm{C}$ & $25^{\circ} \mathrm{C}$ & $30^{\circ} \mathrm{C}$ & $35^{\circ} \mathrm{C}$ & $40^{\circ} \mathrm{C}$ & $45^{\circ} \mathrm{C}$ \\
\hline $100: 0$ & 46,5 & 38,4 & 24,6 & 2,1 & 0 & 39,6 & 32,6 & 21,8 & 8,1 & 0 & - & - & - \\
\hline $80: 20$ & 39,4 & 28,9 & 13,2 & 0 & - & 36,5 & 28,1 & 18,8 & 7,0 & 0 & - & - & - \\
\hline $60: 40$ & 42,8 & 31,4 & 15,8 & 0 & - & 31,4 & 24,2 & 15,3 & 9,0 & 0 & - & - & - \\
\hline $40: 60$ & 26,2 & 13,0 & 3,4 & 0 & - & 25,3 & 19,0 & 12,9 & 8,6 & 4,1 & 0 & - & - \\
\hline $20: 80$ & 22,9 & 9,2 & 3,2 & 0 & - & 26,6 & 20,2 & 15,3 & 11,9 & - & 3,4 & 0 & - \\
\hline $0: 100$ & 30,6 & 16,1 & 6,7 & 0 & - & 28,3 & 23,2 & 18,9 & 16,1 & - & 10,6 & - & 0 \\
\hline
\end{tabular}


52.

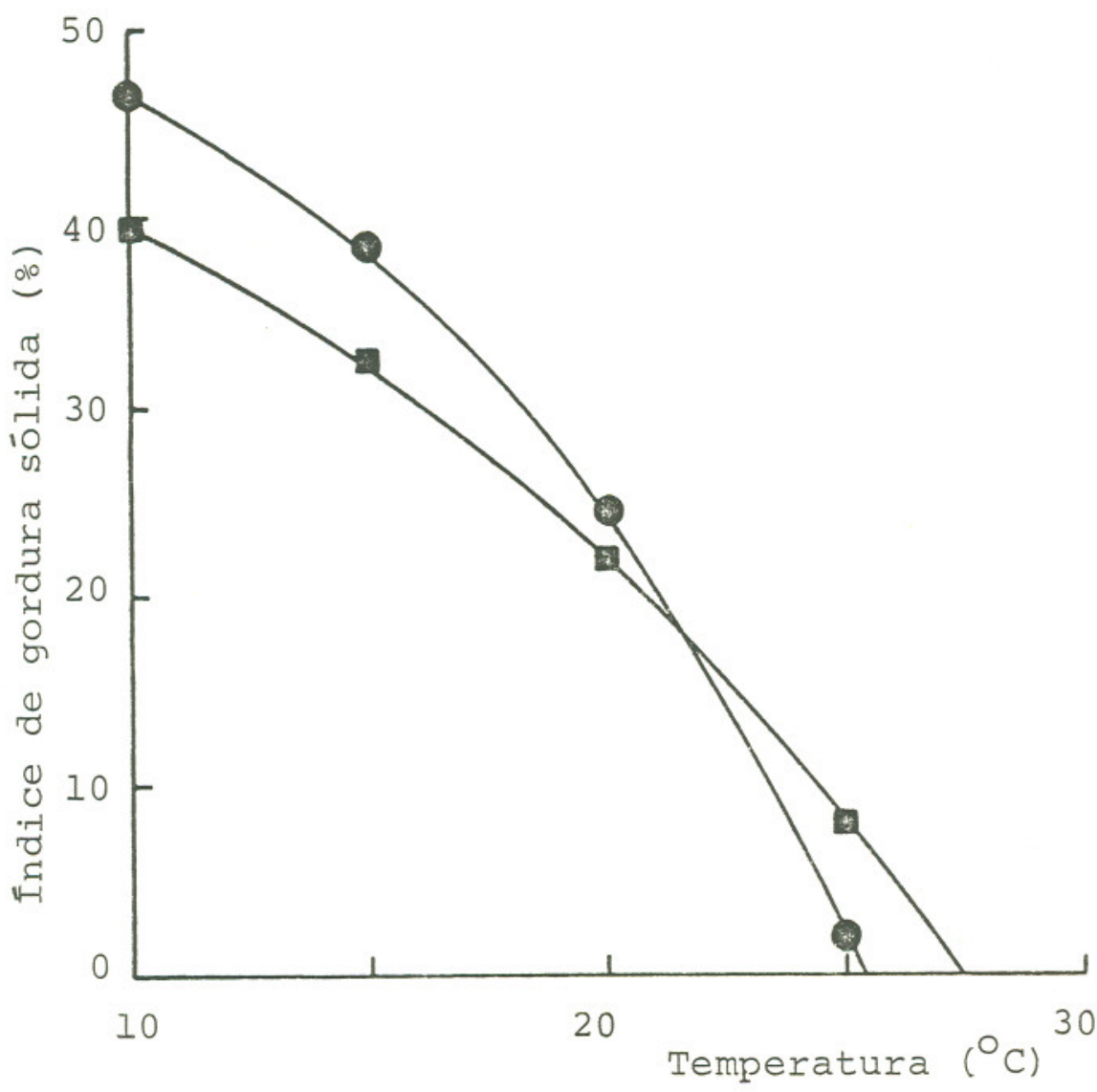

FIGURA 9. Curvas de sólidos para a reação de interesterificação de gordura de babaçu.

(O) antes

( apoós 


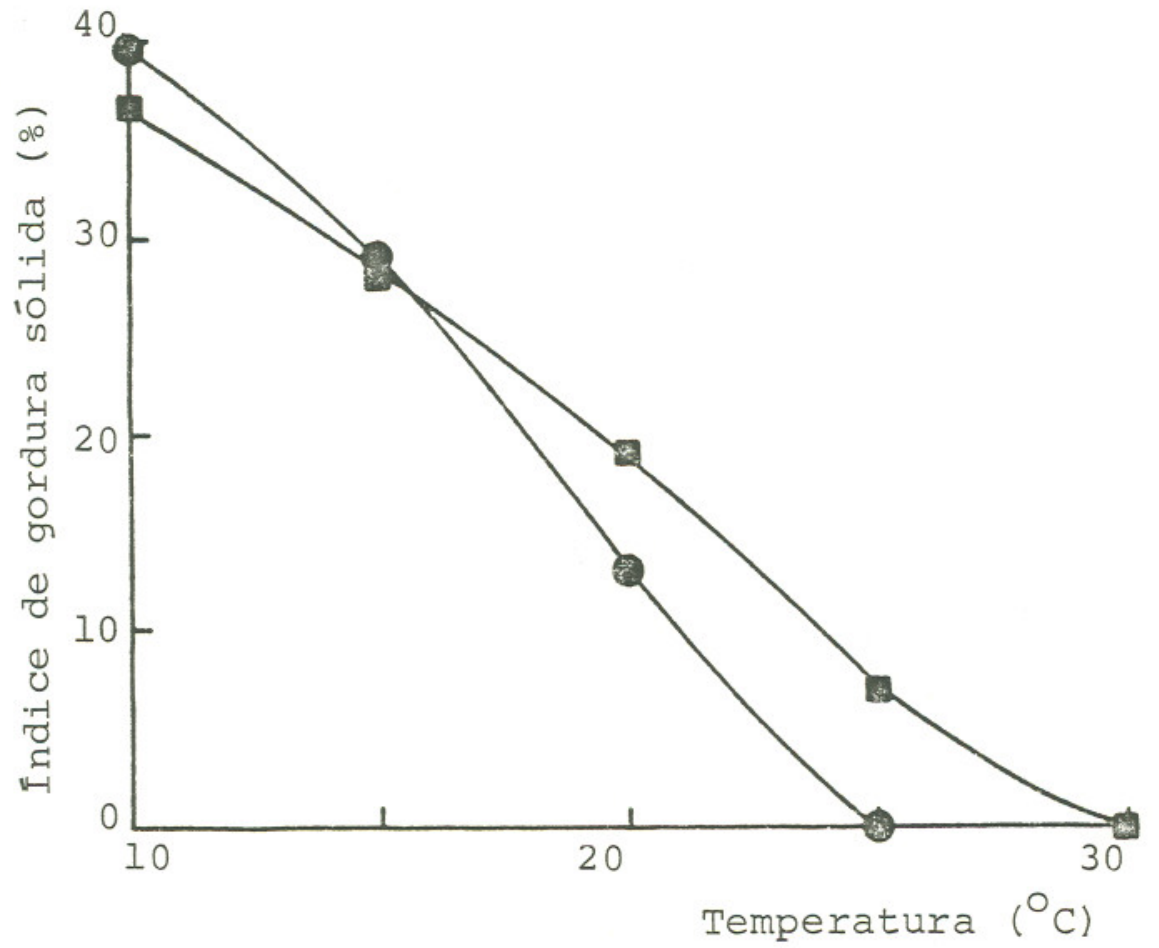

FIGURA 10. Curvas de sólidos para a reação de interesterificação de babaçu e dendê neutralizado na proporção respectiva de $80: 20$.

(O) antes

(घ) apōs 
54.

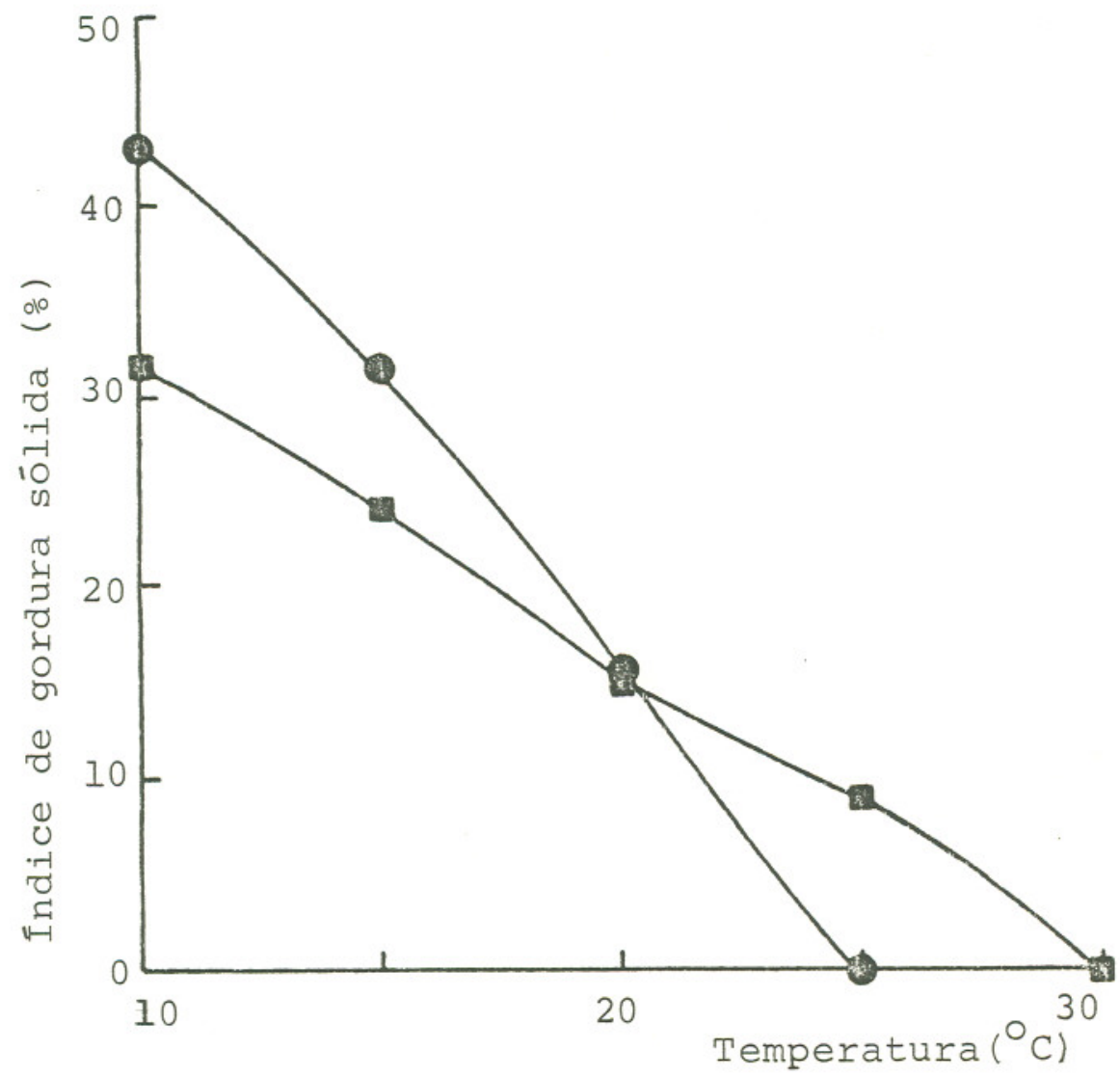

FIGURA 11. Curvas de sólidos para a reação de interesterificação de babaçu e dendê neutralizado na proporção respectiva de 60:40

(O) antes

(1) após 
55.

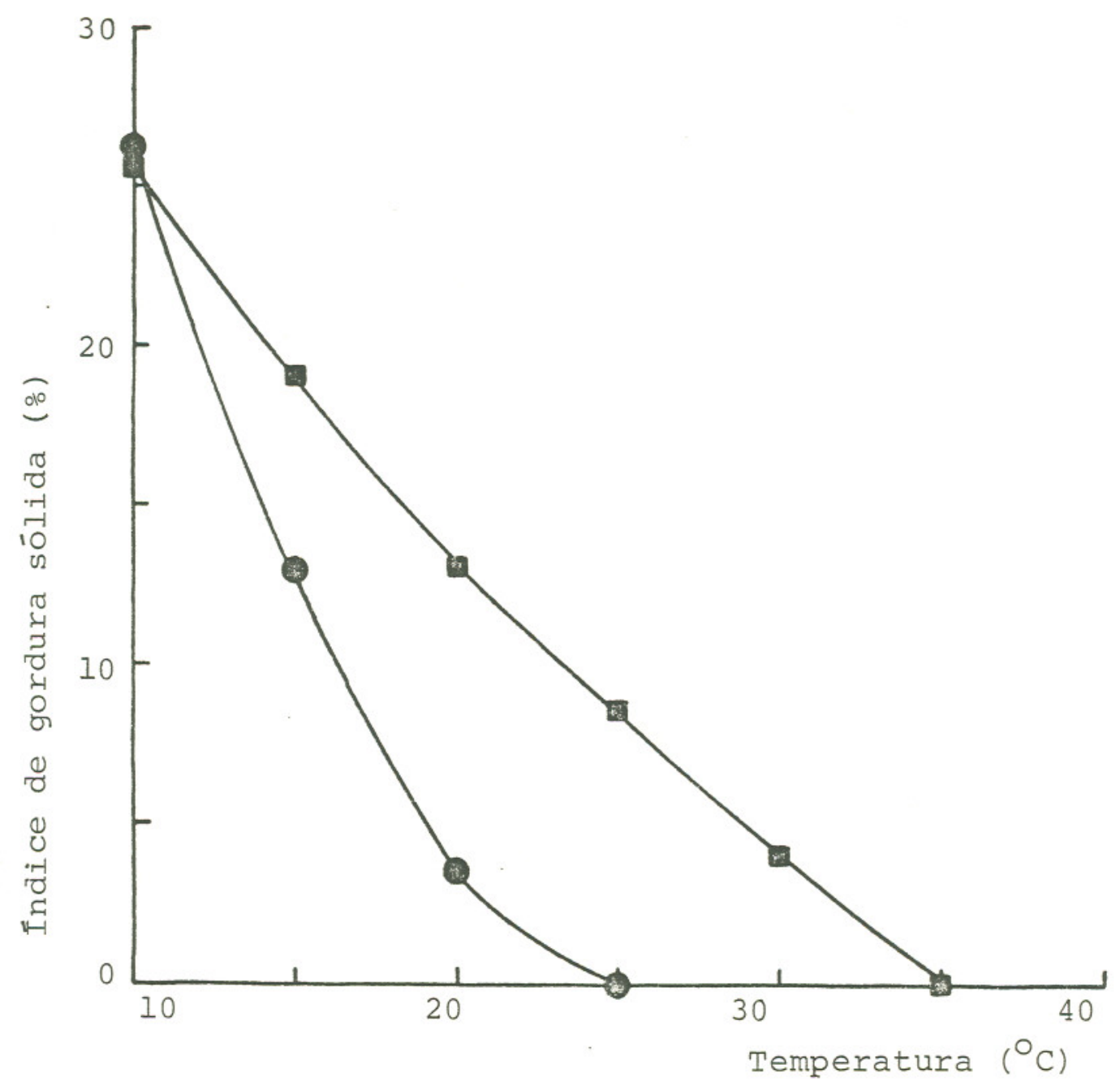

FIGURA 12. Curvas de sólidos para a reação de interesterificação de babaçu e dendê neutralizado na proporção respectiva de 40:60.

(1) antes

(a) após 


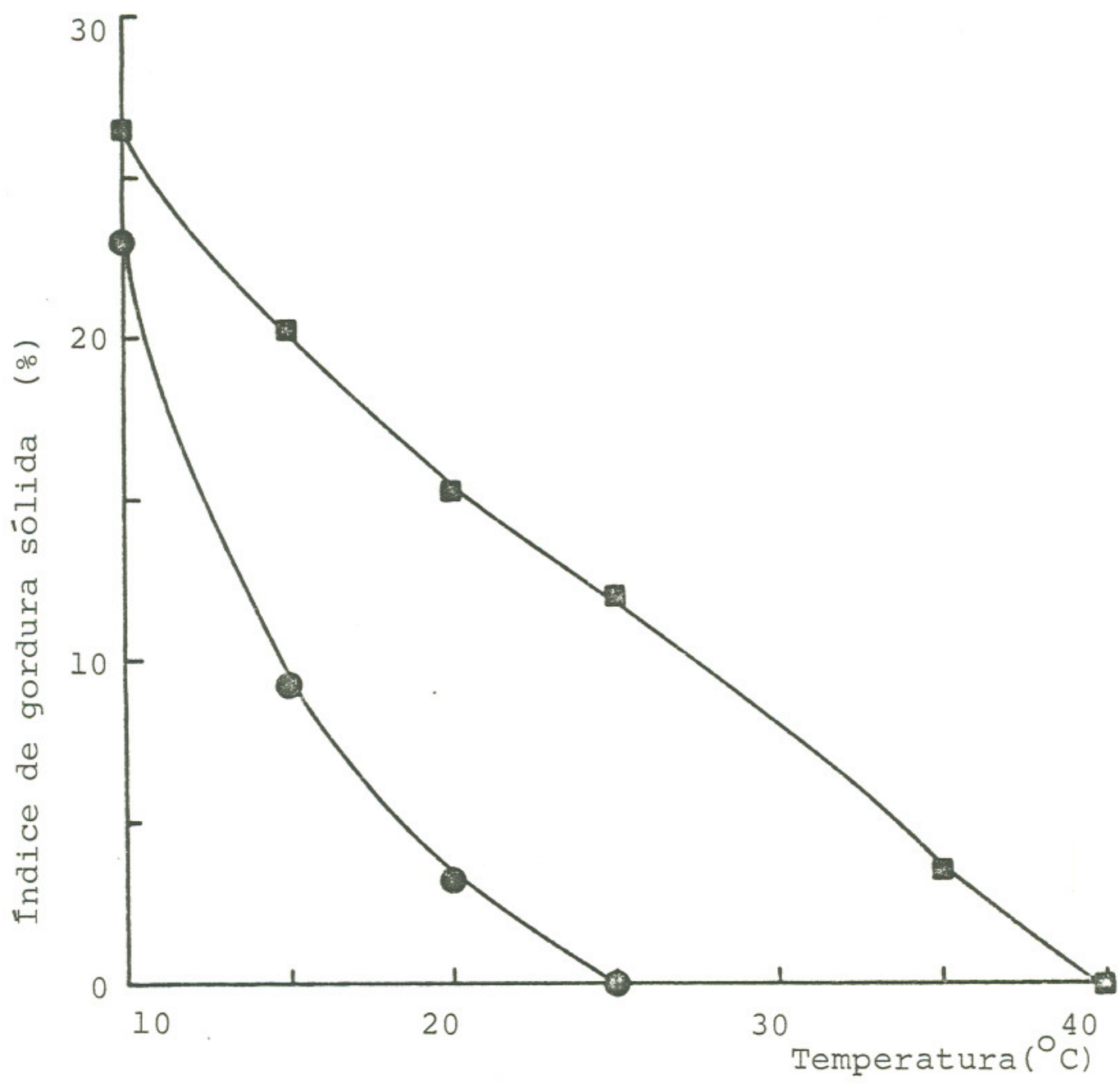

FIGURA 13. Curvas de sólidos para a reação de interesterificação de babaçu e dendê neutrą lizado na proporção respectiva de 20:80. (O) antes

( $)$ apōs 


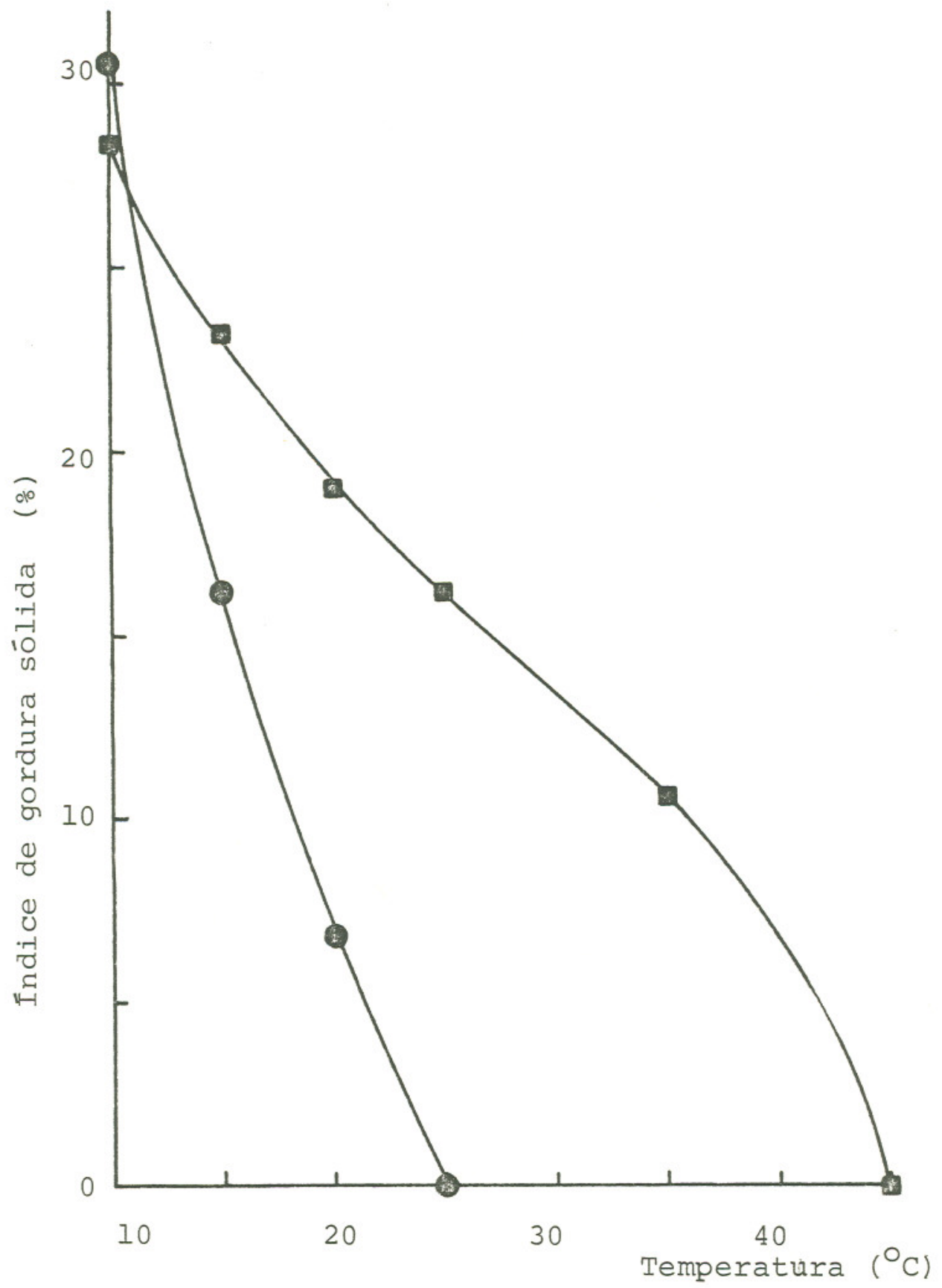

FIGURA 14. Curvas de sölidos para a reação de interes terificação de azeite de dendê neutralizado.

(O) antes

(1) apös 
TABELA 5. Temperaturas correspondentes a diversos indices de gordura sōlida para misturas em proporções variáveis de gordura de babaçu e azeite de dendê neutra lizado antes do rearranjo.

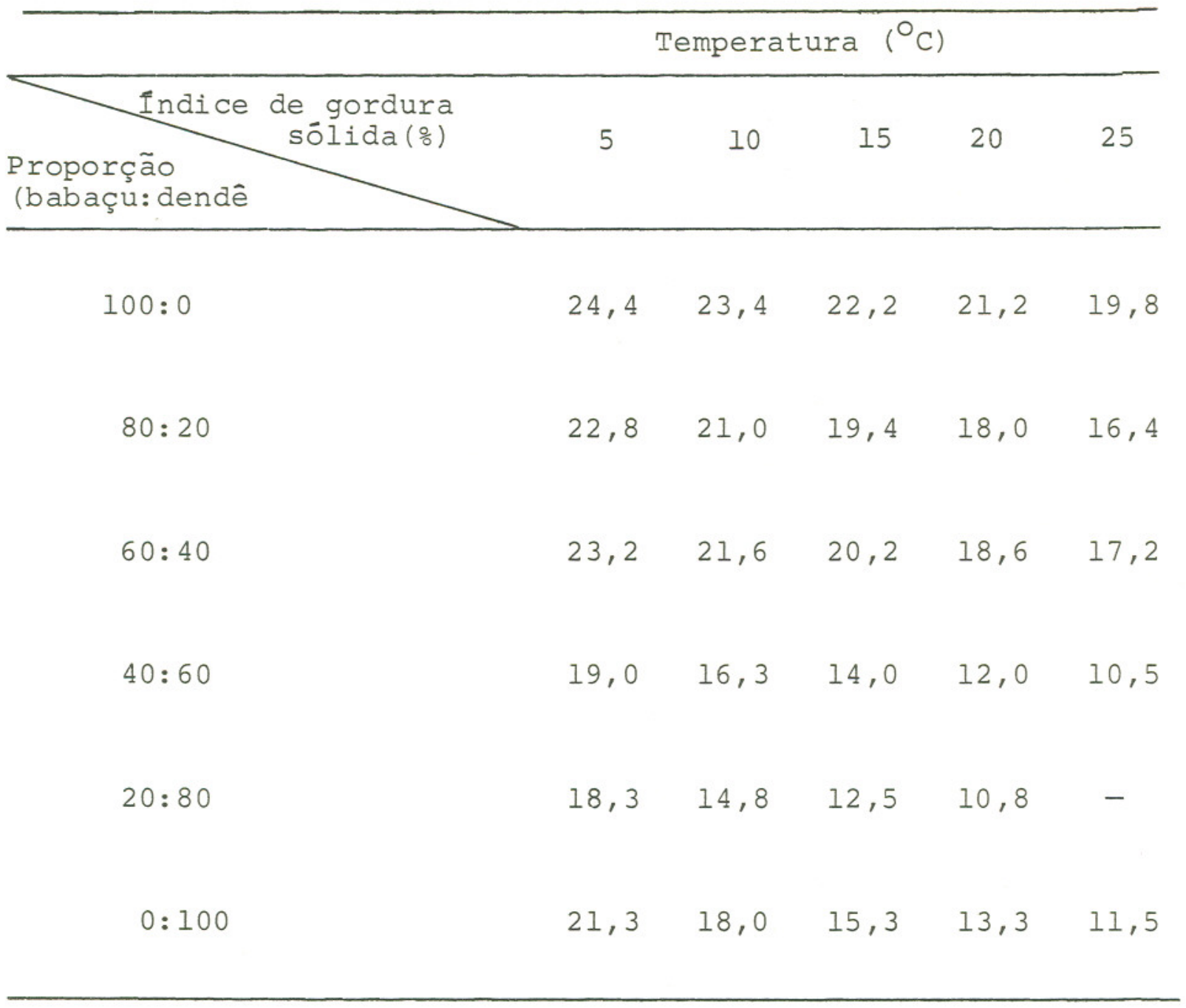


TABELA 6. Temperaturas correspondentes a diversos indices de gordura sólida para misturas em proporções variáveis de gordura de babaçu e azeite de dendê neutra lizado apōs o rearranjo.

\begin{tabular}{|c|c|c|c|c|c|}
\hline & & Tempe & tura & $\left({ }^{\circ} \mathrm{C}\right)$ & \\
\hline \multicolumn{6}{|l|}{$\begin{array}{l}\text { Proporção } \\
\text { (babaçu: dendê) }\end{array}$} \\
\hline $100: 0$ & 26,0 & 24,5 & 22,8 & 20,9 & 18,7 \\
\hline $80: 20$ & 26,2 & 23,8 & 21,6 & 19,4 & 16,6 \\
\hline $60: 40$ & 27,4 & 24,0 & 20,0 & 17,2 & 14,4 \\
\hline $40: 60$ & 29,0 & 23,3 & 18,3 & 14,1 & 10,5 \\
\hline $20: 80$ & 33,4 & 27,4 & 20,5 & 15,3 & 10,9 \\
\hline $0: 100$ & 41,7 & 35,8 & 27,0 & 18,8 & 12,7 \\
\hline
\end{tabular}


60.

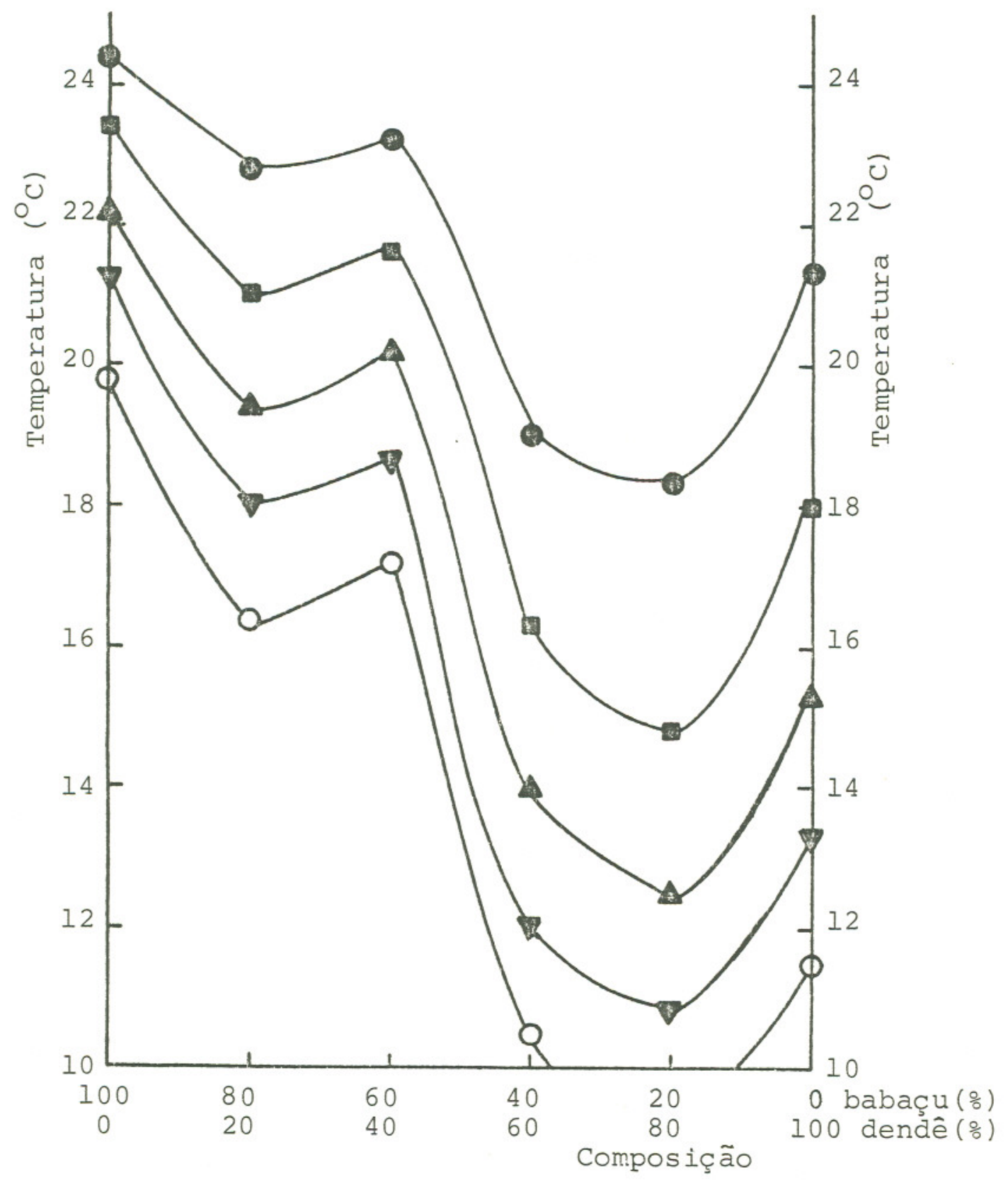

FIGURA 15. Diagrama de curvas iso-sōlidas da mistura de babaçu e dendê neutralizado.

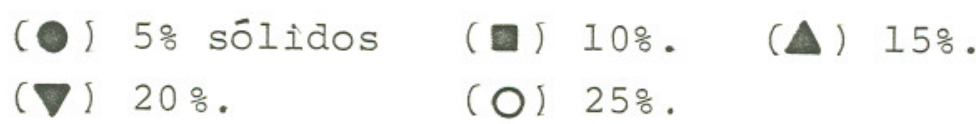


61.

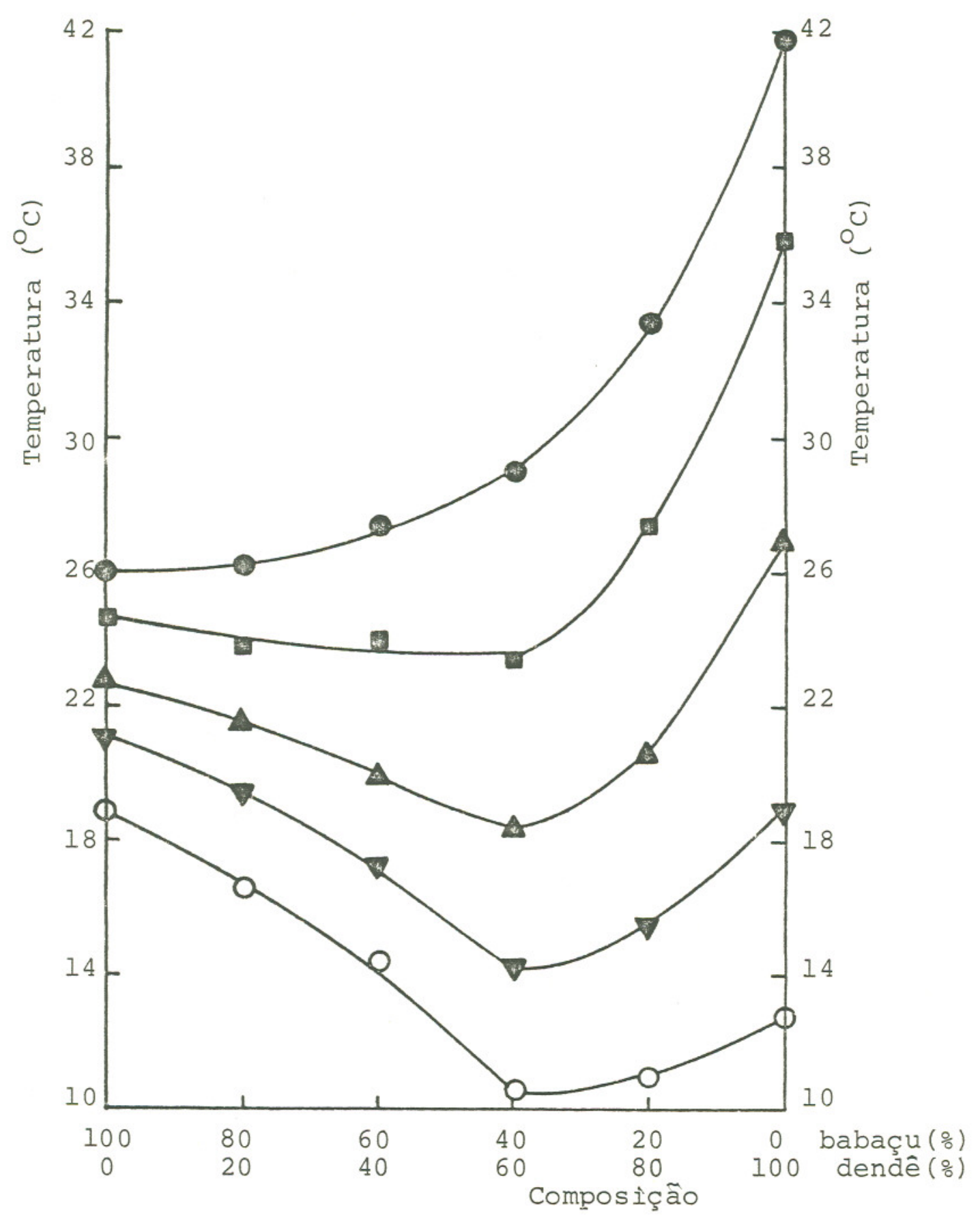

FIGURA 16. Diagrama de curvas iso-sōlidas da mistura de babaçu e dendê neutralizado apōs o rearranjo.

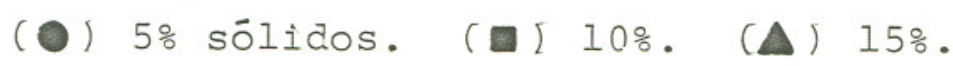

( $\nabla$ ) $20 \%$ (O) $25 \%$. 


\section{3 - Composição em ácidos graxos}

A tabela 7 mostra a composição em ácidos graxos das misturas de gordura de babaçu e azeite de dendê neutralizado antes e após a randomização. Comprova-se que o processo de interesterificação não provoca alteração na composição em ácidos graxos como um todo. As diferenças observadas são inerentes ao método de anālise.

As tabelas de 8 a 13 apresentam os ácidos graxos da posição central do glicerol durante as reações de interesterificação. A partir destes resultados calcula-se a proporção de cada ácido graxo presente na posição 2 pela equação $(35,54)$ :

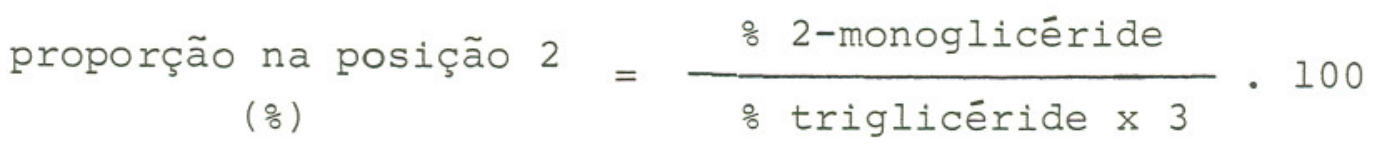

Nas tabelas de 14 a 19 e nas figuras de 17 a 22 é apresentada a variação da proporção de ácidos gra xos na posição 2 durante os rearranjos efetuados.

$\mathrm{Na}$ distribuição ao acaso dos äcidos graxos, a proporção na posição 2 será de $1 / 3$ ou 33,3\%. Dessa forma, numa gordura natural, desvios significativos acima ou abaixo desse valor indicam alta ou baixa preferência de um determinado ācido graxo em relação àquela posição.

Na gordura de babaçu e no azeite de den dê antes do rearranjo verifica-se preferência dos ácidos oléico e linoléico pela posição 2, enquanto que os ácidos graxos saturados distribuem-se principalmente nas posições 
TABELA 7. Composição em ācidos graxos de misturas em proporções variāveis de gordura de babaçu e azelte de dendê neutralizado antes e após as reações de interesterificação

\begin{tabular}{|c|c|c|c|c|c|c|c|c|c|c|c|c|}
\hline \multirow{4}{*}{$\begin{array}{l}\text { Ācido } \\
\text { graxo }\end{array}$} & \multicolumn{12}{|c|}{ \% em massa } \\
\hline & \multicolumn{12}{|c|}{ Proporção (babaçu: dendê) } \\
\hline & \multicolumn{2}{|c|}{$100: 0$} & \multicolumn{2}{|c|}{$80: 20$} & \multicolumn{2}{|c|}{$60: 40$} & \multicolumn{2}{|c|}{$40: 60$} & \multicolumn{2}{|c|}{$20: 80$} & \multicolumn{2}{|c|}{$0: 100$} \\
\hline & Antes & Apōs & Antes & Apōs & Antes & Apōs & Antes & Apōs & Antes & Apōs & Antes & Apōs \\
\hline $\mathrm{C}_{6}$ & $\mathrm{TR}^{\mathrm{a}}$ & TR & - & - & - & - & $\mathrm{TR}$ & $\mathrm{TR}$ & - & - & - & - \\
\hline $\mathrm{C}_{8}$ & 7,5 & 8,5 & 5,4 & 6,5 & 6,3 & 3,2 & 4,4 & 5,8 & 1,9 & 1,8 & - & - \\
\hline $\mathrm{C}_{10}$ & 9,1 & 7,9 & 5,2 & 4,7 & 3,9 & 3,5 & 3,0 & 2,8 & 1,5 & 1,3 & - & - \\
\hline $\mathrm{C}_{12}$ & 27,3 & 28,3 & 27,6 & 25,9 & 25,1 & 23,2 & 18,4 & 18,5 & 11,3 & 9,4 & 0,1 & 0,1 \\
\hline $\mathrm{C}_{14}$ & 19,3 & 17,7 & 13,2 & 13,5 & 10,0 & 11,6 & 7,2 & 7,4 & 4,2 & 3,8 & 1,0 & 1,0 \\
\hline $\mathrm{C}_{16}$ & 11,0 & 10,5 & 17,2 & 16,7 & 19,9 & 22,8 & 26,0 & 25,0 & 29,8 & 30,9 & 38,5 & 36,7 \\
\hline $\mathrm{C}_{18}$ & 3,8 & 4,4 & 3,6 & 4,2 & 3,5 & 4,2 & 3,5 & 3,6 & 4,5 & 4,0 & 5,4 & 4,5 \\
\hline $\mathrm{C}_{18: 1}$ & 18,7 & 19,2 & 22,7 & 23,3 & 24,6 & 26,3 & 29,0 & 28,9 & 36,1 & 37,8 & 42,8 & 44,7 \\
\hline $\mathrm{C}_{18: 2}$ & 3,3 & 3,5 & 5,1 & 5,2 & 6,7 & 5,2 & 8,5 & 8,0 & 10,7 & 11,0 & 12,2 & 13,0 \\
\hline $\mathrm{C}_{18: 3}$ & - & - & $\mathrm{TR}$ & $\mathrm{TR}$ & $\mathrm{TR}$ & $\mathrm{TR}$ & - & - & $\mathrm{TR}$ & $\mathrm{TR}$ & $\mathrm{TR}$ & $\mathrm{TR}$ \\
\hline
\end{tabular}


64.

TABELA 8. Porcentagem de ācidos graxos na posição 2 durante a reação de interesterificação de gordura de babaçu

\begin{tabular}{|c|c|c|c|c|}
\hline \multirow{3}{*}{ Ácido graxo } & \multicolumn{4}{|c|}{$\%$ em massa } \\
\hline & \multicolumn{4}{|c|}{ Tempo (min) } \\
\hline & 0 & 5 & 10 & 30 \\
\hline $\mathrm{C}_{8}$ & - & 1,2 & 1,3 & $\mathrm{TR}$ \\
\hline $\mathrm{C}_{10}$ & 2,3 & 6,0 & 5,0 & 4,8 \\
\hline $\mathrm{C}_{12}$ & 39,3 & 28,6 & 33,7 & 31,3 \\
\hline $\mathrm{C}_{14}$ & 13,0 & 20,8 & 19,2 & 20,3 \\
\hline $\mathrm{C}_{16}$ & 3,7 & 14,9 & 14,0 & 14,9 \\
\hline $\mathrm{C}_{17}$ & $T^{a}$ & - & - & - \\
\hline $\mathrm{C}_{18}$ & 1,3 & 6,1 & 5,8 & 6,6 \\
\hline$C_{18: 1}$ & 35,9 & 19,3 & 18,2 & 18,8 \\
\hline$C_{18: 2}$ & 4,5 & 3,1 & 2,8 & 3,3 \\
\hline$C_{18: 3}$ & $\mathrm{TR}$ & - & - & - \\
\hline
\end{tabular}

$\mathrm{T} T \mathrm{R}=$ traços 
TABELA 9. Porcentagem de ácidos graxos na posição 2 durante a reação de interesterificação de gordura de babaçu e azeite de dencê neutralizado na proporção respectiva de 80:20.

\begin{tabular}{|c|c|c|c|c|c|}
\hline \multirow{3}{*}{ Ācido graxo } & \multicolumn{5}{|c|}{ \% em massa } \\
\hline & \multicolumn{5}{|c|}{ tempo (min) } \\
\hline & 0 & 5 & 10 & 15 & 30 \\
\hline $\mathrm{C}_{8}$ & 0,9 & 2,7 & 3,5 & 3,8 & 5,0 \\
\hline $\mathrm{C}_{10}$ & 1,7 & 3,8 & 5,0 & 4,5 & 5,5 \\
\hline $\mathrm{C}_{12}$ & 48,3 & 38,7 & 35,3 & 33,0 & 29,0 \\
\hline $\mathrm{C}_{14}$ & 7,5 & 12,4 & 14,1 & 15,2 & 16,1 \\
\hline $\mathrm{C}_{16}$ & 3,4 & 11,1 & 16,8 & 18,5 & 17,1 \\
\hline $\mathrm{C}_{18}$ & 0,6 & 2,5 & 3,9 & 3,4 & 4,4 \\
\hline$C_{18: 1}$ & 32,0 & 24,4 & 18,4 & 18,5 & 19,7 \\
\hline$C_{18: 2}$ & 5,6 & 4,4 & 3,0 & 3,1 & 3,2 \\
\hline
\end{tabular}


TABELA 10. Porcentagem de ácidos graxos na posição 2 duran te a reação de interesterificação de gordura de babaçu e azeite de cendê neutralizado na propor ção respectiva de $60: 40$.

\begin{tabular}{|c|c|c|c|c|c|}
\hline \multirow{3}{*}{ Áciđo graxo } & \multicolumn{5}{|c|}{$\%$ em massa } \\
\hline & \multicolumn{5}{|c|}{ Tempo (min) } \\
\hline & 0 & 5 & 10 & 15 & 30 \\
\hline $\mathrm{C}_{8}$ & $T^{a}$ & 1,2 & 1,5 & 2,4 & 7,4 \\
\hline $\mathrm{C}_{10}$ & 1,1 & 1,9 & 2,1 & 3,5 & 3,7 \\
\hline $\mathrm{C}_{12}$ & 34,6 & 30,6 & 27,3 & 23,9 & 20,1 \\
\hline $\mathrm{C}_{14}$ & 5,7 & 7,7 & 9,3 & 10,7 & 10,1 \\
\hline$C_{16}$ & 4,9 & 9,4 & 17,0 & 20,4 & 19,8 \\
\hline $\mathrm{C}_{18}$ & 0,6 & 1,4 & 2,9 & 3,7 & 3,5 \\
\hline $\mathrm{C}_{18: 1}$ & 44,0 & 39,9 & 33,6 & 30,0 & 27,9 \\
\hline$C_{18: 2}$ & 9,1 & 7,9 & 6,3 & 5,4 & 7,5 \\
\hline$C_{18: 3}$ & - & - & - & $\mathrm{TR}$ & $\mathrm{TR}$ \\
\hline
\end{tabular}


TABELA 11. Porcentagem de ácidos graxos na posição 2 durante a reação de interesterificação de gordura de babaçu e azeite de dendê neutralizado na proporção respectiva de 40:60.

\begin{tabular}{|c|c|c|c|c|c|}
\hline \multirow{3}{*}{ Ácido graxo } & \multicolumn{5}{|c|}{$\%$ em massa } \\
\hline & \multicolumn{5}{|c|}{ Tempo (min) } \\
\hline & 0 & 5 & 10 & 15 & 45 \\
\hline $\mathrm{C}_{8}$ & 0,4 & 1,1 & 0,5 & 1,3 & 2,5 \\
\hline$C_{10}$ & 1,0 & 1,8 & 2,0 & 2,5 & 3,2 \\
\hline$c_{12}$ & 26,0 & 21,6 & 18,3 & 19,2 & 20,2 \\
\hline $\mathrm{C}_{14}$ & 4,6 & 6,0 & 8,3 & 8,4 & 7,9 \\
\hline$c_{16}$ & 6,6 & 17,8 & 28,5 & 30,8 & 31,4 \\
\hline$c_{18}$ & 0,5 & 2,3 & 4,7 & 4,6 & 4,6 \\
\hline$C_{18: 1}$ & 49,1 & 39,9 & 31,6 & 27,8 & 25,7 \\
\hline$C_{18: 2}$ & 11,8 & 9,5 & 6,1 & 5,4 & 4,5 \\
\hline
\end{tabular}


TABELA 12. Porcentagem de ácidos graxos na posição 2 durante a reação de interesterificação de gordura de babaçu e azeite de dendê neutralizado na proporção respectiva de 20:80.

\begin{tabular}{|c|c|c|c|c|c|}
\hline \multirow{3}{*}{ Åcido graxo } & \multicolumn{5}{|c|}{$\therefore$ em massa } \\
\hline & \multicolumn{5}{|c|}{ Tempo (min) } \\
\hline & 0 & 5 & 10 & 15 & 45 \\
\hline $\mathrm{C}_{8}$ & $T R^{a}$ & $\mathrm{TR}$ & $\mathrm{TR}$ & $\mathrm{TR}$ & 0,9 \\
\hline$C_{10}$ & 0,5 & 0,7 & 0,7 & 0,9 & 1,3 \\
\hline$c_{12}$ & 16,6 & 15,6 & 15,1 & 12,4 & 12,2 \\
\hline$C_{14}$ & 2,2 & 3,1 & 3,2 & 3,9 & 5,1 \\
\hline $\mathrm{C}_{16}$ & 7,2 & 11,1 & 17,3 & 27,5 & 34,4 \\
\hline$C_{17}$ & $\mathrm{TR}$ & - & $\mathrm{TR}$ & $\mathrm{TR}$ & $\mathrm{TR}$ \\
\hline $\mathrm{C}_{18}$ & 0,9 & 1,3 & 2,5 & 3,6 & 5,1 \\
\hline$C_{18: 1}$ & 60,6 & 57,5 & 51,0 & 43,8 & 34,7 \\
\hline$C_{18: 2}$ & 12,0 & 10,7 & 10,2 & 7,9 & 6,3 \\
\hline$C_{18: 3}$ & - & - & - & $\mathrm{TR}$ & $\mathrm{TR}$ \\
\hline
\end{tabular}

${ }{ }_{T R}=$ traços 
TABELA 13. Porcentagem de ácidos graxos na posição 2 durante a reação de interesterificação de azeite de dendê neutralizado

\begin{tabular}{|c|c|c|c|c|c|}
\hline \multirow{3}{*}{ Ácido graxo } & \multicolumn{5}{|c|}{$\%$ em massa } \\
\hline & \multicolumn{5}{|c|}{ Tempo (min) } \\
\hline & 0 & 5 & 10 & 15 & 45 \\
\hline $\mathrm{C}_{12}$ & 0,2 & 0,2 & 0,3 & 0,4 & 0,4 \\
\hline $\mathrm{C}_{14}$ & 0,5 & 0,4 & 0,9 & 1,2 & 1,4 \\
\hline $\mathrm{C}_{16}$ & 7,3 & 12,4 & 29,0 & 40,1 & 45,9 \\
\hline$c_{18}$ & 0,8 & 1,7 & 3,8 & 5,0 & 5,8 \\
\hline$C_{18: 1}$ & 74,8 & 71,4 & 53,1 & 43,5 & 37,9 \\
\hline$C_{18: 2}$ & 16,4 & 13,9 & 12,9 & 9,8 & 8,6 \\
\hline$C_{18: 3}$ & - & - & - & $\mathrm{TR}^{\mathrm{a}}$ & TR \\
\hline
\end{tabular}

a $T R=$ traços 
TABELA 14. Proporção de ācidos graxos na posição 2 durante a reação de interesterificação de gordura de babaçu

\begin{tabular}{|c|c|c|c|c|}
\hline \multirow{3}{*}{ Ácido graxo } & \multicolumn{4}{|c|}{ Proporção na posição 2 (\%) } \\
\hline & \multicolumn{4}{|c|}{ Tempo (min) } \\
\hline & 0 & 5 & 10 & 30 \\
\hline $\mathrm{C}_{10}$ & 8,4 & 22,0 & 18,3 & 17,6 \\
\hline$C_{12}$ & 48,0 & 34,9 & 41,1 & 38,2 \\
\hline$C_{14}$ & 22,6 & 36,1 & 33,3 & 35,2 \\
\hline $\mathrm{C}_{16}$ & 11,2 & 45,2 & 42,4 & 45,2 \\
\hline$c_{18}$ & 11,4 & 53,5 & 50,9 & 57,9 \\
\hline$C_{18: 1}$ & 64,0 & 34,4 & 32,4 & 33,5 \\
\hline$C_{18: 2}$ & 46,9 & 32,3 & 29,2 & 34,4 \\
\hline
\end{tabular}


TABELA 15. Proporção de ácidos graxos na posição 2 durante a reação de interesterificação de gordura de babaçu e azeite de dendê neutralizado na propor ção respectiva de 80:20.

\begin{tabular}{|c|c|c|c|c|c|}
\hline \multirow{3}{*}{ Ācido graxo } & \multicolumn{5}{|c|}{ Proporção na posição 2 (\%) } \\
\hline & \multicolumn{5}{|c|}{ Tempo (min) } \\
\hline & 0 & 5 & 10 & 15 & 30 \\
\hline $\mathrm{C}_{8}$ & 5,6 & 16,7 & 21,6 & 23,5 & 30,9 \\
\hline $\mathrm{C}_{10}$ & 10,9 & 24,4 & 32,1 & 28,9 & 35,3 \\
\hline $\mathrm{C}_{12}$ & 58,3 & 46,7 & 42,6 & 39,9 & 35,0 \\
\hline $\mathrm{C}_{14}$ & 18,9 & 31,3 & 35,6 & 38,4 & 40,7 \\
\hline $\mathrm{C}_{16}$ & 6,6 & 21,5 & 32,6 & 35,9 & 33,1 \\
\hline $\mathrm{C}_{18}$ & 5,6 & 23,2 & 36,1 & 31,5 & 40,7 \\
\hline $\mathrm{C}_{18: 1}$ & 47,0 & 35,8 & 27,0 & 27,2 & 28,9 \\
\hline $\mathrm{C}_{18: 2}$ & 36,6 & 28,8 & 19,6 & 20,3 & 20,9 \\
\hline
\end{tabular}


TABELA 16. Proporção de ácidos graxos na posição 2 durante a reação de interesterificação de gordura de babaçu e azeite de dendê neutralizado na propor ção respectiva de 60:40

\begin{tabular}{cccccc}
\hline \multirow{2}{*}{ Ácido graxo } & \multicolumn{5}{c}{ Proporção na posição 2 (\%) } \\
\cline { 2 - 6 }$C_{10}$ & 9,4 & 16,2 & 18,0 & 29,9 & 31,6 \\
$C_{12}$ & 46,0 & 40,6 & 36,3 & 31,7 & 26,7 \\
$C_{14}$ & 19,0 & 25,7 & 31,0 & 35,7 & 33,7 \\
$C_{16}$ & 8,2 & 15,8 & 28,5 & 34,2 & 33,2 \\
$C_{18}$ & 5,7 & 13,3 & 27,6 & 35,2 & 33,3 \\
$C_{18: 1}$ & 59,6 & 54,1 & 45,5 & 40,7 & 37,8 \\
$C_{18: 2}$ & 45,3 & 39,3 & 31,3 & 26,9 & 37,3 \\
& & & & & \\
\hline
\end{tabular}


TABELA 17. Proporção de ácidos graxos na posição 2 durante a reação de interesterificação de gordura de babaçu e azeite de dendê neutralizado na propor ção respectiva de 40:60.

\begin{tabular}{|c|c|c|c|c|c|}
\hline \multirow{3}{*}{ Ácido graxo } & \multicolumn{5}{|c|}{ Proporção na posição 2 (\%) } \\
\hline & \multicolumn{5}{|c|}{ Tempo (min) } \\
\hline & 0 & 5 & 10 & 15 & 45 \\
\hline $\mathrm{C}_{8}$ & 3,0 & 8,3 & 3,8 & 9,9 & 18,9 \\
\hline $\mathrm{C}_{10}$ & 11,1 & 20,0 & 22,2 & 27,8 & 35,6 \\
\hline $\mathrm{C}_{12}$ & 47,1 & 39,1 & 33,2 & 34,8 & 36,6 \\
\hline $\mathrm{C}_{14}$ & 21,3 & 27,8 & 38,4 & 38,9 & 36,6 \\
\hline $\mathrm{C}_{16}$ & 8,5 & 22,8 & 36,5 & 39,5 & 40,3 \\
\hline $\mathrm{C}_{18}$ & 4,8 & 21,9 & 44,8 & 43,8 & 43,8 \\
\hline$C_{18: 1}$ & 56,4 & 45,9 & 36,3 & 32,0 & 29,5 \\
\hline $\mathrm{C}_{18: 2}$ & 46,3 & 37,3 & 23,9 & 21,2 & 17,7 \\
\hline
\end{tabular}


TABELA 18. Proporção de ácidos graxos na posição 2 durante a reação de interesterificação de gordura de babaçu e azeite de dendê neutralizado na proporção respectiva de 20:80

\begin{tabular}{|c|c|c|c|c|c|}
\hline \multirow{3}{*}{ Ācido graxo } & \multicolumn{5}{|c|}{ Proporção na posição 2 (\%) } \\
\hline & \multicolumn{5}{|c|}{ Tempo (min) } \\
\hline & 0 & 5 & 10 & 15 & 45 \\
\hline $\mathrm{c}_{10}$ & 11,1 & 15,6 & 15,6 & 20,0 & 28,9 \\
\hline $\mathrm{C}_{12}$ & 49,0 & 46,0 & 44,5 & 36,6 & 36,0 \\
\hline $\mathrm{C}_{14}$ & 17,5 & 24,6 & 25,4 & 31,0 & 40,5 \\
\hline$c_{16}$ & 8,1 & 12,4 & 19,4 & 30,8 & 38,5 \\
\hline $\mathrm{C}_{18}$ & 6,7 & 9,6 & 18,5 & 26,7 & 37,8 \\
\hline $\mathrm{C}_{18: 1}$ & 56,0 & 53,1 & 47,1 & 40,4 & 32,0 \\
\hline$C_{18: 2}$ & 37,4 & 33,3 & 31,8 & 24,6 & 19,6 \\
\hline
\end{tabular}


TABELA 19. Proporção de ácidos graxos na posição 2 durante a reação de interesterificação de azeite de dendê neutralizaço.

\begin{tabular}{|c|c|c|c|c|c|}
\hline \multirow{3}{*}{ Acido graxo } & \multicolumn{5}{|c|}{ Proporção na posição 2 (\%) } \\
\hline & \multicolumn{5}{|c|}{ Tempo (min) } \\
\hline & 0 & 5 & 10 & 15 & 45 \\
\hline $\mathrm{C}_{14}$ & 16,7 & 13,3 & 30,0 & 40,0 & 46,7 \\
\hline$C_{16}$ & 6,3 & 10,7 & 25,1 & 34,7 & 39,7 \\
\hline $\mathrm{C}_{18}$ & 4,9 & 10,5 & 23,5 & 30,9 & 35,8 \\
\hline$c_{18: 1}$ & 58,3 & 55,6 & 41,4 & 33,9 & 29,5 \\
\hline$C_{18: 2}$ & 44,8 & 38,0 & 35,2 & 26,8 & 23,5 \\
\hline
\end{tabular}


76.

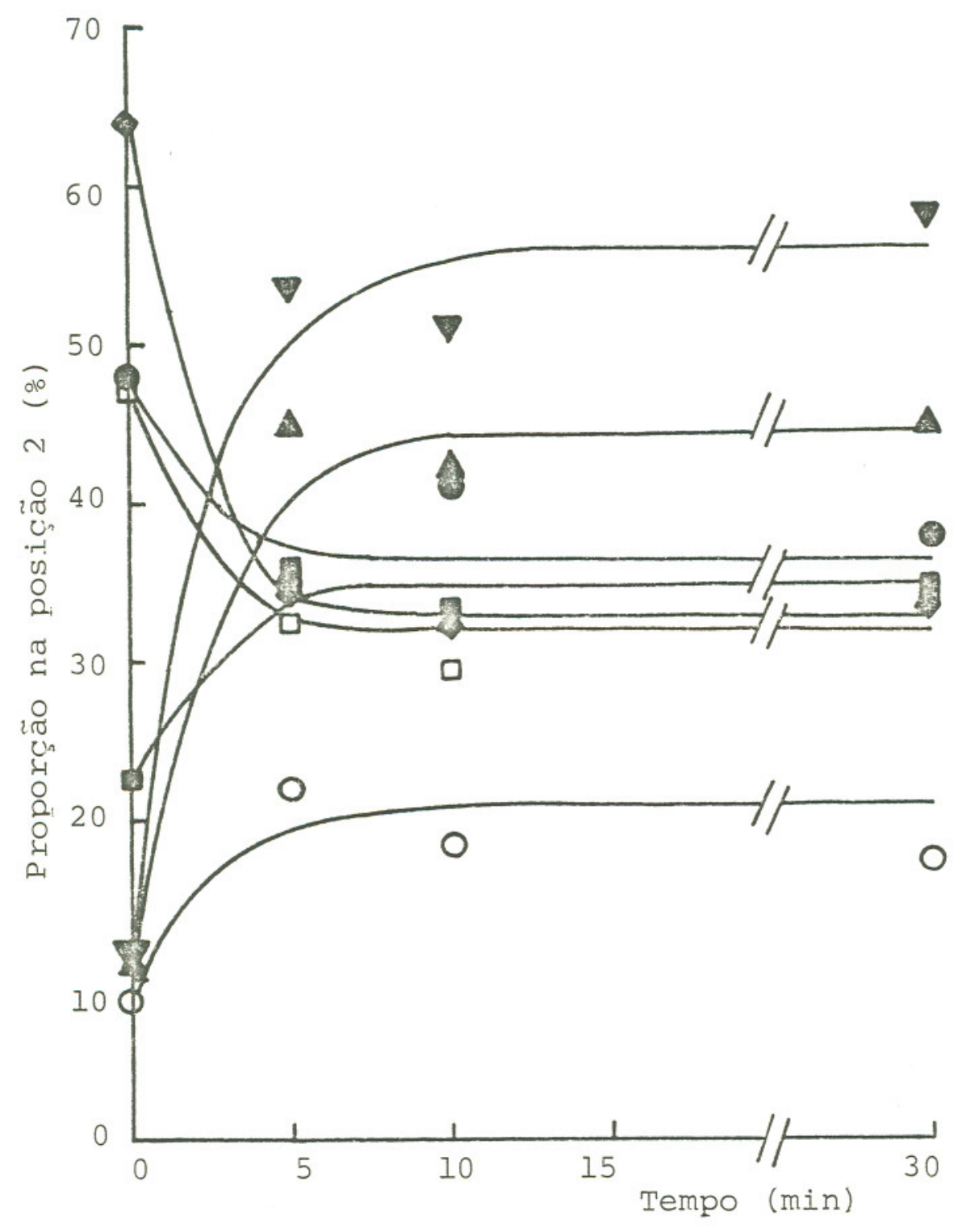

FIGURA 17. Proporção de ácídos graxos na posição 2 em função do tempo para a reação de interesterificação de gordura de babaçu.

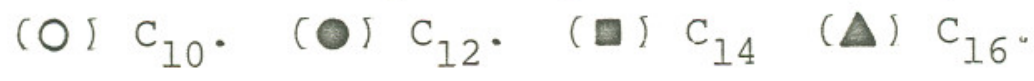
$\begin{array}{llll}(\nabla) C_{18} & (\diamond) C_{18: 1} & (\square) C_{18: 2}\end{array}$ 


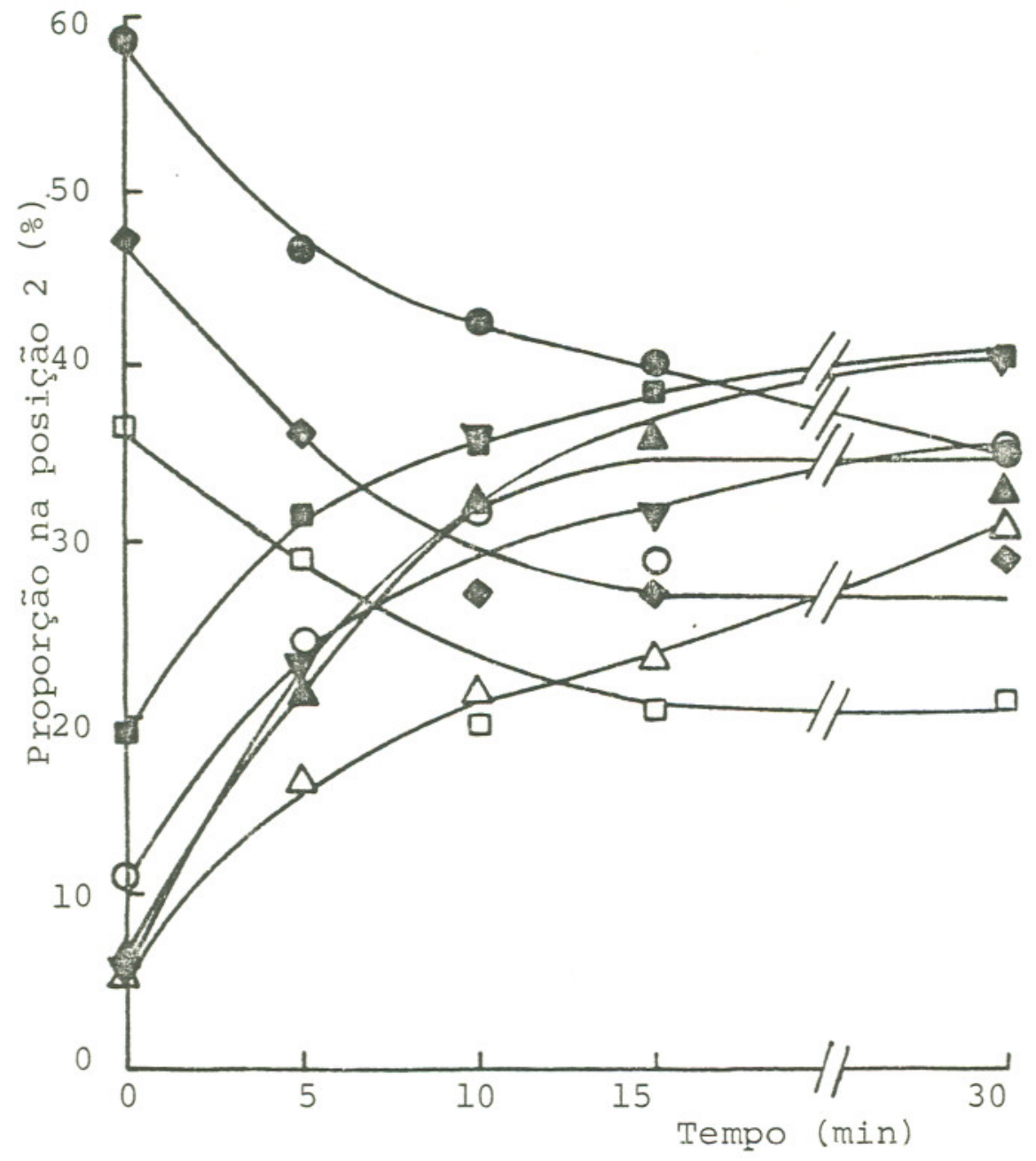

FIGURA 18. Proporção de ācidos graxos na posição 2 em função do tempo para a reação de interesterificação de babaçu e dendê neutralizado na proporção respectiva de $80: 20$.
( $\triangle)^{C_{8}} \cdot(\mathrm{O}) \mathrm{C}_{10}$.
(o) $\mathrm{C}_{12} \cdot$
(ㄷ) $\mathrm{C}_{14}$.
$(\Delta) \mathrm{C}_{16} \cdot(\nabla) \mathrm{C}_{18}$
(ब) $C_{18: 1}$
(ㅁ) $C_{18: 2^{\circ}}$ 


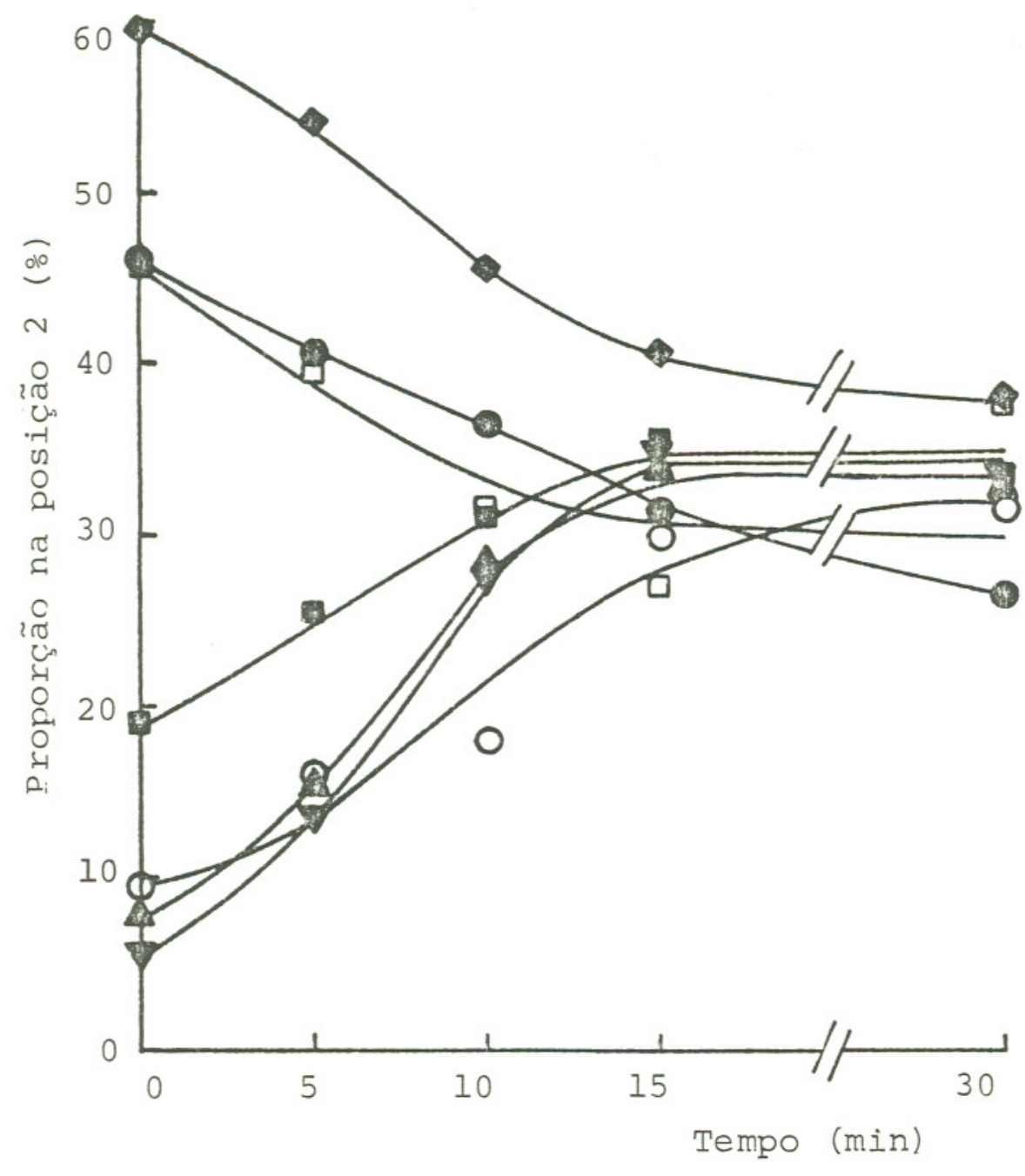

FIGURA 19. Proporção de ācidos graxos na posição $2 \mathrm{em}$ função do temoo para a reação de intereste rificação de babaçu e dendê neutralizado na proporção respectiva de 60:40.

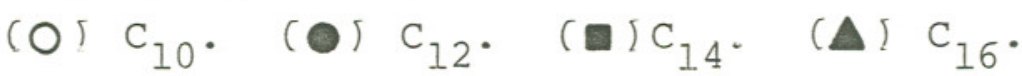

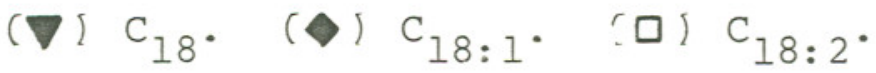


79 .

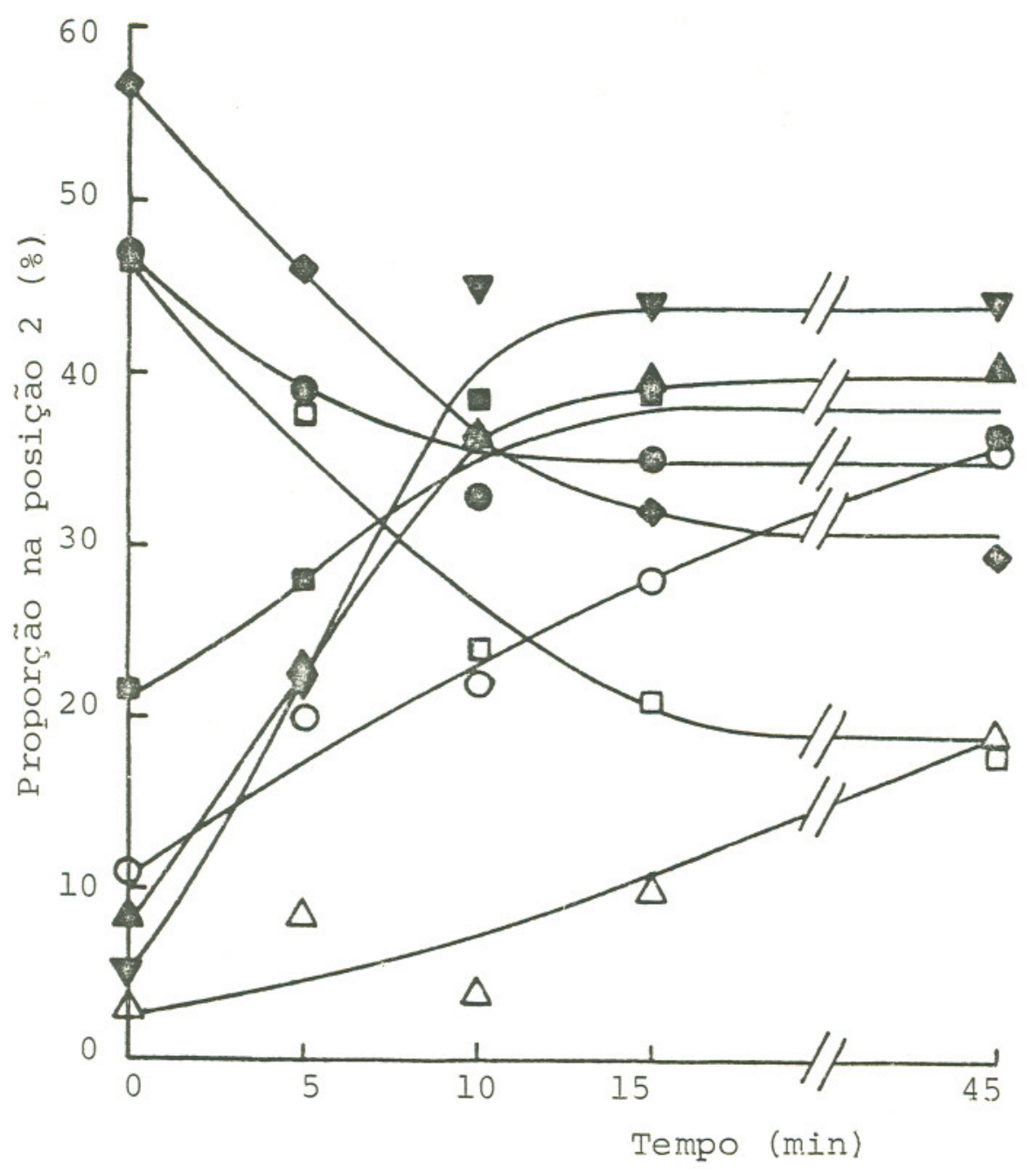

FIGURA 20. Proporção de ácidos graxos na posição 2 em função do tempo para a reação de interesterificação de babaçu e dendê neutralizado na proporção respectiva de 40:60.
$(\Delta) \mathrm{C}_{8} \cdot(\mathrm{O}) \mathrm{C}_{10} \cdot(\bullet) \mathrm{C}_{12}$.
(a) $\mathrm{C}_{14}$.

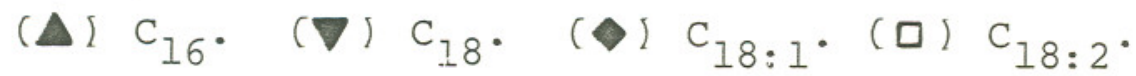




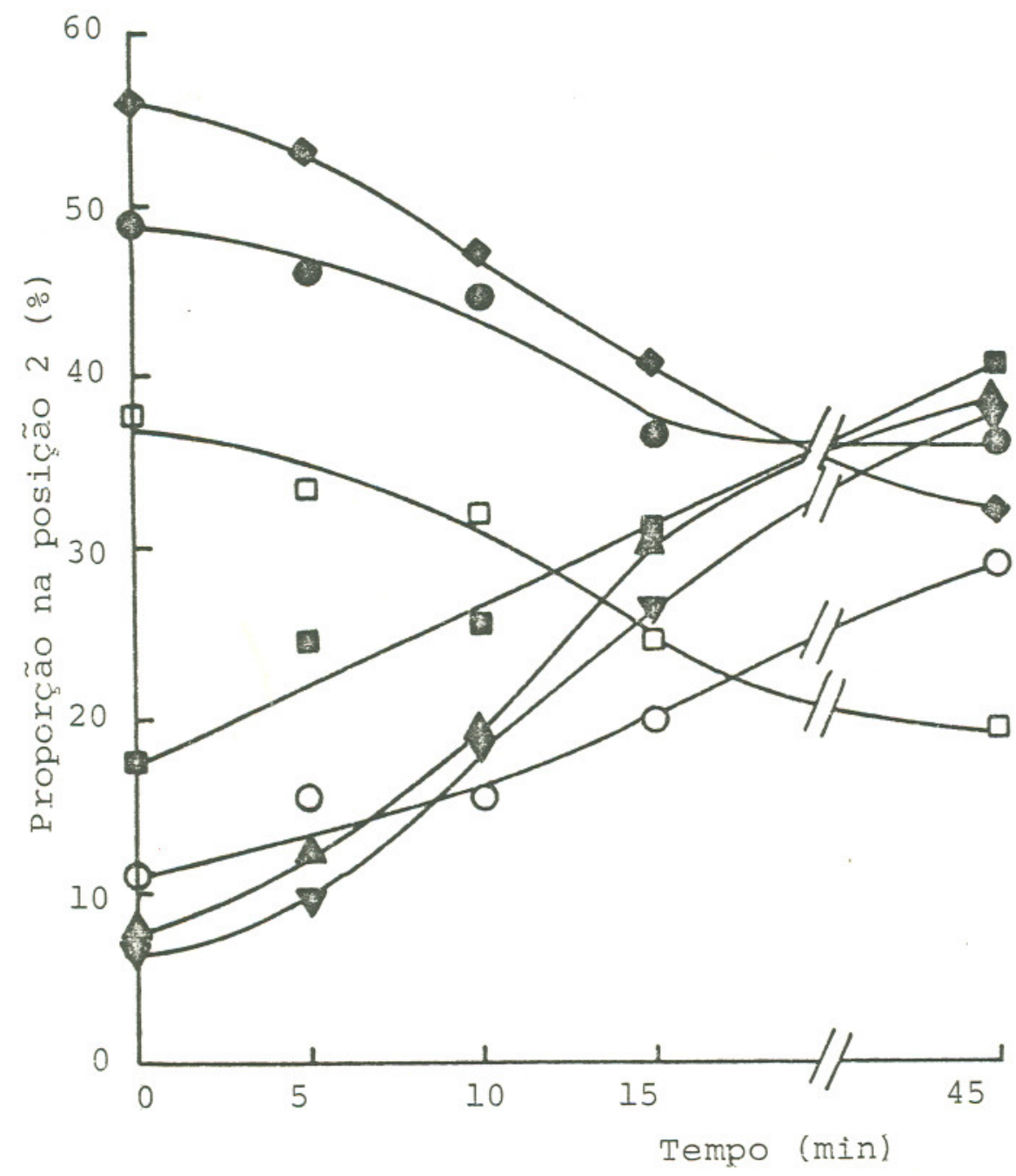

FIGURA 21. Proporção de ácidos graxos na posição $2 \mathrm{em}$ função do tempo para a reação de intereste rificação de babaçu e dendê neutralizado na proporção respectiva de 20:80.

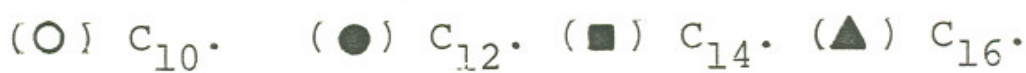

$(\nabla) \mathrm{C}_{18} \cdot(\bullet) \mathrm{C}_{18: 1} \cdot(\square) \mathrm{C}_{18: 2^{\circ}}$ 


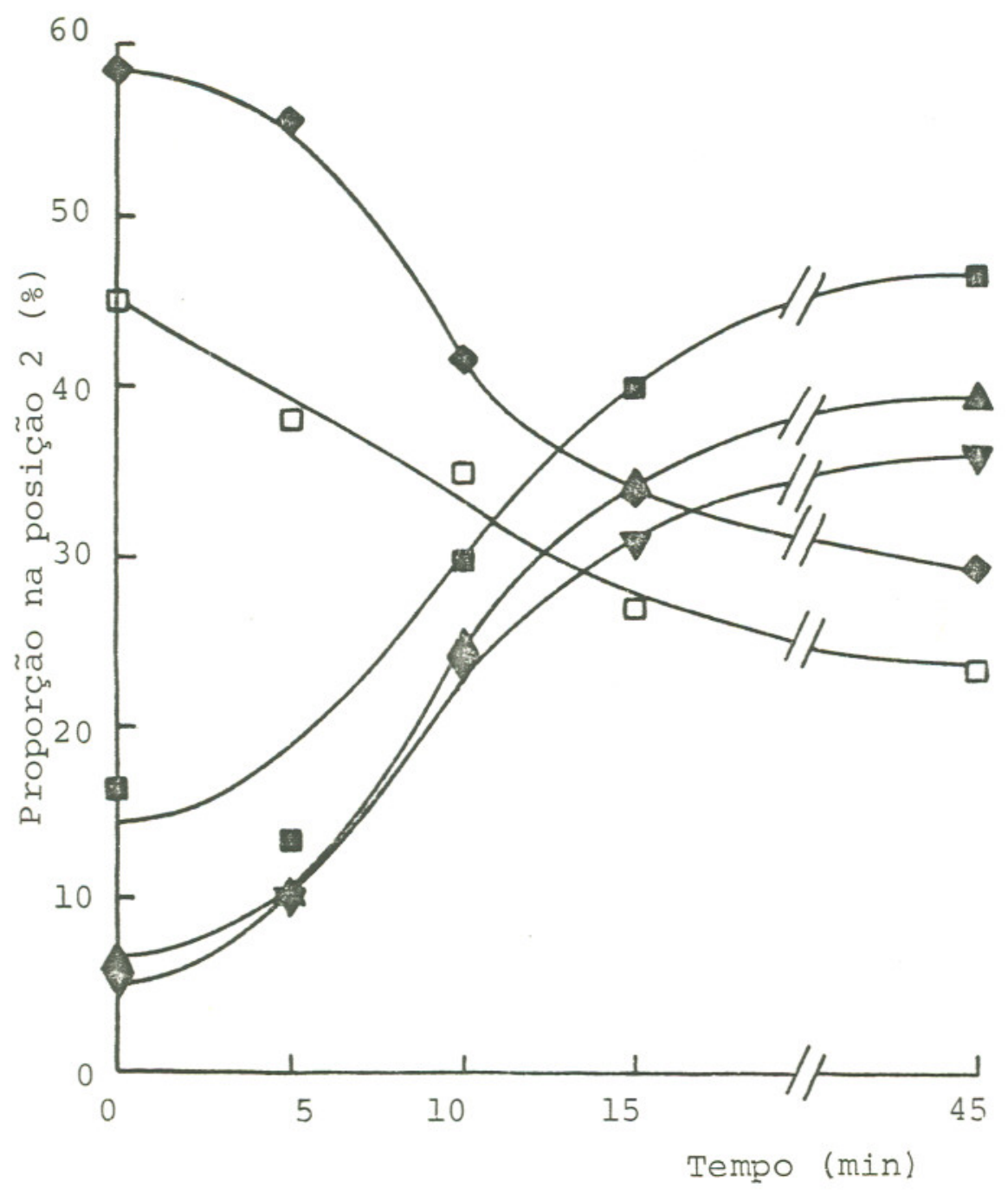

FIGURA 22. Proporção de ácidos graxos na posição 2 em função do tempo para a reação de interesterificação de azeite de dendê neutralizado.

(घ) $\mathrm{C}_{14} \cdot(\boldsymbol{\Delta}) \mathrm{C}_{16} \cdot(\boldsymbol{\nabla}) \mathrm{C}_{18} \cdot(\bullet) \mathrm{C}_{18: 1^{\prime}}$ (口) $\mathrm{C}_{18: 2}$. 
1 e 3, exceção feita ao ácido lāurico. Esta é uma característica tendência de distribuição de ácidos graxos de gorduras naturais de vegetais (17). Nas gorduras de coco e de caroço de palma, o ácido lāurico tambēm se coloca preferen cialmente na posição central do glicerol $(24,26)$.

Em função do processo de interesterificação ao acaso, os ácidos saturados aumentam sua participa ção na posição central, enquanto que os insaturados tendem a diminuíla, até ser atingido o equilíbrio.

Teoricamente, após o rearranjo, todos os ácidos graxos apresentariam proporção na posição 2 igual a 33,\%. Contudo, tratando-se de resultados experimentais, ocorrem desvios para mais ou para menos. Estes desvios tam bēm são observados em outros trabalhos $(27,54,55)$.

\section{4 - Composição em triglicérides}

As tabelas de 20 a 25 e as figuras de 23 a 28 mostram a variação na composição em triglicérides durante as reações de interesterificação com proporções variáveis de gordura de babaçu e azeite de dendê neutralizado.

Para a gordura de babaçu, antes do rearranjo, os valores são aproximados aos das composições de outras gorduras do grupo do ácido lāurico, como as de coco e caroço de palma (13).

Para o azeite de dencê, antes do rearranjo, os resultados são comparáveis aos da fração oleína do óleo de palma (75). 
TABELA 20. Composição em triglicérides durante a reação de interesterificação de gordura de babaçu.

\begin{tabular}{|c|c|c|c|c|}
\hline \multirow{3}{*}{$\begin{array}{l}\text { Triglicéride } \\
\text { (Número de carbonos }{ }^{a} \text { ) }\end{array}$} & \multicolumn{4}{|c|}{ \% em massa } \\
\hline & \multirow[b]{2}{*}{0} & \multicolumn{3}{|c|}{ Tempo (min) } \\
\hline & & 5 & 10 & 30 \\
\hline $\mathrm{C}_{20}$ & $\mathrm{TR}^{\mathrm{b}}$ & $\mathrm{TR}$ & $\mathrm{TR}$ & $\mathrm{TR}$ \\
\hline $\mathrm{C}_{22}$ & $\mathrm{TR}$ & 0,3 & 0,3 & 0,3 \\
\hline$C_{24}$ & $\mathrm{TR}$ & 0,3 & 0,3 & 0,3 \\
\hline$C_{26}$ & 0,1 & 0,7 & 0,6 & 0,8 \\
\hline$C_{28}$ & 0,3 & 0,9 & 0,9 & 0,9 \\
\hline $\mathrm{C}_{30}$ & 1,2 & 1,3 & 1,3 & 1,3 \\
\hline$C_{32}$ & 7,1 & 4,8 & 4,4 & 4,3 \\
\hline$C_{34}$ & 9,7 & 6,9 & 6,4 & 5,6 \\
\hline$c_{36}$ & 15,7 & 13,7 & 13,5 & 12,7 \\
\hline$c_{38}$ & 14,1 & 14,7 & 14,5 & 15,5 \\
\hline $\mathrm{C}_{40}$ & 9,4 & 11,9 & 12,2 & 13,1 \\
\hline$C_{42}$ & 9,0 & 16,3 & 16,9 & 17,9 \\
\hline$C_{44}$ & 6,5 & 11,4 & 11,5 & 11,4 \\
\hline$C_{46}$ & 6,0 & 6,8 & 6,9 & 6,9 \\
\hline $\mathrm{C}_{48}$ & 8,3 & 7,2 & 7,4 & 7,0 \\
\hline$C_{50}$ & 4,2 & 2,0 & 2,1 & 1,7 \\
\hline$C_{52}$ & 3,7 & 0,8 & 0,8 & 0,3 \\
\hline$C_{54}$ & 4,7 & $T R$ & $\mathrm{TR}$ & - \\
\hline
\end{tabular}

$\mathrm{a}=$ Não foram considerados os átomos de carbono do glicerol.

$\mathrm{b}=$ Traços. 
TABELA 21. Composição em triglicérides durante a reação de interesterificação de gordura de babaçu e azeite de dendê neutralizado na proporção respectiva de $80: 20$.

\begin{tabular}{|c|c|c|c|c|c|c|}
\hline \multirow{3}{*}{\multicolumn{2}{|c|}{$\begin{array}{l}\text { Triglicéride } \\
\text { (Nümero de carbonos }{ }^{a} \text { ) }\end{array}$}} & \multicolumn{5}{|c|}{$\%$ em massa } \\
\hline & & \multicolumn{5}{|c|}{ Tempo (min) } \\
\hline & & 0 & 5 & 10 & 15 & 30 \\
\hline & $\mathrm{C}_{20}$ & - & $T R$ & $\mathrm{TR}$ & $T R$ & $\mathrm{TR}$ \\
\hline & $c_{22}$ & $T_{R}^{b}$ & 0,1 & 0,1 & 0,1 & 0,1 \\
\hline & $C_{24}$ & $\mathrm{TR}$ & 0,1 & 0,1 & 0,1 & 0,1 \\
\hline & $c_{26}$ & 0,1 & 0,3 & 0,3 & 0,5 & 0,4 \\
\hline & $\mathrm{C}_{28}$ & 0,2 & 0,4 & 0,4 & 0,6 & 0,6 \\
\hline & $\mathrm{C}_{30}$ & 0,9 & 0,9 & 0,8 & 0,9 & 0,8 \\
\hline & $c_{32}$ & 4,6 & 3,2 & 2,5 & 2,1 & 2,7 \\
\hline & $\mathrm{C}_{34}$ & 6,5 & 5,0 & 3,9 & 2,8 & 3,1 \\
\hline & $c_{36}$ & 10,2 & 10,1 & 8,1 & 7,3 & 8,1 \\
\hline & $C_{38}$ & 11,0 & 9,1 & 9,7 & 11,4 & 9,9 \\
\hline & $C_{40}$ & 7,4 & 9,0 & 10,4 & 12,1 & 11,7 \\
\hline & $\mathrm{C}_{42}$ & 6,2 & 11,4 & 16,7 & 17,6 & 15,9 \\
\hline & $\mathrm{C}_{44}$ & 4,8 & 7,7 & 11,1 & 12,0 & 12,6 \\
\hline & $C_{46}$ & 5,2 & 8,5 & 10,6 & 12,5 & 12,4 \\
\hline & $C_{48}$ & 6,2 & 9,8 & 13,3 & 11,6 & 12,6 \\
\hline & $C_{50}$ & 14,7 & 9,8 & 5,4 & 3,8 & 4,4 \\
\hline & $C_{52}$ & 15,9 & 10,8 & 5,1 & 3,5 & 3,5 \\
\hline & $C_{54}$ & 6,1 & 3,8 & 1,5 & 1,1 & 1,1 \\
\hline
\end{tabular}


TABELA 22. Composição em triglicérides durante a reação de interesterificação de gordura de babaçu e azeite de dendê neutralizado na proporção respectiva de 60:40.

\begin{tabular}{|c|c|c|c|c|c|}
\hline \multirow{3}{*}{$\begin{array}{l}\text { Triglicéride } \\
\text { (Número de carbonos }{ }^{a} \text { ) }\end{array}$} & \multicolumn{5}{|c|}{$\%$ em massa } \\
\hline & \multicolumn{5}{|c|}{ Tempo (min) } \\
\hline & 0 & 5 & 10 & 15 & 30 \\
\hline $\mathrm{C}_{20}$ & - & $\mathrm{TR}$ & $\mathrm{TR}$ & $\mathrm{TR}$ & $\mathrm{TR}$ \\
\hline $\mathrm{C}_{22}$ & - & 0,1 & 0,1 & 0,1 & 0,1 \\
\hline $\mathrm{C}_{24}$ & - & 0,1 & 0,1 & 0,1 & 0,1 \\
\hline $\mathrm{C}_{26}$ & $\mathrm{TR}^{\mathrm{b}}$ & 0,3 & 0,3 & 0,3 & 0,3 \\
\hline $\mathrm{C}_{28}$ & 0,1 & 0,3 & 0,3 & 0,3 & 0,3 \\
\hline $\mathrm{C}_{30}$ & 0,6 & 0,6 & 0,5 & 0,5 & 0,6 \\
\hline$c_{32}$ & 2,7 & 2,7 & 1,9 & 1,5 & 1,1 \\
\hline $\mathrm{C}_{34}$ & 4,6 & 4,0 & 2,9 & 2,0 & 1,4 \\
\hline$c_{36}$ & 8,5 & 7,0 & 6,4 & 4,7 & 3,9 \\
\hline $\mathrm{C}_{38}$ & 7,3 & 6,6 & 6,6 & 5,9 & 6,4 \\
\hline $\mathrm{C}_{40}$ & 4,2 & 5,4 & 6,6 & 7,6 & 8,8 \\
\hline $\mathrm{C}_{42}$ & 3,9 & 5,7 & 8,5 & 10,9 & 13,5 \\
\hline $\mathrm{C}_{44}$ & 3,0 & 4,6 & 8,0 & 10,5 & 11,4 \\
\hline $\mathrm{C}_{46}$ & 3,2 & 5,0 & 9,5 & 13,0 & 16,0 \\
\hline $\mathrm{C}_{48}$ & 4,7 & 7,0 & 10,0 & 13,4 & 15,6 \\
\hline$c_{50}$ & 23,1 & 20,4 & 15,0 & 11,5 & 8,8 \\
\hline$c_{52}$ & 25,4 & 22,1 & 17,0 & 12,9 & 8,4 \\
\hline$C_{54}$ & 8,7 & 8,1 & 6,3 & 4,8 & 3,3 \\
\hline
\end{tabular}


TABELA 23. Composição em triglicérides durante a reação de interesterificação de gordura de babaçu e azeite de dendê neutralizado na proporção respectiva de $40: 60$.

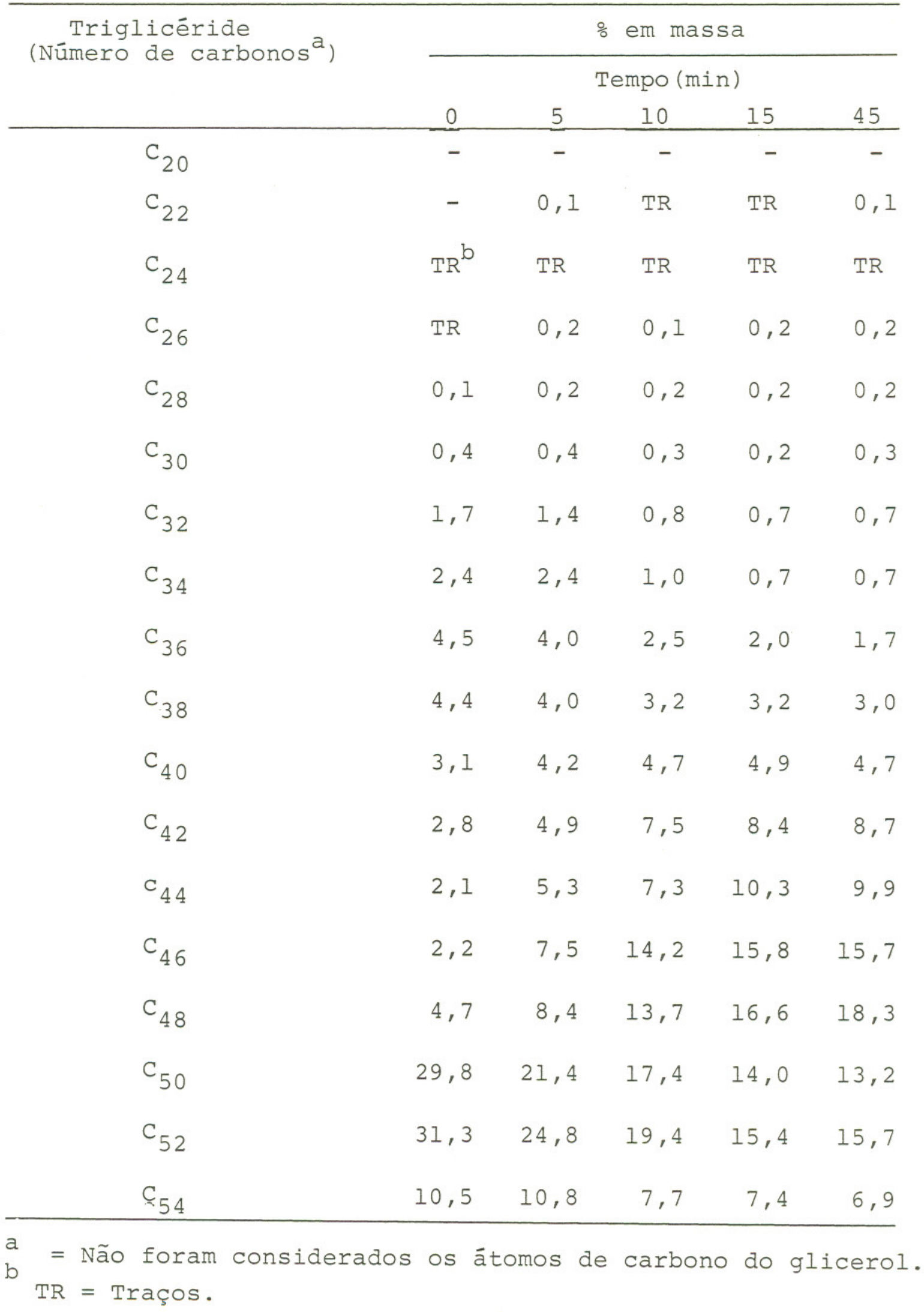


TABELA 24. Composição em triglicérides durante a reação de interesterificação de gordura de babaçu e azeite de dendê neutralizado na porporção respectiva de $20: 80$.

\begin{tabular}{|c|c|c|c|c|c|}
\hline \multirow{3}{*}{$\begin{array}{l}\text { Triglicéride } \\
\text { (Nümero de carbonos }{ }^{a} \text { ) }\end{array}$} & \multicolumn{5}{|c|}{ \% em massa } \\
\hline & \multirow[b]{2}{*}{0} & \multirow{2}{*}{\multicolumn{3}{|c|}{ Tempo (min) }} & \multirow[b]{2}{*}{45} \\
\hline & & & & & \\
\hline $\mathrm{C}_{20}$ & - & - & - & - & - \\
\hline $\mathrm{C}_{22}$ & - & 0,1 & 0,1 & 0,1 & $\mathrm{TR}$ \\
\hline $\mathrm{C}_{24}$ & - & $T R^{b}$ & $T R$ & $T R$ & $\mathrm{TR}$ \\
\hline $\mathrm{C}_{26}$ & - & 0,1 & 0,1 & 0,1 & 0,1 \\
\hline $\mathrm{C}_{28}$ & - & 0,1 & $\mathrm{TR}$ & $\mathrm{TR}$ & 0,1 \\
\hline $\mathrm{C}_{30}$ & 0,2 & 0,1 & 0,2 & 0,1 & 0,1 \\
\hline $\mathrm{C}_{32}$ & 0,8 & 0,8 & 0,7 & 0,4 & 0,2 \\
\hline $\mathrm{C}_{34}$ & 1,1 & 1,1 & 0,8 & 0,6 & 0,3 \\
\hline $\mathrm{C}_{36}$ & 1,8 & 1,8 & 1,5 & 1,2 & 0,6 \\
\hline $\mathrm{C}_{38}$ & 1,6 & 1,4 & 1,4 & 1,4 & 0,8 \\
\hline $\mathrm{C}_{40}$ & 0,9 & 1,0 & 1,1 & 1,6 & 1,9 \\
\hline $\mathrm{C}_{42}$ & 1,0 & 1,2 & 1,9 & 3,1 & 4,0 \\
\hline $\mathrm{C}_{44}$ & 1,2 & 1,4 & 2,3 & 4,1 & 6,4 \\
\hline $\mathrm{C}_{46}$ & 1,4 & 1,8 & 4,7 & 7,3 & 12,4 \\
\hline $\mathrm{C}_{48}$ & 3,6 & 4,2 & 6,3 & 10,0 & 16,3 \\
\hline $\mathrm{C}_{50}$ & 35,2 & 33,3 & 32,2 & 25,9 & 19,8 \\
\hline$C_{52}$ & 39,4 & 39,2 & 33,4 & 31,0 & 25,8 \\
\hline$C_{54}$ & 11,8 & 12,4 & 13,3 & 13,1 & 11,2 \\
\hline
\end{tabular}


88.

TABELA 25. Composição em triglicérides durante a reação de interesterificação de azeite de dendê neutraliza do.

\begin{tabular}{|c|c|c|c|c|c|}
\hline \multirow{3}{*}{$\begin{array}{l}\text { Triglicéride } \\
\text { (Número de carbonos }{ }^{a} \text { ) }\end{array}$} & \multicolumn{5}{|c|}{$\%$ em massa } \\
\hline & \multicolumn{5}{|c|}{ Tempo (min) } \\
\hline & 0 & 5 & 10 & 15 & 45 \\
\hline$C_{46}$ & $T_{R}^{b}$ & $\mathrm{TR}$ & $\mathrm{TR}$ & 0,9 & 0,8 \\
\hline$C_{48}$ & 2,3 & 3,2 & 4,8 & 7,1 & 8,7 \\
\hline$C_{50}$ & 42,8 & 38,6 & 35,3 & 31,4 & 31,7 \\
\hline$C_{52}$ & 41,7 & 44,6 & 43,3 & 42,1 & 39,1 \\
\hline$C_{54}$ & 13,2 & 13,6 & 16,6 & 18,5 & 19,7 \\
\hline
\end{tabular}

$a=$ Não foram considerados os átomos de carbono do glicerol.

$\mathrm{b} T \mathrm{~T}=$ Traços . 

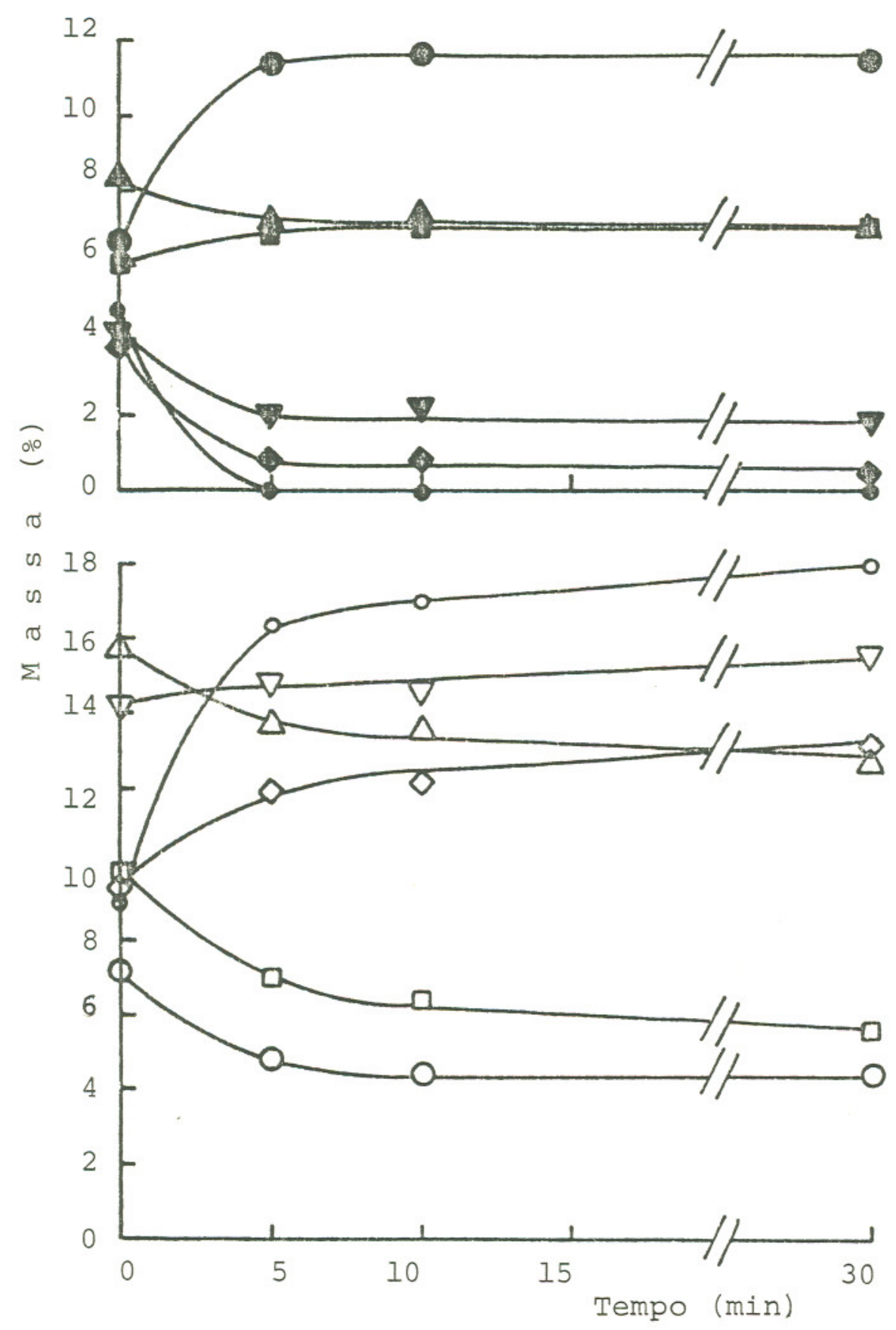

FIGURA 23. Porcentagem em massa de triglicērides em função do tempo para a reação de interes terificação de gordura de babaçu.
(O) $\mathrm{C}_{32}$
(口) $\mathrm{C}_{34}$
( $\triangle$ ) $C_{36}$
$(\nabla) \quad C_{38}$
(১) $C_{40}(0) C_{42}$
(อ) $\mathrm{C}_{44}$
(घ) $\mathrm{C}_{46}$
(A) $\mathrm{C}_{48}$
(V) $\mathrm{C}_{50}$
(ब) $C_{52}$
(e) $C_{54}$ 

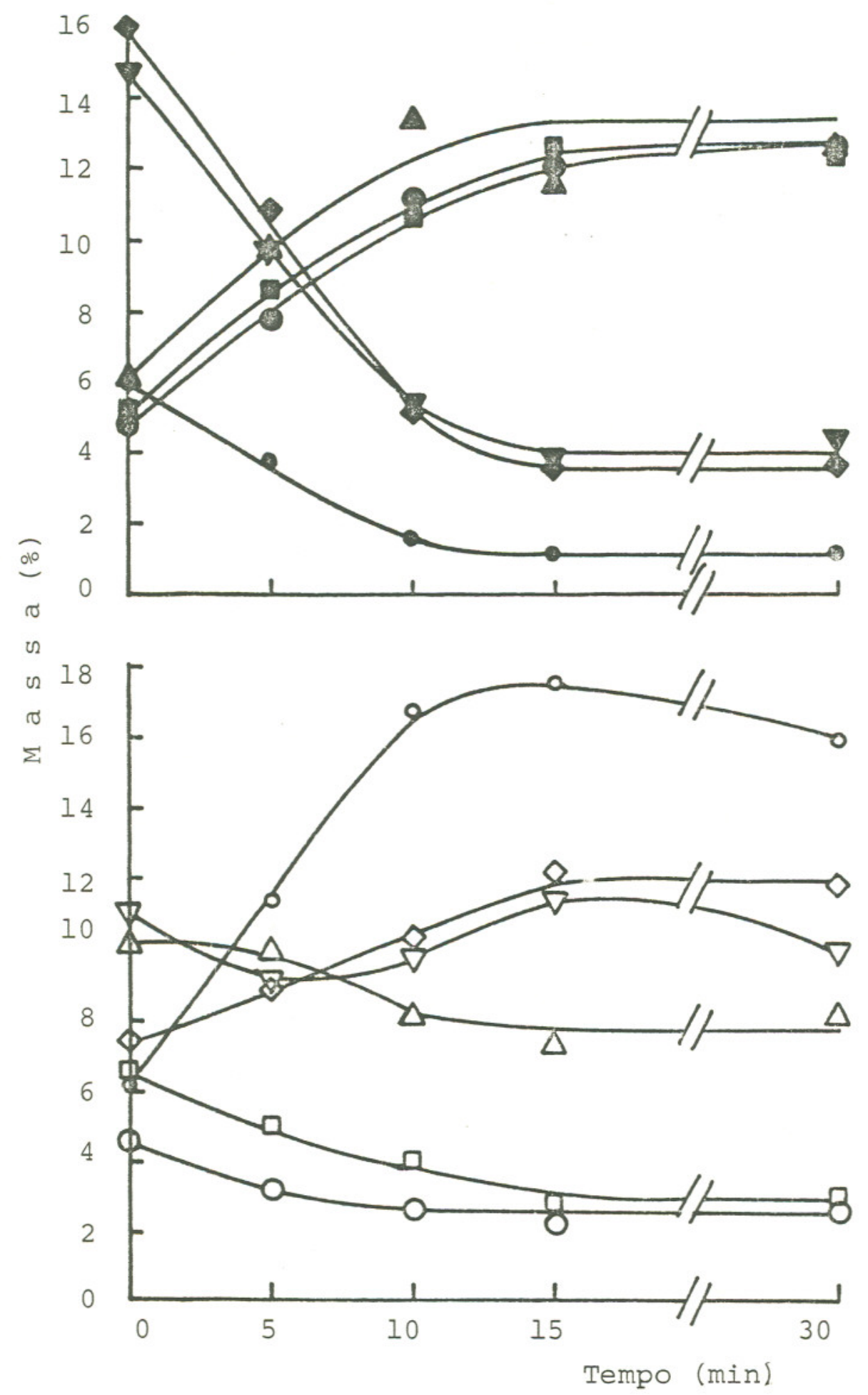

FIGURA 24. Por centagem em massa de triglicérides em função do tempo para a reação de intereste rificação de babaçu e dendê neutralizado na proporção respectiva de 80:20.
(O) $\mathrm{C}_{32}$
(ㅁ) $\mathrm{C}_{34}$
$(\Delta) \quad C_{36}$
$(\nabla) \quad C_{38}$
$(\diamond) \mathrm{C}_{40} \quad(0) \mathrm{C}_{42}$
(-) $\mathrm{C}_{44}$
(घ) $\mathrm{C}_{46}$
(A) $\mathrm{C}_{48}$
( $) \mathrm{C}_{50}$
(४) $\mathrm{C}_{52}$
(•) $\mathrm{C}_{5} \mathrm{~s}$ 

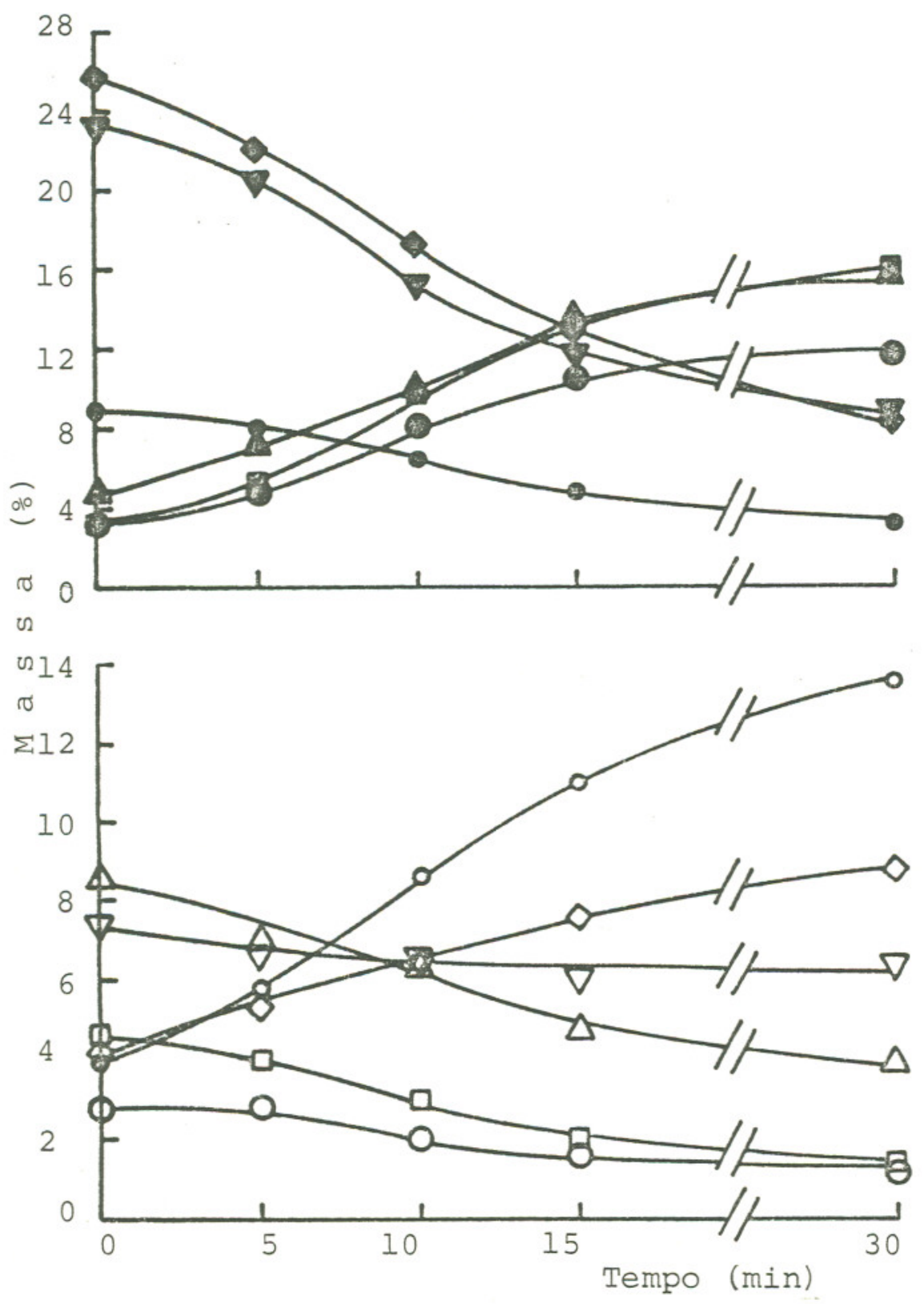

FIGURA 25. Porcentagem em massa de triglicērides em função do tempo para a reação de interesterificação de babaçu e dendê neutralizado na proporção respectiva de $60: 40$.
(O) $\mathrm{C}_{32}$
(ㅁ) $\mathrm{C}_{34}$
$(\Delta) C_{36}$
$(\nabla) \quad C_{38}$
$(\diamond) \mathrm{C}_{40}$
(०) $\mathrm{C}_{42}$ (O) $\mathrm{C}_{44}$
(घ) $\mathrm{C}_{46}$
(A) $\mathrm{C}_{48}$
$(\nabla) \quad \mathrm{C}_{50}$
(•) $\mathrm{C}_{52} \quad\left(\bullet \mathrm{C}_{54}\right.$ 
92.

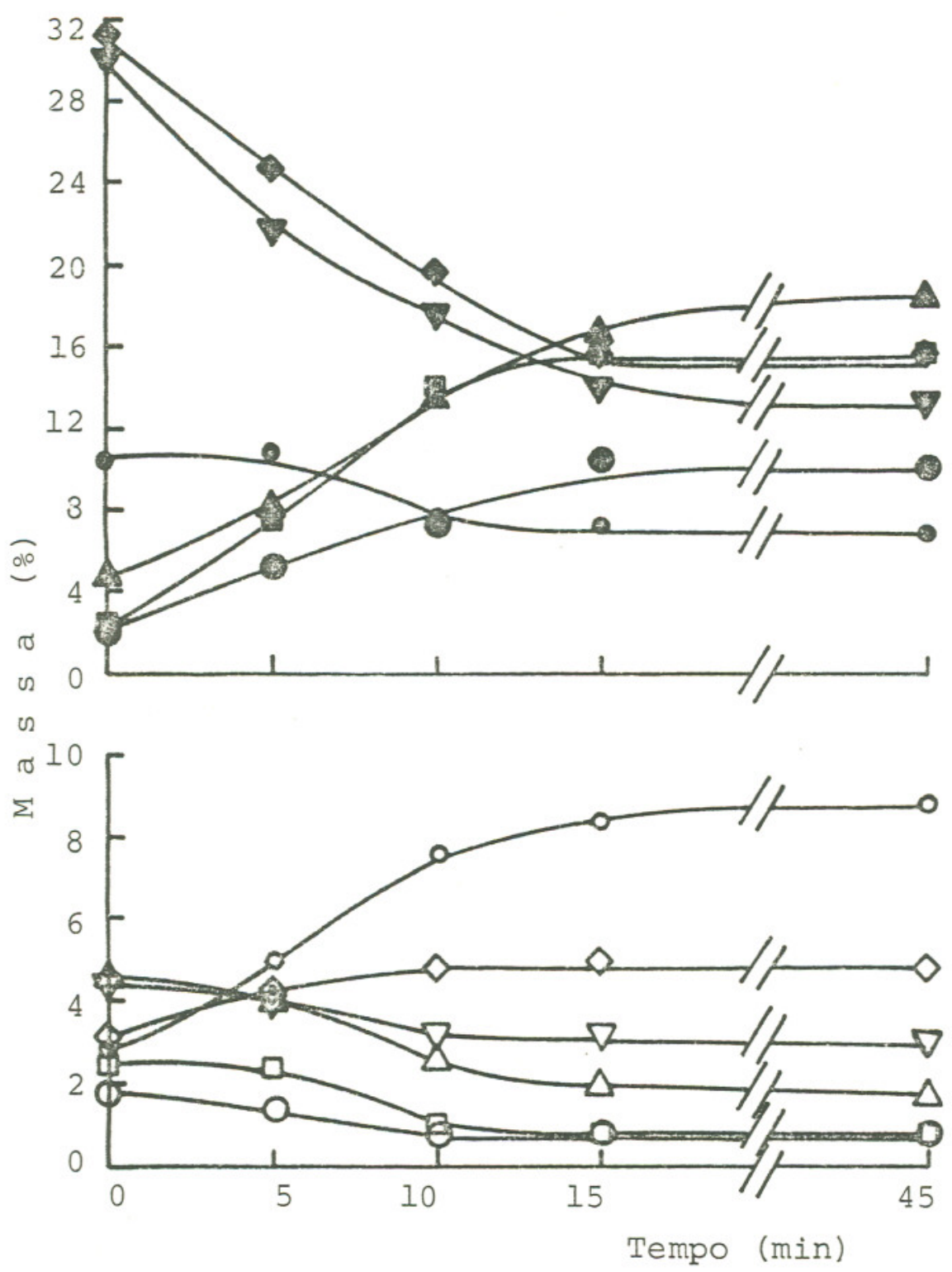

FIGURA 26. Porcentagem em massa de triglicērides em função do tempo para a reação de intereste rificação de babaçu e dendê neutralizado na proporção respectiva de 40:60.
(O) $\mathrm{C}_{32}$
() $\mathrm{C}_{34}$
( $\triangle$ ) $C_{36}$
$(\nabla) \quad C_{38}$
$(\diamond) \mathrm{C}_{40} \quad(0) \mathrm{C}_{42}$
(O) $\mathrm{C}_{44}$
(a) $\mathrm{C}_{46}$
(A) $\mathrm{C}_{48}$
$(\nabla) C_{50}$
$(\bullet) C_{52}$
(•) $\mathrm{C}_{54}$ 


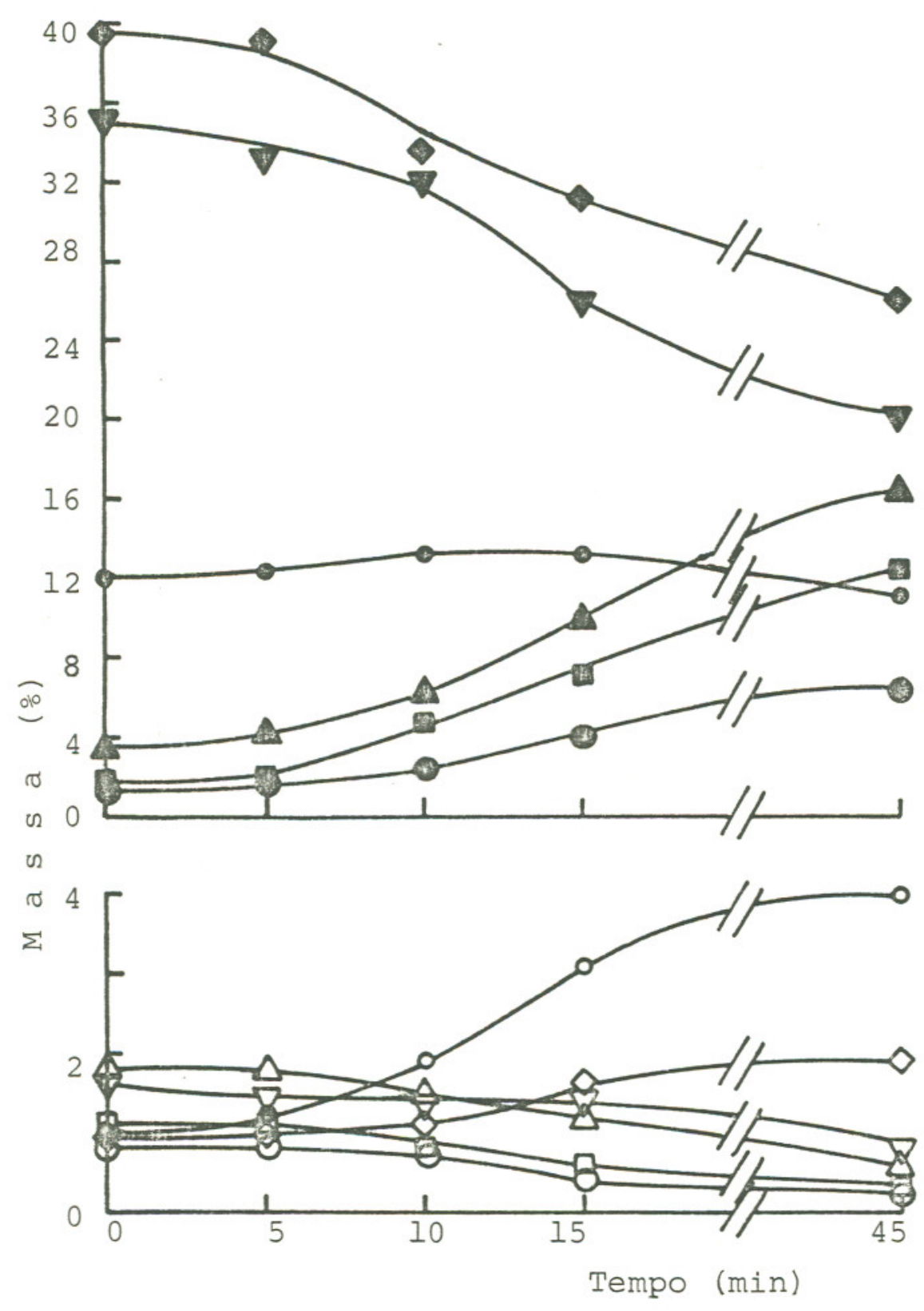

FIGURA 27. Porcentagem em massa de triglicērides em função do tempo para a reação de interesterificação de babaçu e dendê neutralizą do na proporção respectiva de 20:80.
(O) $\mathrm{C}_{32}$
(口) $\mathrm{C}_{34}$
( $\Delta$ ) $C_{36}$
$(\nabla) \mathrm{C}_{38}$
$(\diamond) \mathrm{C}_{40} \quad(0) \mathrm{C}_{42}$
(०) $\mathrm{C}_{44}$
(घ) $\mathrm{C}_{46}$
$(\Delta) C_{48} \quad(\nabla) \quad C_{50}$
(•) $\mathrm{C}_{52}$
(-) $\mathrm{C}_{54}$ 


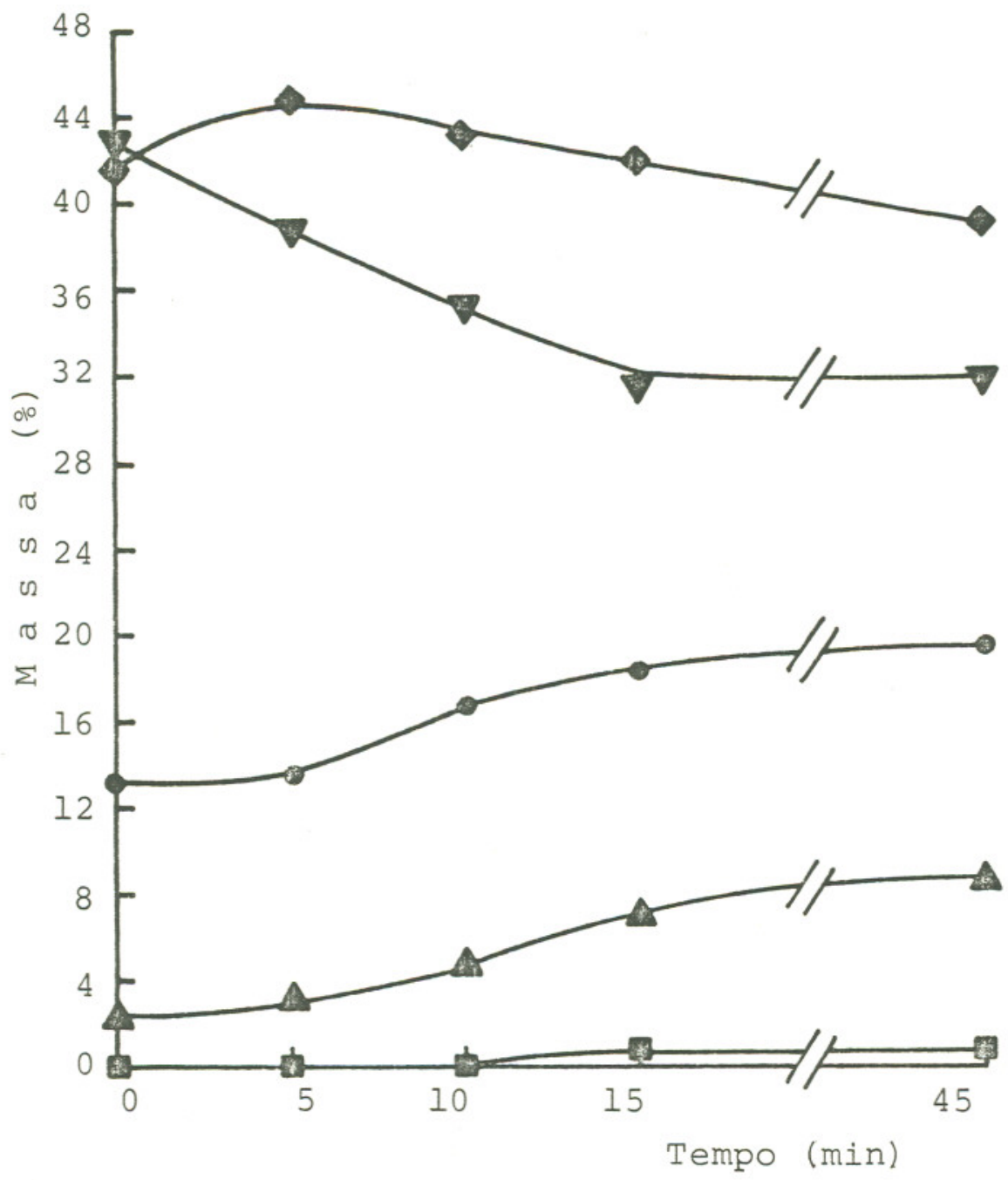

FIGURA 28. Porcentagem em massa de triglicērides em função do tempo para a reação de interesterificação de azeite de dendê neutraliza do.

(घ) $\mathrm{C}_{46}$

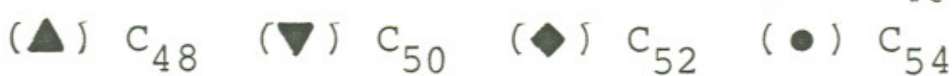


Observa-se que, em função da redistribui ção dos ācidos graxos nos triglicēric̉es, a composição destes vai se alterando durante a reação, atē ser atingido o equilíbrio.

As figuras de 29 a 34 , apresentadas na forma de histogramas, evidenciam a significativa mudança no perfil dos triglicérides provocada pelo rearranjo ao acaso.

A partir dos resultados computados para a composição glicerídica, os triglicérides individuais foram agrupados en função do nümero de átomos de carbono. Estes resultados são apresentados nas tabelas 26 e 27 .

Comparando-se os resultados obtidos expe rimentalmente com os valores calculados, verifica-se melhor concordância após as reações de interesterificação.

ROSSELI et $\underline{a}$. $(75,76)$ provaram que a teoria de distribuição 1,3-random-2-random proporciona precí são razoável na estimativa da composição triglicerídica da. maioria das gorduras naturais. Entretanto, ela não se aplica com a mesma precisão a gorduras fracionadas, sendo este 0 caso do azeite de dendê utilizado neste trabalho.

Esta teoria dá uma representação precisa da composição glicerídica de gorduras naturais que contenham principalmente ácidos graxos de 16 e 18 átomos de carbono (84).

As mesmas teorias de distribuição citadas foram empregadas no cálculo da composição para grupos de triglicérides, lembrando das limitações mencionadas. Nesta 
FIGURA 29. Porcentagem em massa de triglicérides em função do número de ātomos de carbono para a reação de interesterificação de gor dura de babaçu.

$$
\text { (口) antes (घ) após }
$$

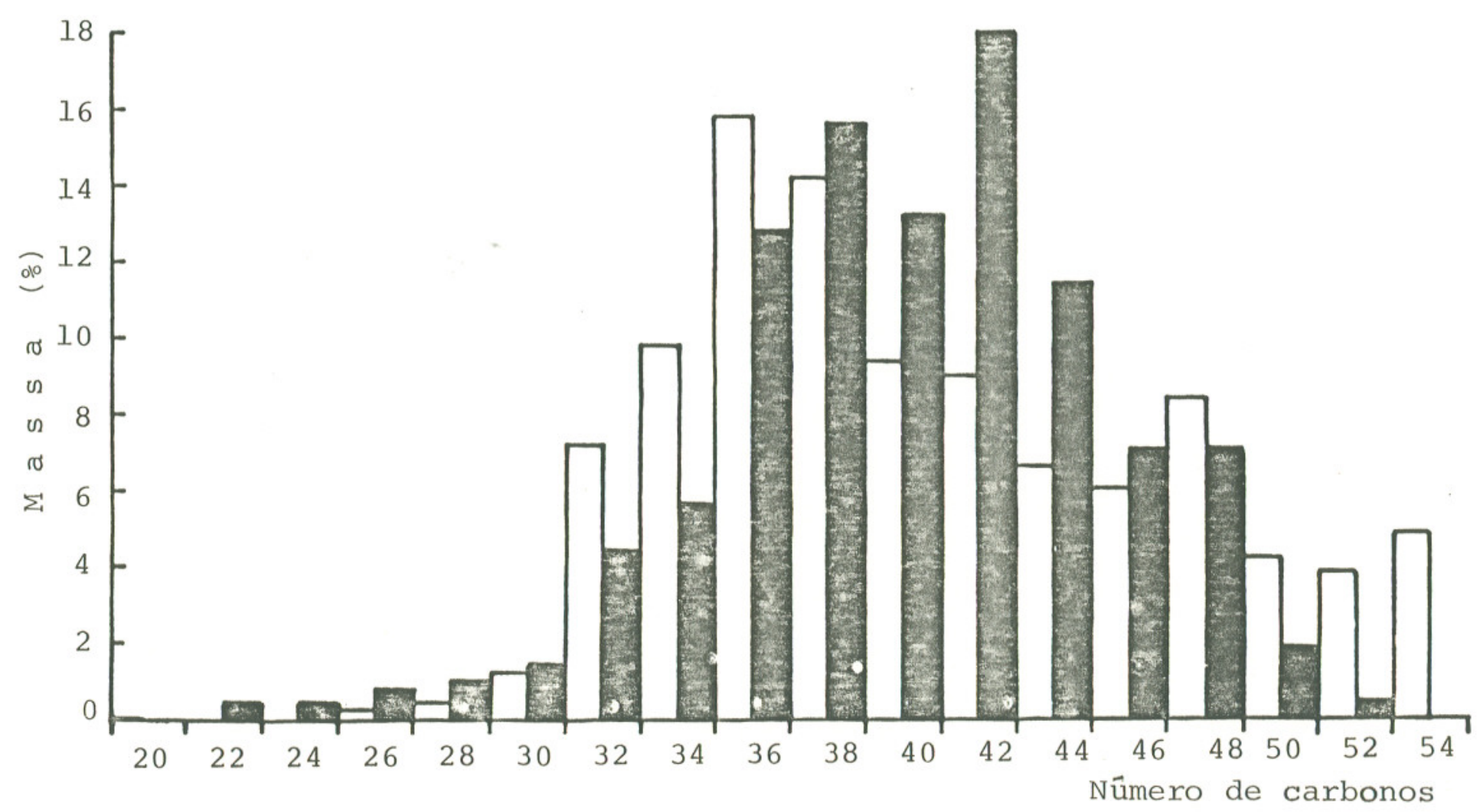


FIGURA 30. Porcentagem em massa de triglicērides em função do número de âtomos de carbono para a reação de interesterificação de babaçu e dendê neutralizado na proporção respectiva de 80:20.

$$
\text { (口) antes (ㅁ) apōs }
$$

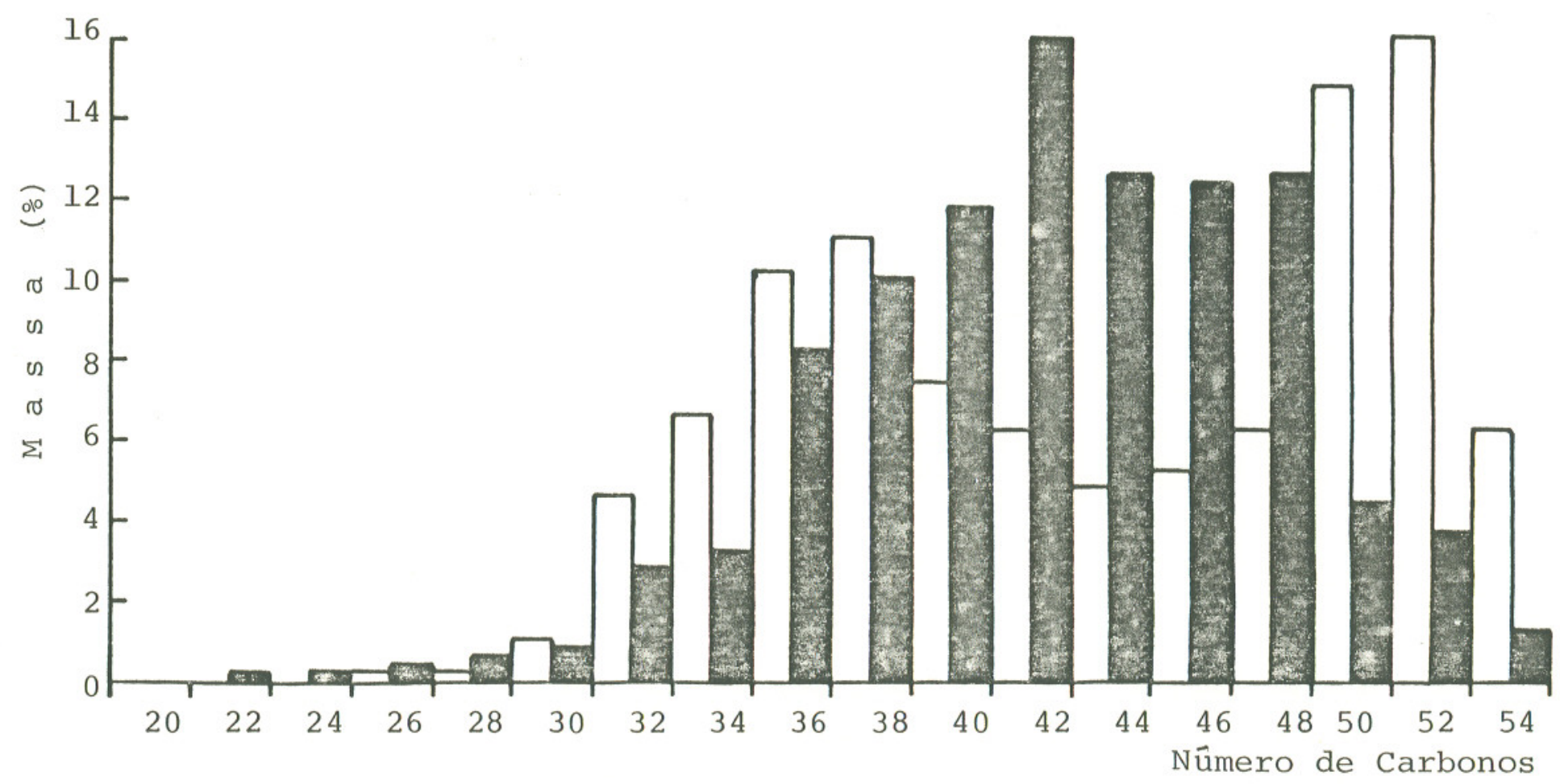


FIGURA 31. Porcentagem em massa de triglicérides em função do nümero de ātomos de carbono para a reação de interesterificação de babaçu e dendê neutralizado na proporção respectî va de 60:40.

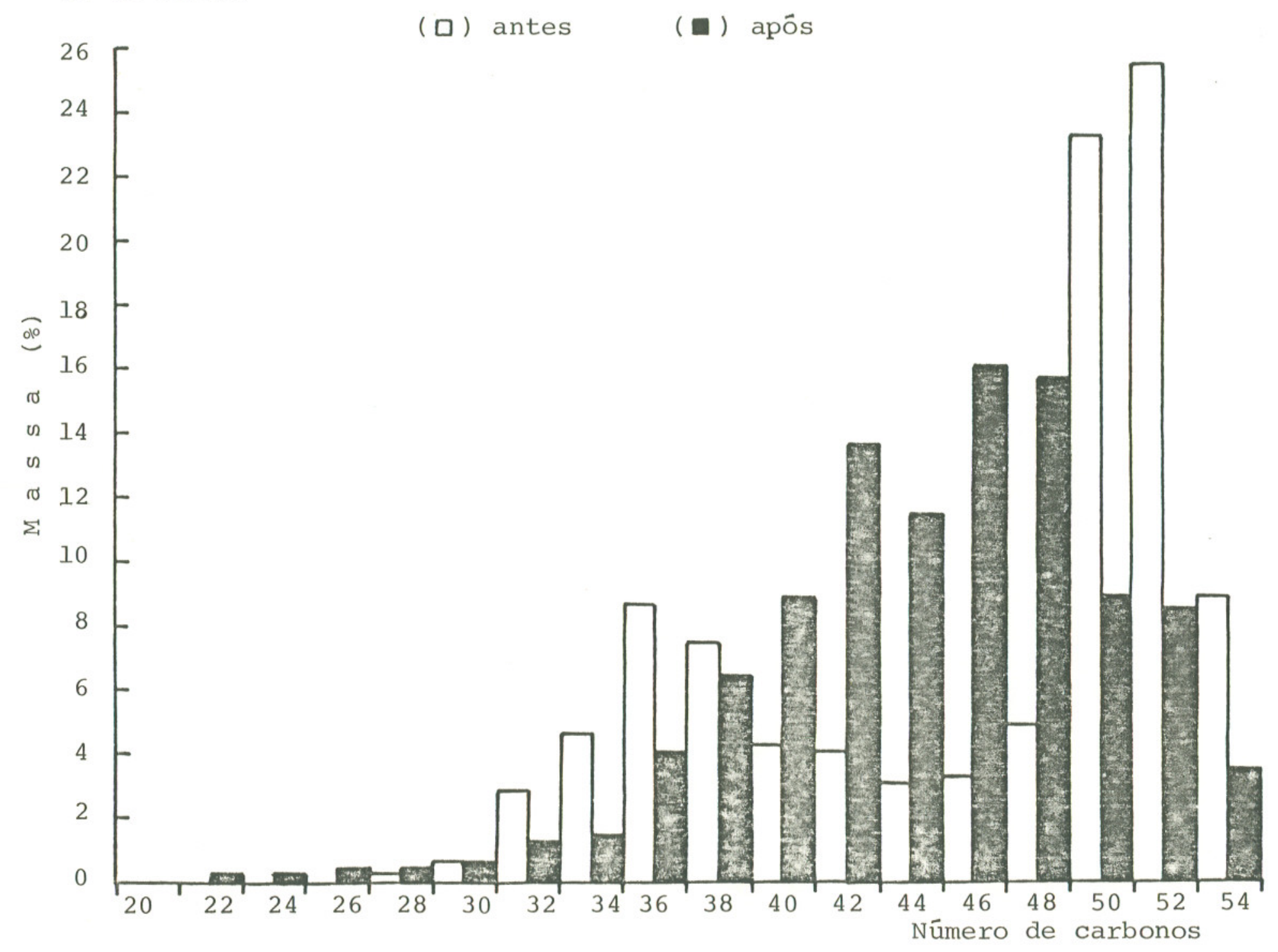


FIGURA 32. Porcentagem em massa de triglicêrides em função do nûmero de ătomos de carbono para a reação de interesterificação de babaçu e dendê neutralizado na proporção respectiva de 40:60.

(ㅁ) antes (घ) apös

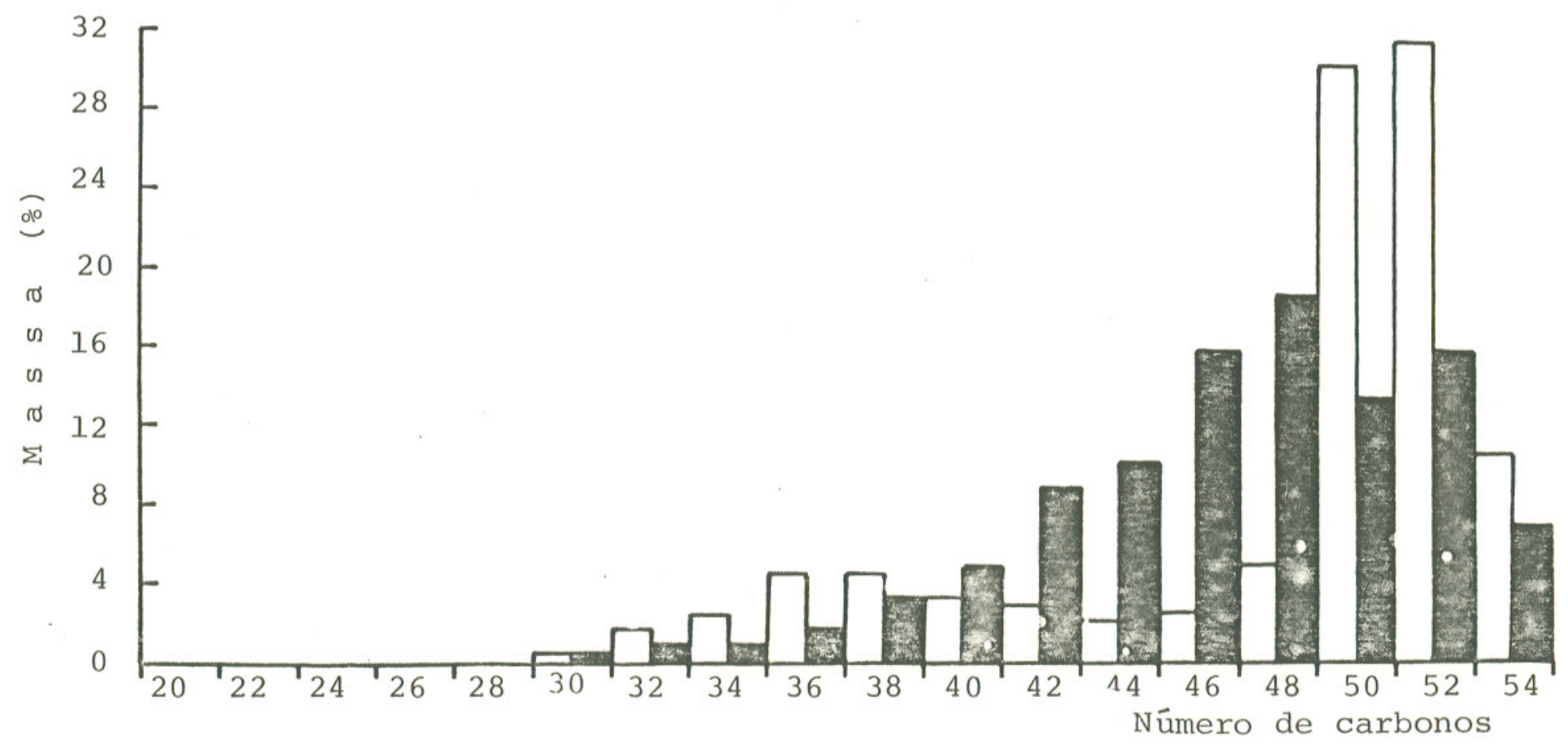


FIGURA 33. Porcentagem em massa de triglicérides em função do número de átomos de carbono para a reação de interesterificação de babaçu e dendê neutralí zado na proporção respectiva de 20:80.

(ㅁ) antes

(घ) apōs
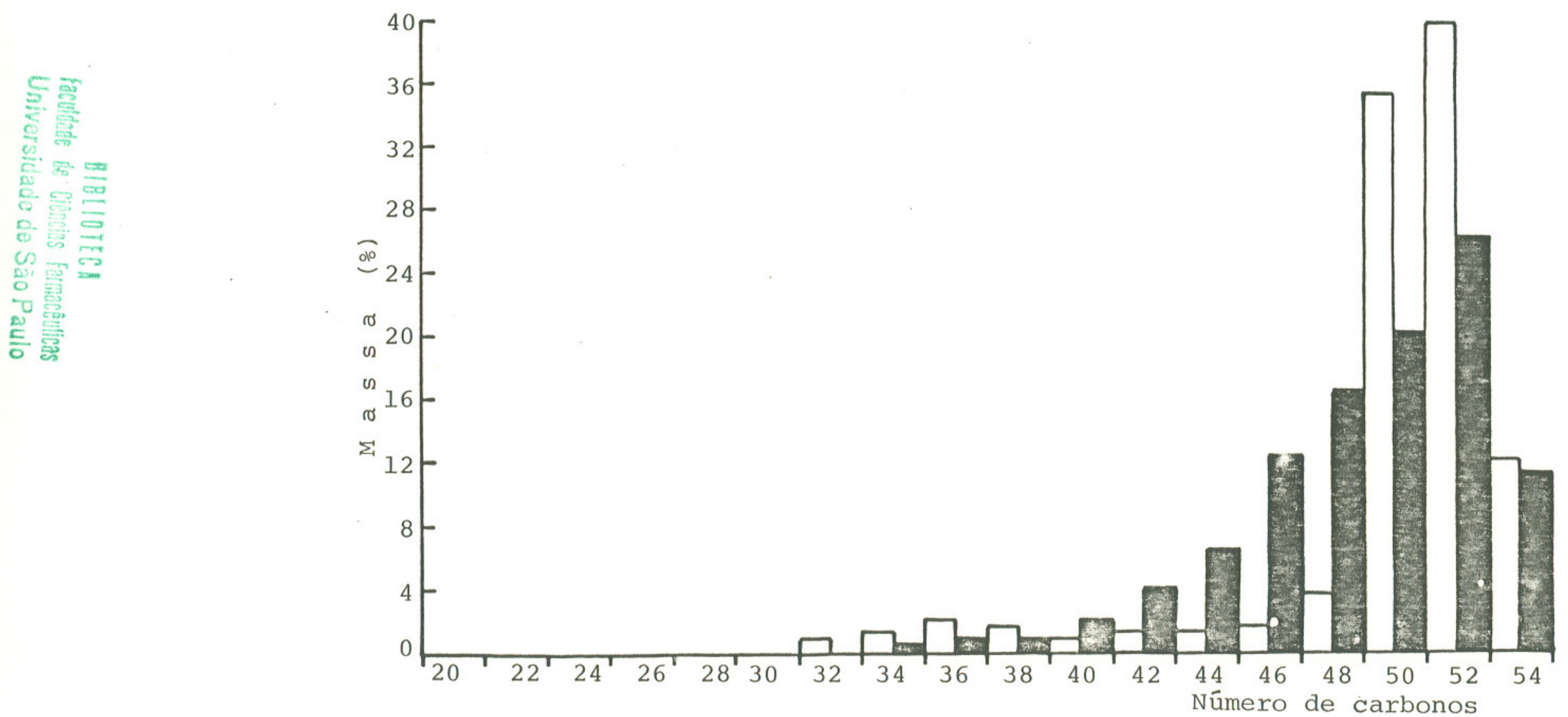


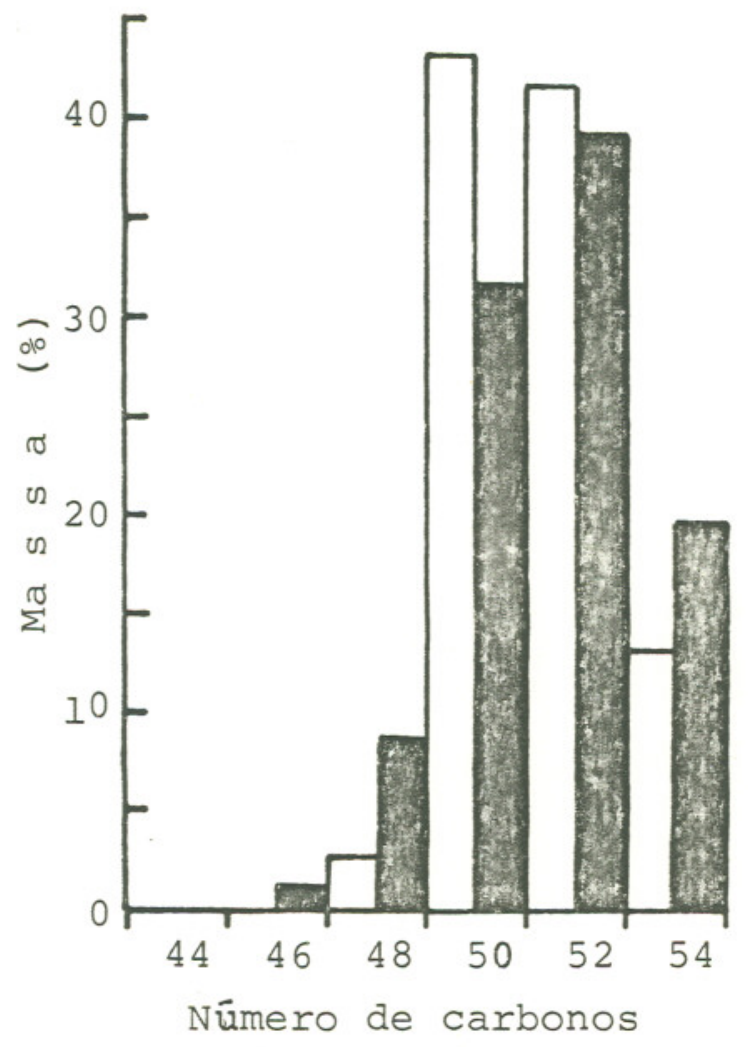

FIGURA 34. Porcentagem em massa de triglicérides em função do número de átomos de carbono pa ra a reação de interesterificação de azeite de dendê neutralizado.

$(\square)$ antes I apös 
TABELA 26. Valores calculados para triglicérides de misturas em proporções variáveis de gordura de babaçu e azeite de dendê neutralizado

\begin{tabular}{|c|c|c|c|c|c|c|}
\hline \multirow{3}{*}{$\begin{array}{l}\text { Triglicéride } \\
\text { (No de carbonosa) }\end{array}$} & \multicolumn{6}{|c|}{$\because$ em massa } \\
\hline & \multicolumn{6}{|c|}{ Proporção (babaçu: dendê) } \\
\hline & $100: 0$ & $80: 20$ & $60: 40$ & $40: 60$ & $20: 80$ & $0: 1.0 .0$ \\
\hline $\mathrm{C}_{24}$ & 0,0 & 0,0 & 0,0 & 0,0 & 0,0 & - \\
\hline $\mathrm{C}_{26}$ & 0,0 & 0,0 & 0,0 & 0,0 & 0,0 & - \\
\hline$C_{28}$ & 0,6 & 0,5 & 0,4 & 0,2 & 0,1 & - \\
\hline $\mathrm{C}_{30}$ & 1,4 & 1,1 & 0,8 & 0,6 & 0,3 & - \\
\hline $\mathrm{C}_{32}$ & 3,2 & 2,6 & 1,9 & 1,3 & 0,6 & - \\
\hline$C_{34}$ & 5,9 & 4,7 & 3,5 & 2,4 & 1,2 & - \\
\hline$c_{36}$ & 8,4 & 6,7 & 5,0 & 3,4 & 1,7 & 0,0 \\
\hline $\mathrm{C}_{38}$ & 11,9 & 9,5 & 7,1 & 4,8 & 2,4 & 0,0 \\
\hline $\mathrm{C}_{40}$ & 13,6 & 10,9 & 8,2 & 5,4 & 2,7 & 0,0 \\
\hline$C_{42}$ & 14,1 & 11,3 & 8,5 & 5,6 & 2,8 & 0,0 \\
\hline $\mathrm{C}_{44}$ & 13,7 & 11,0 & 8,3 & 5,5 & 2,8 & 0,1 \\
\hline $\mathrm{C}_{46}$ & 10,5 & 8,5 & 6,5 & 4,4 & 2,4 & 0,4 \\
\hline$C_{48}$ & 8,2 & 7,3 & 6,4 & 5,6 & 4,7 & 3,8 \\
\hline$C_{50}$ & 4,9 & 10,2 & 15,6 & 20,9 & 26,3 & 31,6 \\
\hline$C_{52}$ & 2,3 & 11,0 & 19,7 & 28,4 & 37,1 & 45,8 \\
\hline$C_{54}$ & 1,3 & 4,7 & 8,1 & 11,5 & 14,9 & 18,3 \\
\hline
\end{tabular}

a Não foram considerados os ätomos de carbono do glicerol. 
TABELA 27. Valores calculados para triglicérides após as reações de interesterificação com proporções variáveis de babaçu e dendê neutralizado.

Triglicēride (No de carbonos ${ }^{a}$ )
\% em massa

Proporção (babaçu: dendê)

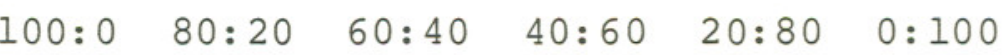

$\mathrm{C}_{24}$

$0,0 \quad 0,0$

0,0

$0,0 \quad 0,0$

$0,2 \quad 0,0$

0,0

0,0

0,0

$\mathrm{c}_{28}$

$0,7 \quad 0,3$

0,3

0,1

0,0

$\mathrm{C}_{30}$

$1,5 \quad 0,6$

0,5

0,2

0,0

$\mathrm{C}_{32}$

3.3

1,8

1,7

0,7

0,1

$\mathrm{C}_{34}$

$5,8 \quad 3,0$

2,4

1,1

0,2

$\mathrm{C}_{36}$

$8,4 \quad 5,7 \quad 4,9$

2,6

0,7

0,0

$\mathrm{c}_{38}$

11,7

8,6

7,4

4,2

1,3

0,0

$\mathrm{C}_{40}$

$13,0 \quad 10,6$

9,1

6,3

$2,6 \quad 0,0$

$\mathrm{C}_{42}$

$14,3 \quad 14,7 \quad 13,6 \quad 10,2$

$5,2 \quad 0,0$

$\mathrm{C}_{44}$

$13,4 \quad 13,5$

12,7

11,5

7,5

0,1

$\mathrm{C}_{46}$

$10,1 \quad 13,3 \quad 14$,

15,4

13,0

0,6

$\mathrm{C}_{48}$

$8,9 \quad 13,0 \quad 14$,

15,

15,4

7,2

$\mathrm{C}_{50}$

$4,8 \quad 6,7 \quad 7,8 \quad 12,0 \quad 17,0 \quad 28,0$

$\mathrm{C}_{52}$

$2,2 \quad 5,1$

7,2

13,

$1,7 \quad 3,1$

4,2

6,9

13,5

22,0

a Não foram considerados os átomos de carbono do glicerol. 
forma, os ácidos graxos são considerados em apenas duas categorias, saturados e insaturados. Portanto, os triglicéri des são divididos, da maneira mais simples possível, em qua tro grupos: tri-saturados, tri-insaturados, di-saturados e di-insaturados. Estes dois últimos, podem ser simétricos ou assimētricos.

Estes resultados são apresentados na tabela 28 e nas figuras 35 e 36 .

As propriedades funcionais relacionadas com estrutura e consistência como pontos de fusão e de amolecimento e indice de gordura sólida são determinadas pelas proporções relativas dos glicerídeos componentes, especialmente os tri e di-saturados (14, 54, 91).

Em todas as reações efetuadas, o rearran jo promoveu aumento no teor de triglicérides tri-saturados. Este fato seria portanto responsāvel pela elevação dos pontos de fusão e de amolecimento, bem como no aumento do indi ce de gordura sólida em temperaturas mais altas, aspectos desejáveis no presente estudo.

\section{5 - Estabilidade à oxidação}

As tabelas 29 e 30 e a figura 37 apresentam os incrementos de massa obtidos no teste de estabilidade à oxidação em estufa a $60^{\circ} \mathrm{C}$.

Os tempos de indução à oxidação foram determinados traçando-se a tangente pelo ramo ascendente da curva até o ponto em que esta cruza com a ordenada cor- 
TABELA 28. Valores calculados para grupos de triglicérides antes e apōs as reações de interesterificação com proporções variāveis de babaçu e dendê neutralizado.

\begin{tabular}{|c|c|c|c|c|c|c|c|c|c|c|c|c|}
\hline \multirow{4}{*}{$\begin{array}{l}\text { Trigli } \\
\text { cēride }\end{array}$} & \multicolumn{12}{|c|}{ \% em massa } \\
\hline & \multicolumn{12}{|c|}{ Proporção (babaçu: dendê) } \\
\hline & \multicolumn{2}{|c|}{$100: 0$} & \multicolumn{2}{|c|}{$80: 20$} & \multicolumn{2}{|c|}{$60: 40$} & \multicolumn{2}{|c|}{$40: 60$} & \multicolumn{2}{|c|}{$20: 80$} & \multicolumn{2}{|c|}{$0: 100$} \\
\hline & Antes & Apōs & Antes & Após & Antes & Após & Antes & Após & Antes & Apōs & Antes & Apōs \\
\hline $\operatorname{SSS}^{\mathrm{a}}$ & 45,3 & 47,4 & 36,9 & 37,6 & 28,6 & 32,4 & 20,2 & 24,4 & 11,9 & 15,1 & 3,5 & 9,1 \\
\hline $\operatorname{III}^{\mathrm{b}}$ & 0,7 & 1,1 & 3,1 & 2,2 & 5,4 & 3,1 & 7,7 & 5,3 & 10,1 & 10,3 & 12,4 & 16,7 \\
\hline SSI & 13,3 & 26,8 & 11,5 & 29,0 & 9,6 & 29,5 & 7,8 & 29,3 & 5,9 & 26,5 & 4,1 & 22,3 \\
\hline SIS & 30,7 & 13,4 & 31,8 & 14,5 & 32,9 & 14,8 & 34,1 & 14,6 & 35,2 & 13,2 & 36,3 & 11,1 \\
\hline IIS & 9,0 & 7,5 & 15,7 & 11,1 & 22,4 & 13,5 & 29,1 & 17,6 & 35,8 & 23,3 & 42,5 & 27,2 \\
\hline ISI & 1,0 & 3,8 & 1,0 & 5,6 & 1,1 & 6,7 & 1,1 & 8,8 & 1,1 & 11,6 & 1,2 & 13,6 \\
\hline
\end{tabular}

${ }^{a_{S}=\text { saturado }} \quad \mathrm{b}_{\mathrm{I}}=$ insaturado 


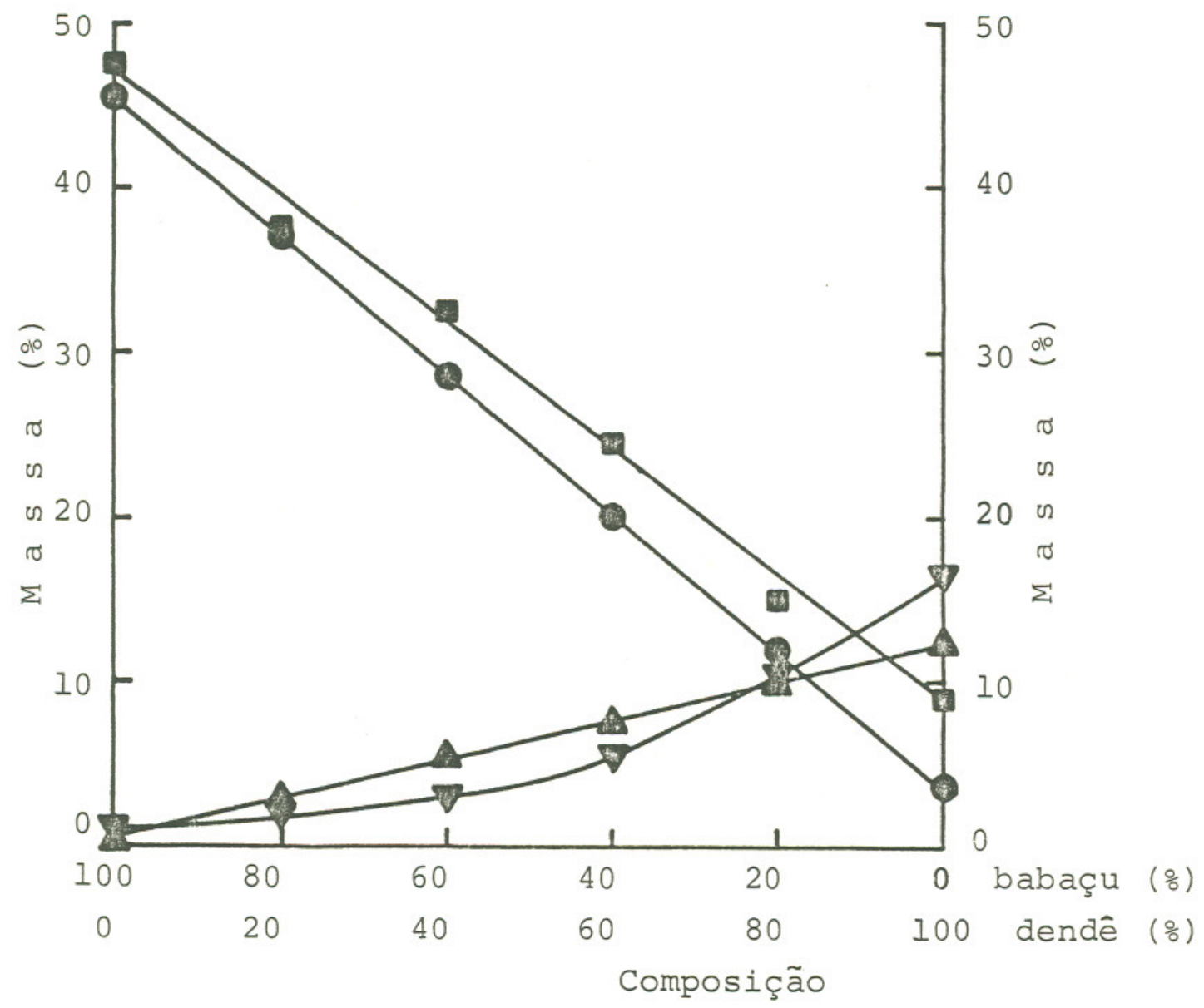

FIGURA 35. Diagrama da mistura de babaçu e dendê neutralizado em função de grupos de triglicérides.

(O) $\mathrm{S}_{3}$ antes

$\left(\Delta I_{3}\right.$ antes

(घ) $\mathrm{s}_{3}$ após

( $\nabla)^{3}$ apōs 
107.

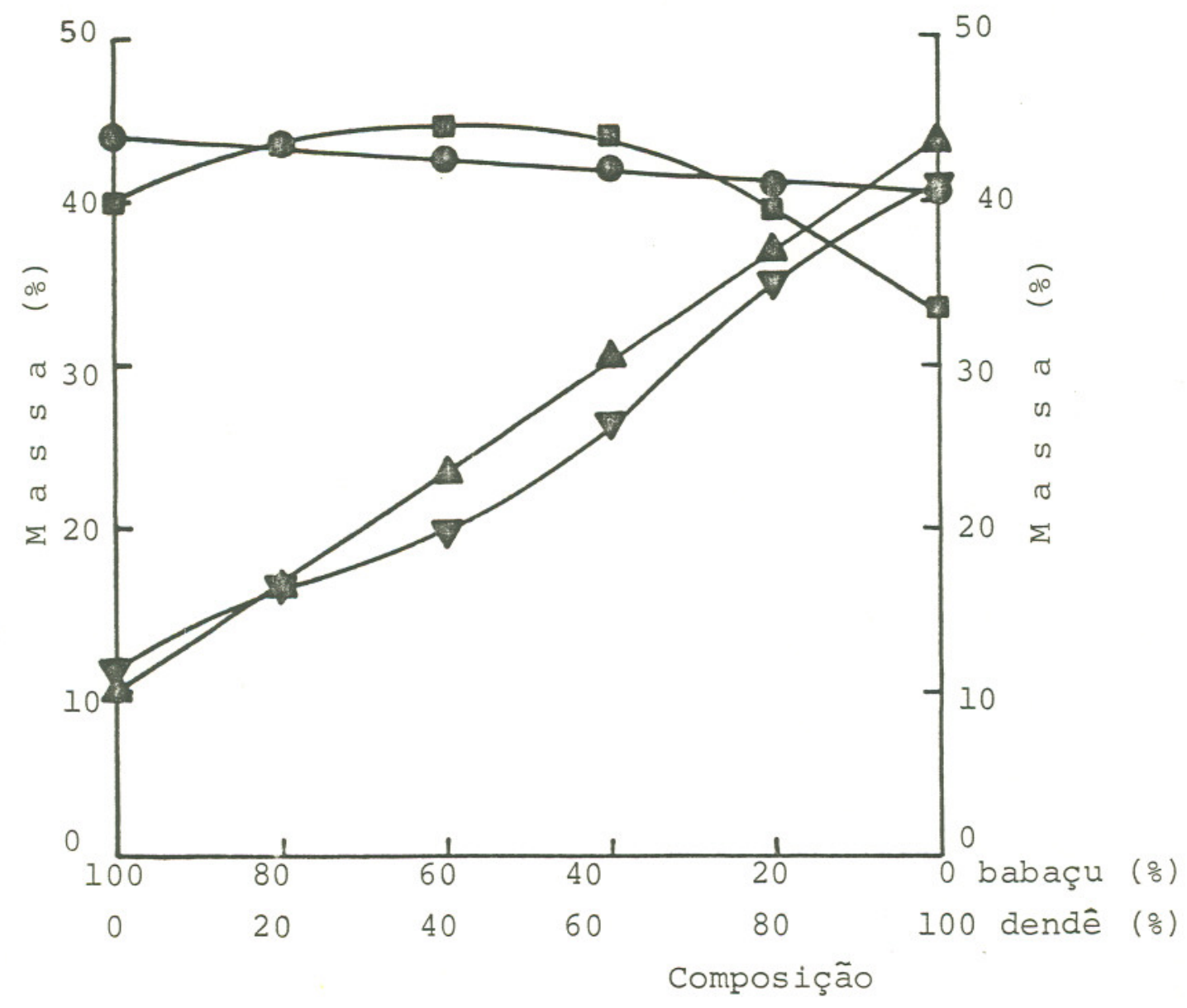

FIGURA 36. Diagrama da mistura de babaçu e dendê neutralizado em função de grupos de triglicérides.
(O) $\mathrm{S}_{2} \mathrm{I}$ antes
(v) $\mathrm{S}_{2} \mathrm{I}$ apōs
(A) $I_{2} S$ antes
$(\nabla) I_{2} S$ apös 
respondente à massa inicial de 1,000g. São apresentados a seguir:

\begin{tabular}{ccc} 
Composição & \multicolumn{2}{c}{$\begin{array}{c}\text { Tempo de indução } \\
\text { Anabaçu: dendê }\end{array}$} \\
Antes Após \\
$100: 0$ & 59,0 & - \\
$80:$ & 83,8 & - \\
$60: 40$ & 62,6 & 55,6 \\
$40: 60$ & 56,8 & 37,4 \\
$20: 80$ & 49,2 & 32,6 \\
$0: 100$ & 41,0 & 27,0
\end{tabular}

Verifica-se que o tempo de indução aumenta à medida que aumenta a saturação das amostras, ou seja, a participação do babaçu. A única exceção foi a gordu ra de babaçu isoladamente antes do rearranjo, cujo tempo de indução mostrou-se inferior ao das composições 80:20 e $60: 40$.

Para a gordura de babaçu e a composição $80 \%$ de babaçu para $20 \%$ de dendê, após o rearranjo, não foi possivel detectar 0 incremento de massa provocado pela oxidação.

Para as demais, o processo de intereste rificação diminuiu o tempo de indução. Isto significa que as amostras randomizadas se tornaram mais susceptiveis à oxidação. Este efeito é decorrente do aumento da concen tração de ācidos graxos insaturados nas posições 1 e 3 do glicerol, produzido pelo rearranjo das gorduras naturais utilizadas $(50,69,88)$. 
TABELA 29. Incrementos de massa obtidos no teste de estabilidade à oxidação antes e apōs as reações de interesterificação com proporções variāveis de babaçu e dendê neutralizado.

\begin{tabular}{|c|c|c|c|c|c|c|c|c|c|c|c|}
\hline \multicolumn{12}{|c|}{ Proporção (babaçu: dendê) } \\
\hline \multicolumn{4}{|c|}{$100: 0$} & \multicolumn{4}{|c|}{$80: 20$} & \multicolumn{4}{|c|}{$60: 40$} \\
\hline \multicolumn{2}{|c|}{ Antes } & \multicolumn{2}{|c|}{ Apōs } & \multicolumn{2}{|c|}{ Antes } & \multicolumn{2}{|c|}{ Apōs } & \multicolumn{2}{|c|}{ Antes } & \multicolumn{2}{|c|}{ Apōs } \\
\hline $\begin{array}{l}\text { Tempo } \\
\text { (dias) }\end{array}$ & $\begin{array}{c}\text { Massa } \\
(\mathrm{g})\end{array}$ & $\begin{array}{l}\text { Tempo } \\
\text { (dias) }\end{array}$ & $\begin{array}{l}\text { Massa } \\
(g)\end{array}$ & $\begin{array}{l}\text { Tempo } \\
\text { (dias) }\end{array}$ & $\begin{array}{l}\text { Massa } \\
(\mathrm{g})\end{array}$ & $\begin{array}{l}\text { Tempo } \\
\text { (dias }\end{array}$ & $\begin{array}{c}\text { Massa } \\
(\mathrm{g})\end{array}$ & 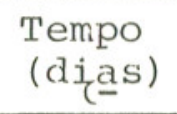 & $\begin{array}{c}\text { Massa } \\
(\mathrm{g})\end{array}$ & $\begin{array}{l}\text { Tempo } \\
\text { (dias) }\end{array}$ & $\begin{array}{c}\text { Massa } \\
(\mathrm{g})\end{array}$ \\
\hline 59 & 0,0007 & - & - & 84 & 0,0007 & - & - & 63 & 0,0036 & 57 & 0,0019 \\
\hline 60 & 0,0010 & - & - & 85 & 0,0018 & - & - & 64 & 0,0045 & 58 & 0.0030 \\
\hline 63 & 0,0026 & - & - & 86 & 0,0033 & - & - & 65 & 0,0054 & 59 & 0,0039 \\
\hline 64 & 0,0032 & - & - & 87 & 0,0049 & - & - & 66 & 0,0054 & 60 & 0,0035 \\
\hline 65 & 0.0042 & - & - & 88 & 0,0059 & - & - & 67 & 0,0071 & 63 & 0,0023 \\
\hline 66 & 0,0040 & - & - & 91 & 0,0073 & - & - & 70 & 0,0121 & 64 & 0,0033 \\
\hline 67 & 0.0041 & - & - & 92 & 0,0070 & - & - & 71 & 0,0120 & 65 & 0,0032 \\
\hline 70 & 0,0049 & - & - & 93 & 0,0082 & - & - & 72 & 0,0121 & 66 & 0,0024 \\
\hline 71 & 0,0048 & - & - & - & - & - & - & 73 & 0,0126 & - & - \\
\hline 72 & 0,0051 & - & - & - & - & - & - & 74 & 0,0115 & - & - \\
\hline 73 & 0.0054 & - & - & - & - & - & - & - & - & - & - \\
\hline
\end{tabular}


TABELA 30. Incrementos de massa obtidos no teste de estabilidade à oxidação antes e após as reações de interesterificação com proporções variáveis de babaçu e dendê neutralı zado.

\begin{tabular}{|c|c|c|c|c|c|c|c|c|c|c|c|}
\hline \multicolumn{12}{|c|}{ Proporção (babaçu: dendê) } \\
\hline \multicolumn{4}{|c|}{$40: 60$} & \multicolumn{4}{|c|}{$20: 80$} & \multicolumn{4}{|c|}{$0: 100$} \\
\hline \multicolumn{2}{|c|}{ Antes } & \multicolumn{2}{|c|}{ Apōs } & \multicolumn{2}{|c|}{ Antes } & \multicolumn{2}{|c|}{ Apōs } & \multicolumn{2}{|c|}{ Antes } & \multicolumn{2}{|c|}{ Apōs } \\
\hline $\begin{array}{l}\text { Tempo } \\
\text { (dias) }\end{array}$ & $\begin{array}{c}\text { Massa } \\
(g)\end{array}$ & $\begin{array}{l}\text { Temipo } \\
\text { (dias) }\end{array}$ & $\begin{array}{c}\text { Massa } \\
\text { (g) }\end{array}$ & $\begin{array}{l}\text { Tempo } \\
\text { (dias) }\end{array}$ & $\begin{array}{c}\text { Massa } \\
(\mathrm{g})\end{array}$ & $\begin{array}{l}\text { Tempo } \\
\text { (dias) }\end{array}$ & $\begin{array}{c}\text { Massa } \\
\text { (g) }\end{array}$ & $\begin{array}{l}\text { Tempo } \\
\text { (dias) }\end{array}$ & $\begin{array}{c}\text { Massa } \\
\text { (g) }\end{array}$ & $\begin{array}{l}\text { Tempo } \\
\text { (dias) }\end{array}$ & $\begin{array}{c}\text { Massa } \\
(g)\end{array}$ \\
\hline 53 & 0,0011 & 38 & 0,0013 & 46 & 0,0014 & 32 & 0,0021 & 39 & 0,0006 & 28 & 0,0041 \\
\hline 56 & 0,0038 & 39 & 0,0039 & 49 & 0,0029 & 35 & 0,0073 & 42 & 0,0058 & 29 & 0,0083 \\
\hline 57 & 0,0050 & 42 & 0,0105 & 51 & 0,0146 & 36 & 0,0109 & 43 & 0,0108 & 30 & 0,0119 \\
\hline 58 & 0,0061 & 43 & 0,0109 & 52 & 0,0152 & 37 & 0,0122 & 44 & 0,0157 & 31 & 0,0157 \\
\hline 59 & 0,0121 & 44 & 0,0115 & 53 & 0,0156 & 38 & 0,0141 & 45 & 0,0178 & 32 & 0,0181 \\
\hline 60 & 0,0127 & 45 & 0,0114 & 56 & 0,0157 & 39 & 0,0149 & 46 & 0,0189 & 35 & 0,0213 \\
\hline 63 & 0,0128 & 46 & 0,0108 & 57 & 0,0172 & 42 & 0,0155 & 49 & 0,0193 & 36 & 0,0205 \\
\hline 64 & 0,0140 & - & - & 58 & 0,0166 & 43 & 0,0152 & 51 & 0,0212 & 37 & 0,0192 \\
\hline 65 & 0,0142 & - & - & 59 & 0,0178 & 44 & 0,0152 & 52 & 0,0208 & 38 & 0,0199 \\
\hline 66 & 0,0131 & - & - & 60 & 0,0170 & 45 & 0,0149 & 53 & 0,0194 & 39 & 0,0205 \\
\hline 67 & 0,0131 & - & - & - & . & 46 & 0,0143 & 56 & 0,0180 & - & - \\
\hline
\end{tabular}


FIGURA 37. Incrementos de massa, obtidos no teste de estabilidade à oxidação, em função do tempo.

$$
\begin{array}{cccc}
\text { babaçu: dendê } & \text { antes } & \text { apōs } \\
100 & 0 & \Delta & \\
80 & 20 & \nabla & \\
60 & 40 & \bullet & 0 \\
40 & 60 & \bullet & \square \\
20 & 80 & \bullet & \diamond \\
0 & 100 & \bullet & \mathbf{0}
\end{array}
$$
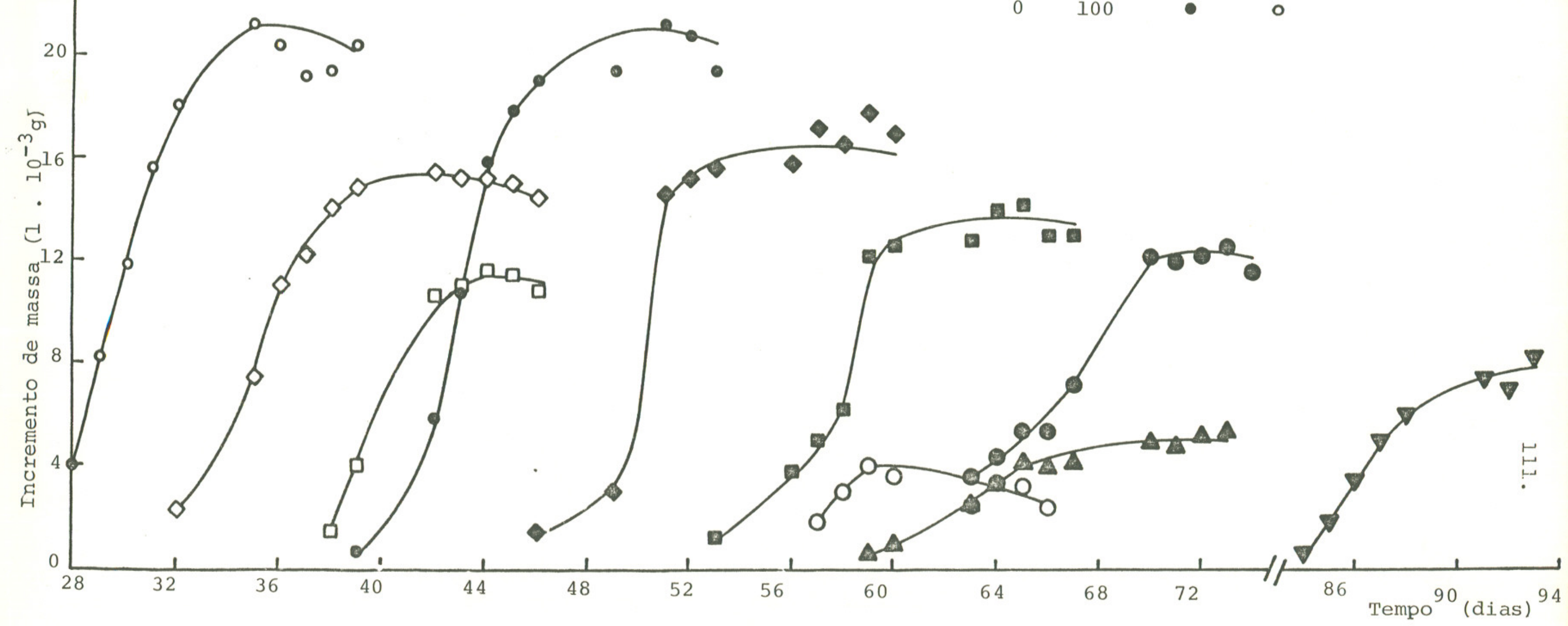
112.

3. MISTURA DE GORDURAS REARRANJADAS E ADIÇÃO DO бLEO DE SOJA

As tabelas 31 e 32 e as figuras 38 e 39 representam os pontos de fusão e de amolecimento e os indi ces de gordura sólida das misturas de gordura de babaçu e azeite de dendê neutralizado rearranjados isoladamente.

Comparando-se estes resultados com aqueles do rearranjo em conjunto das mesmas gorduras, verifi ca-se que há diferenças significativas.

A tabela 33 e a figura 40 correspondem ao diagrama de curvas iso-sólidas destas misturas. Observa-se a formação de um sistema eutētico, cuja composição se situa na faixa de $40 \%$ de babaçu para $60 \%$ de dendê até $20 \%$ de babaçu para $80 \%$ de dendê.

E conveniente salientar que a formação de misturas eutēticas pode apresentar aspectos desejāveis. Por exemplo, em composições de óleos de palma e caroço de palma usadas em bases de margarinas cremosas, este efeito permite a inclusão de níveis apreciavelmente maiores de óleo de palma. Isto não seria possível se não houvesse $\circ$ eutētico (96).

Com a finalidade de se obter bases gordurosas para margarinas do tipo cremoso, a partir da gordura de babaçu e do azeite de dendê interesterificados, é necessāria a adição de um óleo vegetal. Foi utilizado o óleo de soja para diminuir a consistência das gorduras rearranjadas assim como elevar o teor de ácidos graxos poli-insatu rados. 
113.

TABELA 31. Pontos de fusão e de amolecimento de misturas em proporções variáveis de gordura de babaçu e azeite de dendê neutralizado rearranjados isoladamente.

\begin{tabular}{|c|c|c|}
\hline $\begin{array}{c}\text { Proporção } \\
\text { (babaçu: dendê) }\end{array}$ & $\begin{array}{l}\text { Ponto de } \\
\text { fusão } \\
\left({ }^{\circ} \mathrm{C}\right)\end{array}$ & $\begin{array}{c}\text { Ponto de } \\
\text { amolecimento } \\
\left({ }^{\circ} \mathrm{C}\right)\end{array}$ \\
\hline $100: 0$ & 27,0 & 25,2 \\
\hline $80: 20$ & 27,2 & 26,2 \\
\hline $60: 40$ & 38,2 & 27,8 \\
\hline $40: 60$ & 41,2 & 30,8 \\
\hline $20: 80$ & 42,8 & 34,8 \\
\hline $0: 100$ & 44,0 & 37,2 \\
\hline
\end{tabular}


114.

TAABLA 32. Indices de gordura sólida de misturas em proporções variāveis de gordura de babaçu e azeite de dendê neutralizado rearranjados isoladamente.

\begin{tabular}{|c|c|c|c|c|c|c|c|c|}
\hline \multirow{2}{*}{$\begin{array}{c}\text { Proporção } \\
\text { (babaçu: dendê) }\end{array}$} & \multicolumn{8}{|c|}{ Indice de gordura sōlida (\%) } \\
\hline & $10^{\circ} \mathrm{C}$ & $15^{\circ} \mathrm{C}$ & $20^{\circ} \mathrm{C}$ & $25^{\circ} \mathrm{C}$ & $30^{\circ} \mathrm{C}$ & $35^{\circ} \mathrm{C}$ & $40^{\circ} \mathrm{C}$ & $45^{\circ} \mathrm{C}$ \\
\hline $100: 0$ & 39,6 & 32,6 & 21,8 & 8,1 & 0 & - & - & - \\
\hline $80: 20$ & 34,3 & 26,5 & 16,2 & 1,2 & 0 & - & - & - \\
\hline $60: 40$ & 32,9 & 25,3 & 14,7 & 5,5 & 4,2 & 3,2 & 0 & - \\
\hline $40: 60$ & 25,2 & - & 10,5 & 8,1 & 5,9 & 3,8 & 3,4 & 0 \\
\hline $20: 80$ & 22,7 & - & 11,5 & 10,5 & 8,0 & 5,6 & 4,2 & 0 \\
\hline $0: 100$ & 28,3 & 23,2 & 18,9 & 16,1 & - & 10,6 & - & 0 \\
\hline
\end{tabular}




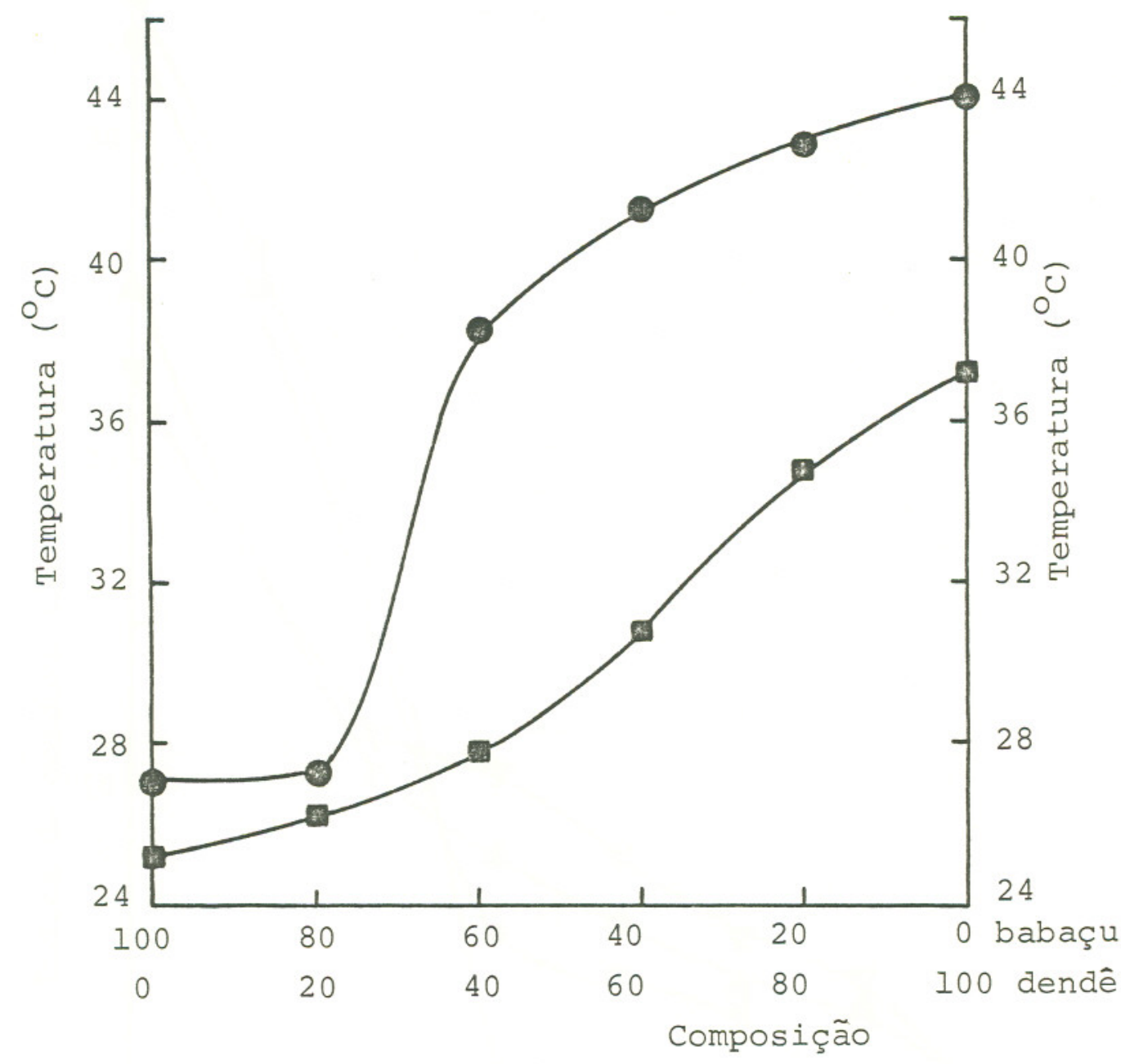

FIGURA 38. Diagrama da mistura de babaçu e dendê neutralizado rearranjados isoladamente em função da temperatura.

(O) ponto de fusão

(v) ponto de amolecimento 


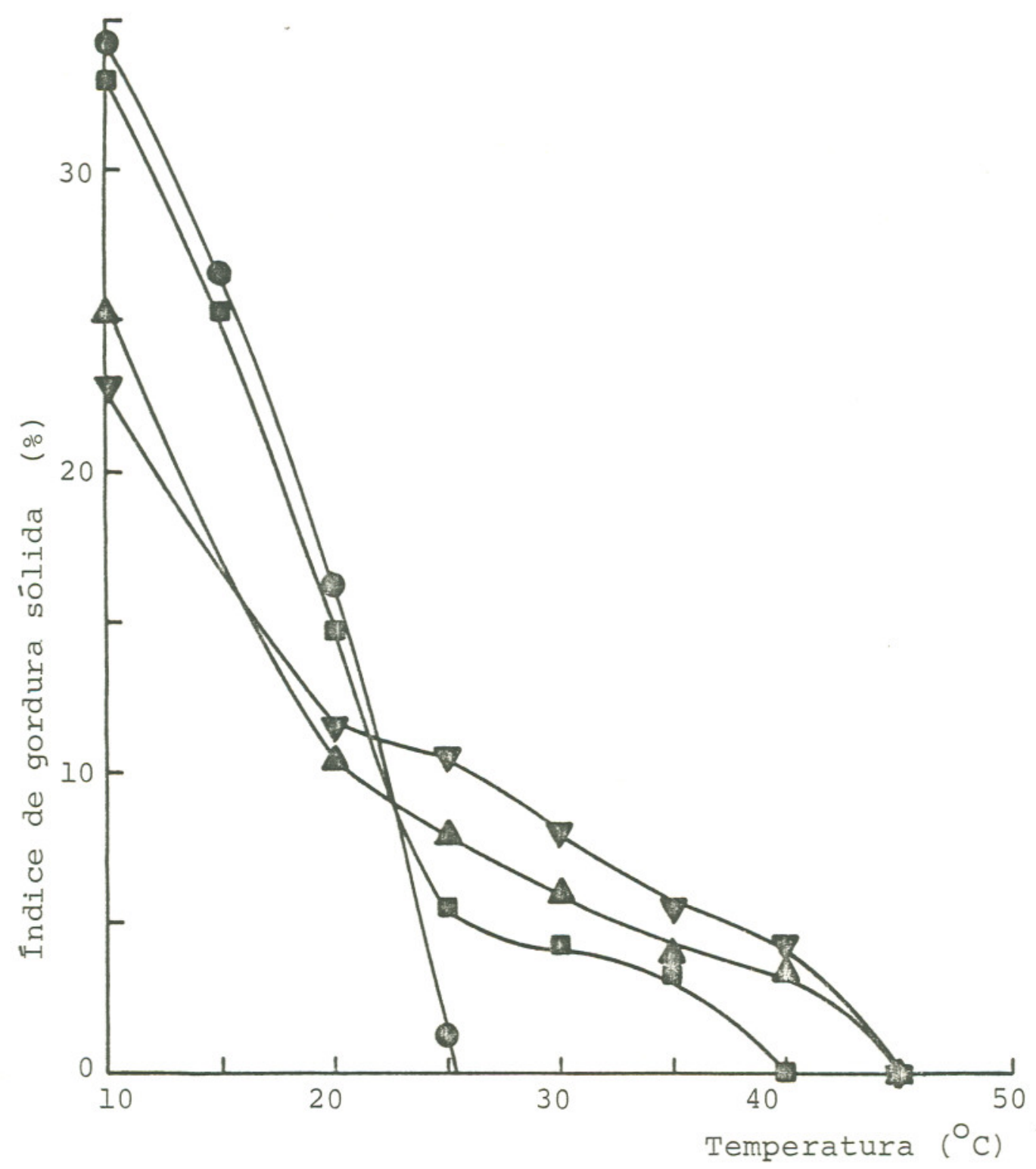

FIGURA 39. Curvas de sólidos de misturas de babaçu e dendê neutralizado rearranjados isoladamente.
(O) $80: 20$
(a) $60: 40$
(A ) $40: 60$
( $\boldsymbol{\nabla}$ ) $20: 80$ 
TABELA 33. Temperaturas correspondentes a diversos indices de gordura sólida para misturas em proporções variāveis de gordura de babaçu e azeite de dendê neutrâ lizado rearranjados isoladamente.

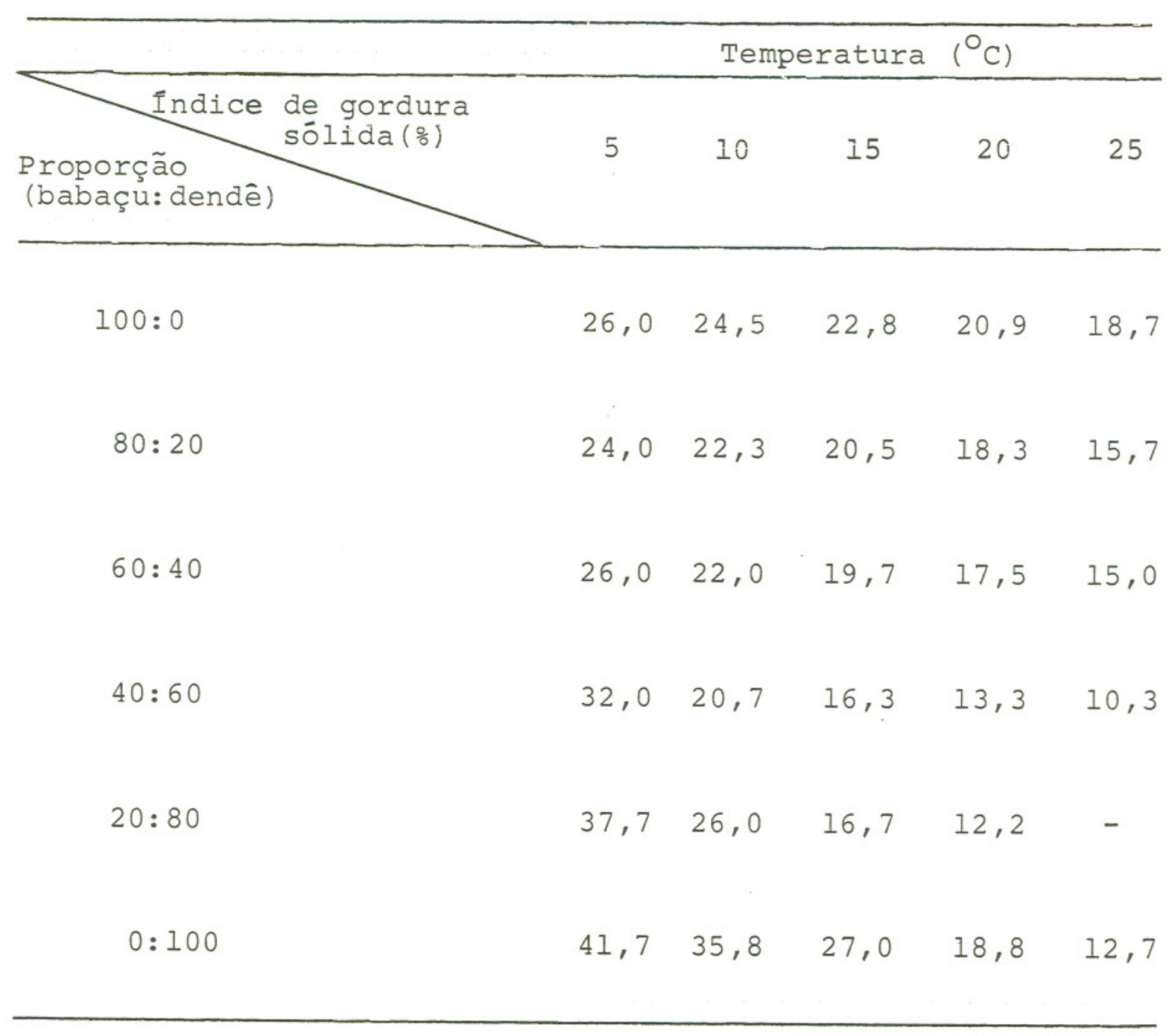




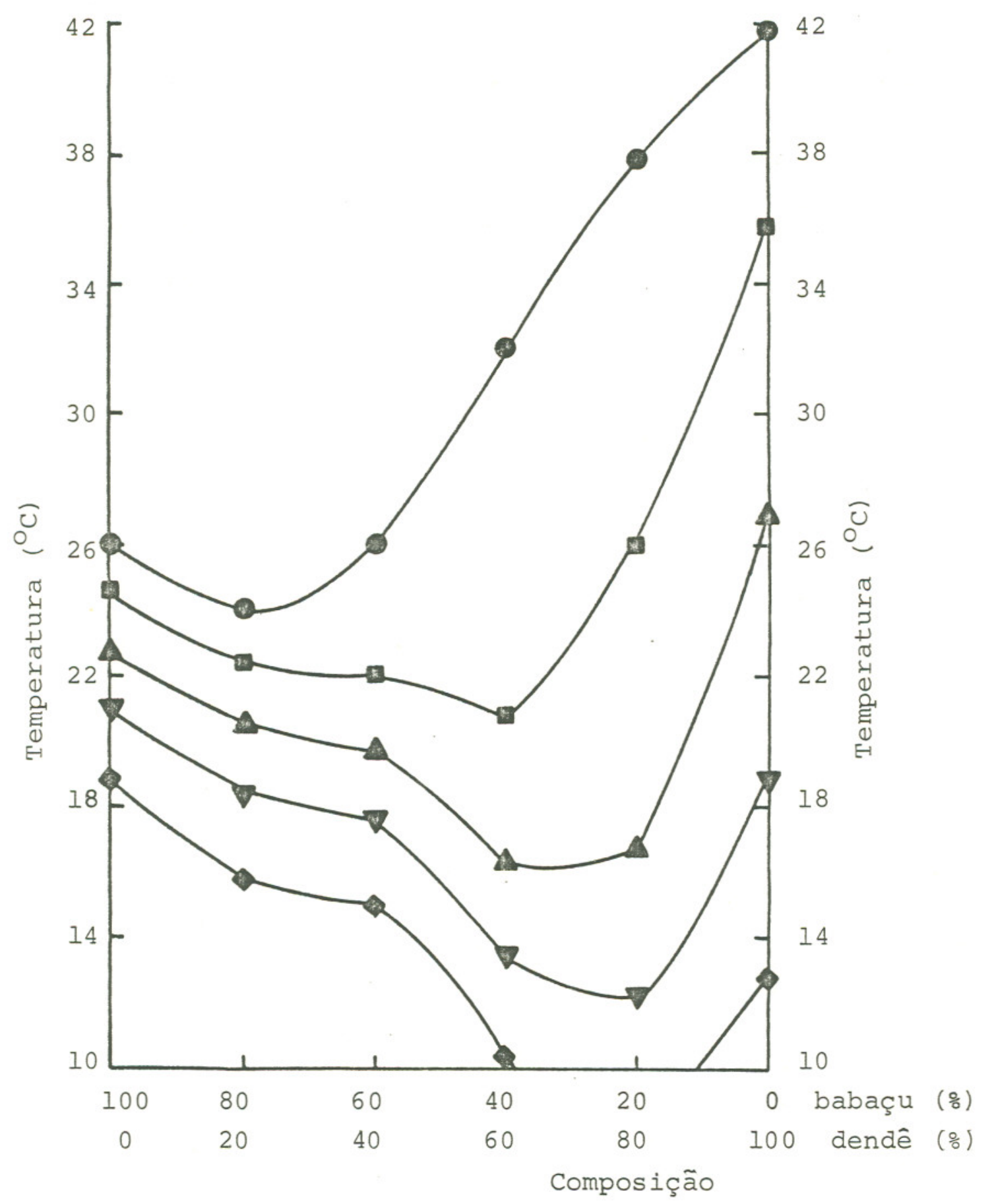

FIGURA 40. Diagrama de curvas iso-sólidas da mistura de babaçu e dendê neutralizado rearranjados iso ladamente.
(C) $5 \%$ sōlidos
(a) $10 \%$.
(A) 15\%.
( $\boldsymbol{\nabla}) 20 \%$.
() $25 \%$ 
Em função dos resultados obtidos, princi palmente com relação aos pontos de fusão e de amolecimento, foram escolhidas duas gorduras: 0 azeite de dendê neutro re arranjado e a mistura de $20 \%$ de babaçu para $80 \%$ de dendê rearranjados isoladamente.

Os resultados da adição do óleo de soja ao azeite de dendê neutralizado interesterificado estão nas tabelas 34 e 35 e nas figuras 41 e 42 .

Os resultados da adição do óleo de soja à mistura de $20 \%$ de babaçu para $80 \%$ de dendê rearranjados isoladamente estão nas tabelas 36 e 37 e nas figuras 43 e 44 .

Em ambos os casos procurou-se chegar a bases com a maior quantidade possível de óleo de soja e que estivessem dentro de faixas de variação de margarinas cremosas comerciais brasileiras (36). Estas são relacionadas a seguir:

\section{Faixa de variacão Média}

Ponto de fusão $\left({ }^{\circ} \mathrm{C}\right)$

Ponto de amolecimento $\left({ }^{\circ} \mathrm{C}\right)$

Indice de gordura sólida (\%)

$10^{\circ} \mathrm{C}$
$20^{\circ} \mathrm{C}$
$25^{\circ} \mathrm{C}$
$30^{\circ} \mathrm{C}$
$35^{\circ} \mathrm{C}$
$40^{\circ} \mathrm{C}$

$$
\begin{array}{ll}
36,5-39,5 & 37,4 \\
31,5-35,3 & 33,5
\end{array}
$$

$\begin{array}{rr}11,0-20,0 & 16,2 \\ 7,0-13,6 & 10,7 \\ 6,0-10,5 & 8,5 \\ 3,7-6,5 & 5,0 \\ 1,5-3,1 & 2,1 \\ 0 & 0\end{array}$


TABELA 34. Pontos de fusão e de amolecimento de misturas em proporções variáveis de azeite de dendê neutralizado rearranjado e óleo de soja

\begin{tabular}{|c|c|c|}
\hline $\begin{array}{c}\text { Proporção } \\
\text { (dendē: soja) }\end{array}$ & $\begin{array}{c}\text { Ponto de } \\
\text { fusão } \\
\left({ }^{\circ} \mathrm{C}\right)\end{array}$ & $\begin{array}{c}\text { Ponto de } \\
\text { amolecimento } \\
\left({ }^{\circ} \mathrm{C}\right)\end{array}$ \\
\hline $100: 0$ & 43,6 & 38,6 \\
\hline $80: 20$ & 42,0 & 37,0 \\
\hline $60: 40$ & 40,0 & 34,0 \\
\hline $50: 50$ & 38,2 & 34,8 \\
\hline $40: 60$ & 36,6 & 29,2 \\
\hline $20: 80$ & 24,6 & 20,4 \\
\hline
\end{tabular}


121.

TABELA 35. Indices de gordura sölida de misturas em proporções variáveis de azeite de dendê neutralizado rearranjado e óleo de soja

\begin{tabular}{|c|c|c|c|c|c|c|c|c|}
\hline \multirow{2}{*}{$\begin{array}{l}\text { Proporção } \\
\text { (dendê: soja) }\end{array}$} & \multicolumn{8}{|c|}{ Indice de gordura sólida (\%) } \\
\hline & $10^{\circ} \mathrm{C}$ & $15^{\circ} \mathrm{C}$ & $20^{\circ} \mathrm{C}$ & $25^{\circ} \mathrm{C}$ & $30^{\circ} \mathrm{C}$ & $35^{\circ} \mathrm{C}$ & $40^{\circ} \mathrm{C}$ & $45^{\circ} \mathrm{C}$ \\
\hline $100: 0$ & 28,3 & 23,2 & 18,9 & 16,1 & - & 10,6 & - & 0 \\
\hline $80: 20$ & 17,7 & - & 10,5 & 9,3 & 7,5 & 5,5 & 4,3 & 0 \\
\hline $60: 40$ & 12,5 & - & 7,5 & 6,5 & 5,1 & 3,6 & 0 & - \\
\hline $50: 50$ & 8,6 & - & 5,1 & 4,6 & 3,6 & 2,7 & 0 & - \\
\hline $40: 60$ & 6,3 & - & 3,9 & 3,3 & 3,4 & 2,9 & 0 & - \\
\hline $20: 80$ & 2,9 & - & 2,1 & 0 & - & - & - & - \\
\hline
\end{tabular}


122.

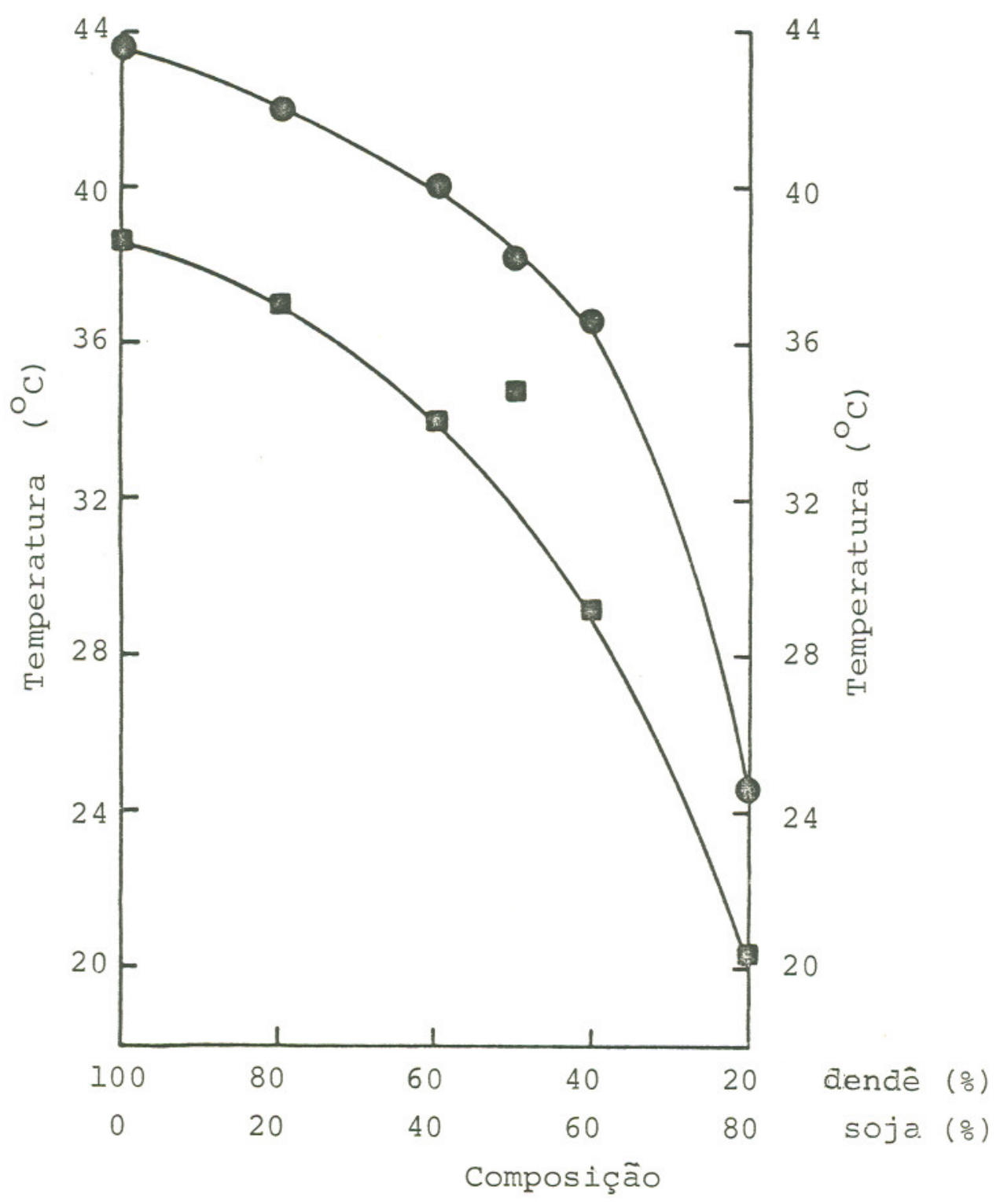

FIGURA 41. Diagrama da mistura de dendê neutralizado rearranjado e óleo de soja em função da temperatura.

(O) ponto de fusão

( ) ponto de amolecimento 


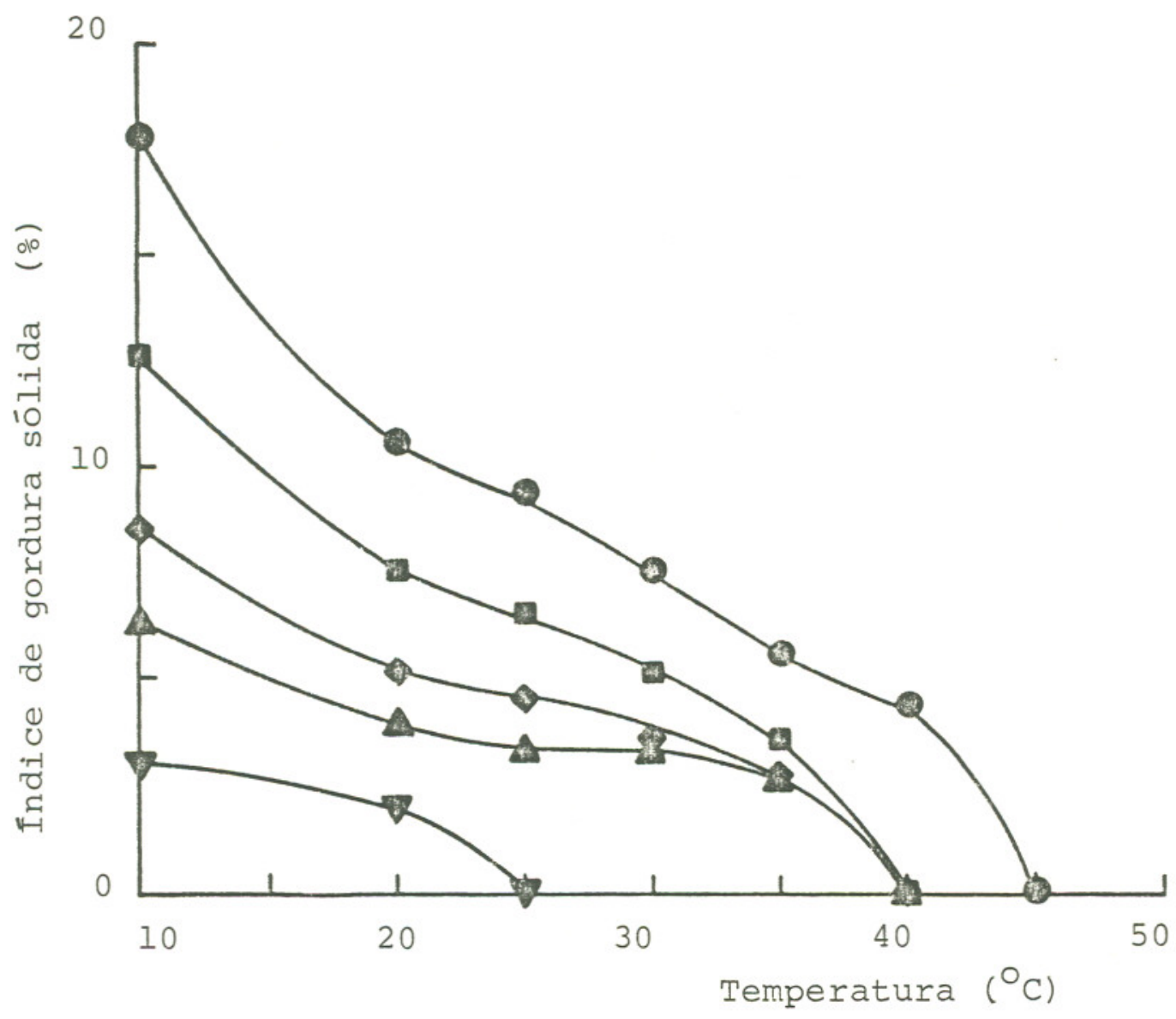

FIGURA 42. Curvas de sólidos de misturas de dendê neutralizado rearranjado e óleo de soja.
(P) $80: 20$
(घ) $60: 40$
(४) 50:50

(A) $40: 60$

( $\boldsymbol{\nabla}$ ) 20:80 
TABELA 36. Pontos de fusão e de amolecimento de babaçu e dendê neutralizado rearranjados isoladamente (20:80) em mistura com proporções variáveis de óleo de soja

\begin{tabular}{|c|c|c|}
\hline $\begin{array}{c}\text { Proporção } \\
\text { (babaçu/denđê: soja) }\end{array}$ & $\begin{array}{c}\text { Ponto de } \\
\text { fusão } \\
\left({ }^{\circ} \mathrm{C}\right)\end{array}$ & $\begin{array}{c}\text { Ponto de } \\
\text { amolecimento) } \\
\left({ }^{\circ} \mathrm{C}\right)\end{array}$ \\
\hline $100: 0$ & 42,4 & 35,4 \\
\hline $80: 20$ & 40,6 & 32,6 \\
\hline $70: 30$ & 39,8 & 32,6 \\
\hline $60: 40$ & 39,4 & 30,8 \\
\hline $40: 60$ & 36,0 & 28,2 \\
\hline $20: 80$ & 22.4 & 16,2 \\
\hline
\end{tabular}


TABELA 37. Indices de gordura sólida de babaçu e dendê neutralizado rearranjados isoladamente (20:80) em mistura com proporções variāveis de óleo de soja

\begin{tabular}{|c|c|c|c|c|c|c|c|}
\hline \multirow{2}{*}{$\begin{array}{c}\text { Proporção } \\
\text { (babaçu/dendê: soja) }\end{array}$} & \multicolumn{7}{|c|}{ Indice de gordura sólida (하) a } \\
\hline & $10^{\circ} \mathrm{C}$ & $20^{\circ} \mathrm{C}$ & $25^{\circ} \mathrm{C}$ & $30^{\circ} \mathrm{C}$ & $35^{\circ} \mathrm{C}$ & $40^{\circ} \mathrm{C}$ & $45^{\circ} \mathrm{C}$ \\
\hline $100: 0$ & 22,7 & 11,5 & 10,5 & 8,0 & 5,6 & 4,2 & 0 \\
\hline $80: 20$ & 16,2 & 7,7 & 7,0 & 5,1 & 3,1 & 0 & - \\
\hline $70: 30$ & 12,9 & 6,3 & 5,4 & 3,6 & 2,5 & 0 & - \\
\hline $60: 40$ & 10,7 & 5,5 & 4,9 & 3,2 & 2,5 & 0 & - \\
\hline $40: 60$ & 4,8 & 2,2 & - & 1,7 & 1,0 & 0 & - \\
\hline $20: 80$ & 1,7 & 0,7 & 0 & - & - & - & - \\
\hline
\end{tabular}




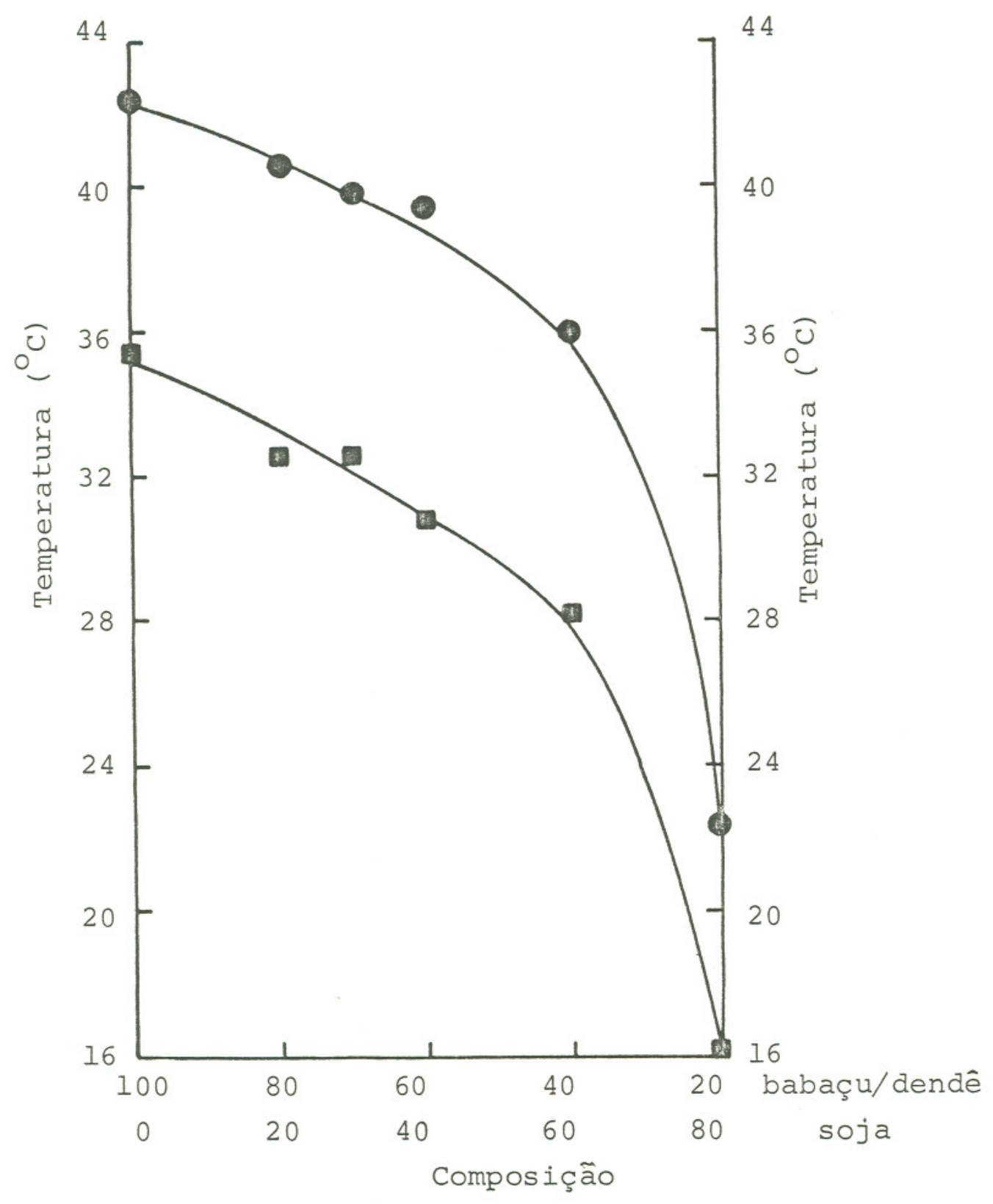

FIGURA 43. Diagrama de babaçu e dendê neutralizado rearranjados isoladamente $(20: 80)$ em mistura com óleo de soja em função da temperatura.

(1) ponto de fusão

(a) ponto de amolecimento 
127.

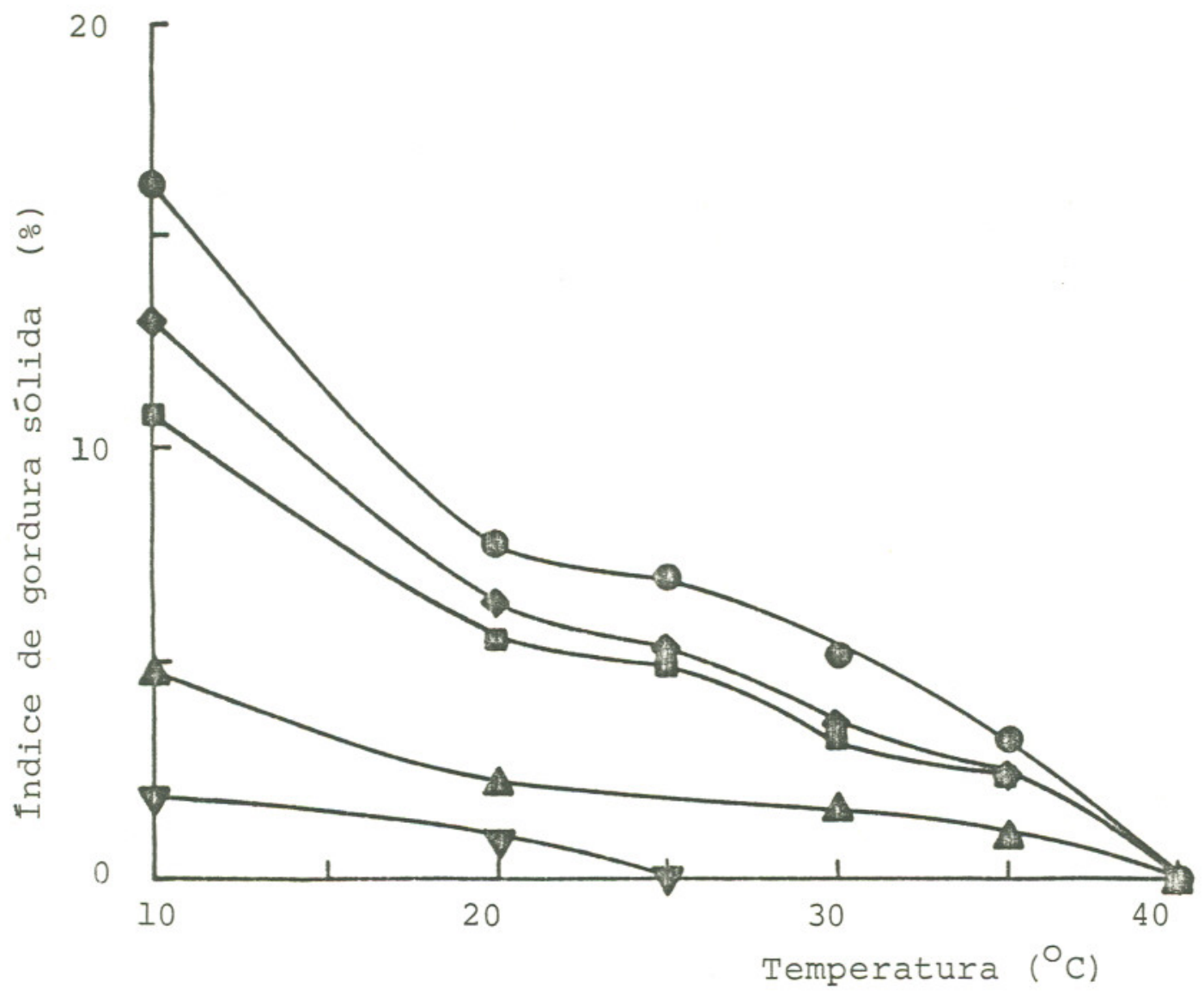

FIGURA 44. Curvas de sólidos de babaçu e dendê neutralizado rearranjados isoladamente $(20: 80)$ em mis tura com óleo de soja.
(C) $80: 20$
$(\bullet) 70: 30$
(a) $60: 40$
(A) $40: 60$
( 7 ) $20: 80$ 
azeite de dendê neutralizado rearranjado e óleo de soja foi aquela correspondente à proporção respectiva de 60:40. Esta foi a que melhor se colocou frente aos padrões considerados. Apenas o ponto de fusão apresentou-se $0,5^{\circ} \mathrm{C}$ acima do limite máximo e o Indice de gordura sólida, a $35^{\circ} \mathrm{C}, 0,5 \%$ tam bém acima. Na proporção de 50:50, a base correspondeu quanto aos pontos de fusão e de amolecimento. Entretanto, apenas o Indice de gordura sólida a $35^{\circ} \mathrm{C}$ obedeceu ao padrão res pectivo.

A base selecionada entre as composições babaçu/dendê rearranjados isoladamente $(20: 80)$ e óleo de so ja foi aquela correspondente à proporção respectiva de 70:30. 0 ponto de fusão apresentou-se $0,3^{\circ} \mathrm{C}$ acima do limite máximo e os Indices de gordura sólida a $20^{\circ} \mathrm{C}, 25^{\circ} \mathrm{C}$ e $30^{\circ} \mathrm{C}$ ligeira mente abaixo do limite minimo. Na proporção de 60:40 o ponto de amolecimento foi inferior ao minimo e a aproximação entre os diversos indices de gordura sólida não foi tão boa.

As bases selecionadas foram analisadas quanto à composição em ácidos graxos, cujos resultados encon tram-se na tabela 38 .

A base composta por azeite de dendê interesterificado e óleo de soja contém 33,4\% de poli-insatura dos, 24,8\% de saturados e apresenta relação poli-insatura dos/saturados igual a 1,4 .

A base composta por gordura de babaçu e azeite de dendê interesterificados e óleo de soja contēm 25,2\% de poli-insaturados, $33,1 \%$ de saturados e apresenta re 
TABELA 38. Composição em ácidos graxos das bases gordurosas selecionadas para preparação de margarinas.

\begin{tabular}{|c|c|c|}
\hline \multirow{2}{*}{ Ácido graxo } & \multicolumn{2}{|c|}{$\%$ em massa } \\
\hline & denđêe:soja & babaçu/dendê: sojab \\
\hline $\mathrm{C}_{8}$ & - & 0,9 \\
\hline$C_{10}$ & - & 0,8 \\
\hline$C_{12}$ & $\mathrm{TR}$ & 4,5 \\
\hline$C_{14}$ & 0,6 & 2,5 \\
\hline$C_{16}$ & 21,0 & 21,4 \\
\hline $\mathrm{C}_{18}$ & 3,2 & 3,0 \\
\hline$C_{18: 1}$ & 41,8 & 41,7 \\
\hline$C_{18: 2}$ & 29,8 & 22,5 \\
\hline$C_{18: 3}$ & 3,6 & 2,7 \\
\hline
\end{tabular}

a dendê neutro rearranjado e soja na proporção respectiva de 60:40

b babaçu e dendê neutro rearranjados isolada mente (20:80) e soja na proporção respectiva de $70: 30$. 
lação poli-insaturados/saturados igual a 0,8.

Os valores da relação poli-insaturados / saturados, quando comparados aos de margarinas comerciais $(36,54,55,89)$ podem parecer baixos. Entretanto, considerando que a interesterificação não produz isômeros trans $(54,55)$, estes valores são reais. Para gorduras hidrogenadas, a verdadeira relação poli-insaturados cis-cis/saturados é menor (66).

4. PREPARAÇÃO DE MARGARINAS

As duas margarinas preparadas a partir das bases selecionadas foram analisadas quanto à consistência a $10^{\circ} \mathrm{C}$.

Para a margarina proveniente da base for mada por azeite de dendê rearranjado e óleo de soja não foi possível a determinação, visto estar excessivamente cremosa. Para a margarina proveniente da base formada por gordura de babaçu e azeite de dendê rearranjados e óleo de soja a pe netração do cone foi igual a $270 \mathrm{~mm} / 10$. Considerando que margarinas cremosas normais estão num intervalo de 160 a 180 mm/10 de penetração, esta segunda margarina obtida experi mentalmente também estava pouco consistente.

Como as bases gordurosas estudadas, do ponto de vista analítico, estão dentro de padrões comerciais normais, há duas possibilidades.

A primeira seria decorrente da tēcnica de preparação, principalmente relacionada com o resfriamento e cristalização não estar compativel com as gorduras utilizạ 
das. Nas duas bases, predomina o azeite de dendê que apresenta cristalização na forma $\beta$-prima (91), sendo esta a estrutura polimórfica mais adequada para margarinas. No entan to, sua cristalização é mais lenta (38), o que exigiria modificação na fase de resfriamento e cristalização.

A segunda possibilidade seria, mantendo a técnica de preparação, alterar os padrões a serem seguidos, principalmente o Indice de gordura sólida. Isto è decorrente do fato de as margarinas comerciais tomadas como pa râmetro serem à base de óleo de soja (36), que cristaliza-se na forma $\beta$ (91).

A partir dos resultados até aqui obtidos, pode-se considerar que o processo de interesterifica ção, visando a fabricação de margarinas a partir de óleos e gorduras de produção nacional, è uma solução alternativa viāvel à hidrogenação de óleos vegetais. 
132 .

\section{CONCLUSÕES}

- A neutralização do azeite de dendê aumentou os pontos de fusão e de amolecimento e o indice de gordura sólida.

- As reações de interesterificação eleva ram os pontos de fusão e de amolecimento das amostras.

- o rearranjo aumentou a plasticidade das gorduras.

- As misturas de gordura de babaçu e azeite de dendê neutralizado formaram sistema eutético. A proporção de $20 \%$ de babaçu para $80 \%$ de dendê foi a mais próxima da composição eutética.

- O rearranjo promoveu aumento no teor de triglicérides tri-saturados.

- o processo de interesterificação diminuiu a estabilidade das gorduras à oxidação.

- As composições estudadas, com a maior quantidade possível de óleo de soja, que melhor se enqua draram frente aos padrões de bases gordurosas de margari 
nas cremosas comerciais brasileiras foram as seguintes:

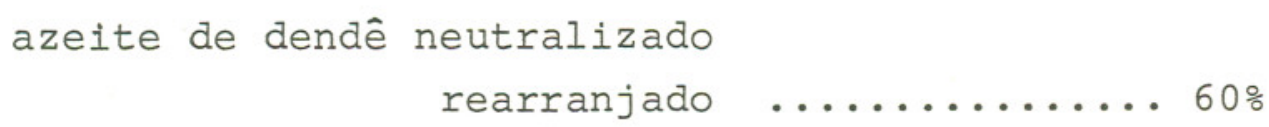

- A base composta por azeite de dendê e óleo de soja atendeu às recomendações nutricionais mencionadas.

- A base composta por azeite de dendê, gordura de babaçu e óleo de soja não atendeu às recomendạ ções nutricionais quanto ao teor máximo de ácidos graxos saturados e à relação minima poli-insaturados/saturados.

- o processo de interesterificação se constitui em alternativa viāvel à hidrogenação de óleos vegetais, visando a produção de margarina. 


\section{REFERENCIAS BIBLIOGRAFICAS}

1. ALFIN-SLATER, R.B.; AFTERGOOD, L.; HANSEN, H.; MORRIS,R. S.; MELNICK, D.; GOODING, C.M. - Nutritional evaluation of inter-esterified fats. J. Am. Oil Chem. Soc., Chicago, $\underline{43}(2): 110-2,1966$.

2. ALPHen, J. van - Hippolyte Mège Mouriès. In: StuYvenberG, J.H. van,ed. - Margarine: an economic, social and scientific history 1869-1969. Toronto, University of Toronto Press, 1969. p. 5-7.

3. AMERICAN OIL CHEMISTS' SOCIETY. Official and tentative methods of analysis. 3.ed. Champaign, 1978. Cd 8-53.

4. AMERICAN OIL CHEMISTS' SOCIETY. Official and tentative methods of analysis. 3.ed. Champaign, 1978. Cc 1-25, Cc 3-25.

5. AMERICAN OIL CHEMISTS' SOCIETY. Official and tentative methods of analysis. 3.ed. Champaign, 1978. Cd 10-57.

6. AMERICAN OIL CHEMISTS' SOCIETy. Official and tentative methods of analysis. 3.ed. Champaign, 1978. Cc $16-60$.

7. ANDERSEN, A.J.C. \& WILLIAMS, P.N. - Margarine. 2.ed. Oxford, Pergamon Press, 1965. p. 21-160.

* De acorcoo com as normas preconizadas pela ASSOCIAÇÃO BRASILEIRA DE NORMAS TECNICAS (ABNT). As abreviaturas dos tîtulos dos periódicos estão de acordo com ○ CHEMICAL ABSTRACTS SERVICE SOURCE IN DEX (CASSI), Columbus, 1980. 
8. APPLEWHItE, T.H. - Nutritional effects of hydrogenated soya oil. J.Am.Oil Chem.Soc., Chicago, 58(3):260 - 9, 1981.

9. BABAÇU: ○ fim da resistencia do coco. Quím. Deriv., são Paulo, 99:32-8, 1974 .

10. BARUfFALDI, R.; FEDELI, E.; CORTESI, N. - Pesquisa sobre gordura de Virola surinamensis. I. Composição acídica, glicerídica e natureza quimica de alguns componentes do insaponificável. Rev. Farm. Bioquím. Univ. São Pau10, $13(1): 91-102,1975$.

11. BARUFFALDI, R.; GIOIELLI, L.A.; SCHUCH, R. - Efeito da degomagem na estabilidade do óleo de soja. Rev. Farm. Bioquím. Univ. São Paulo, $16(1 / 2): 112-121,1980$.

12. BARUfFAld, R.; TSUKUDA, S.; COLOMBO, A.J. - Estabilidade do óleo de girassol helianthus aureus L. - Ação de alguns antioxidantes. Rev. Farm. Bioquím. Univ. São $\underline{\text { Paulo, }} 14(2): 127-44,1976$.

13. BERNHARD, H.R.H. - Opening ceremonies. J. Am. Oil. Chem. Soc, Chicago, 60 (2):137A-40A, 1983.

14. BESSLER, T.R. \& ORTHOEFER, F.T. - Providing lubricity in food fat systems. J.Am. Oil Chem. Soc, Chicago, 60 (10):1765-8, 1983.

15. BEZARD, J. \& BUGAUT, M. - Gas-liquid chromatography of fatty acids and triglycerides from rat adipose tissue. J. Chromatogr. Sci., Niles, $\underline{7}(10): 639-44,1969$. 
16. BOELHOUWER, C. - Trends in the chemistry and technology of lipids. J. Am. Oil Chem.Soc., Chicago, 60(2):409A-14A, 1983 .

17. BROCKERHOFF, H. - Stereospecific analysis of triglycerides. Lipids, Champaign, $\underline{6}(12): 942-56,1971$.

18. BUGAUT, M. \& BEZARD, J. - Comparaison de la structure gly céridique des huiles de coprah et de palmiste. I. Acides gras totaux et groupes de triglycérides. Oléagineux, Paris, $32(6): 277-82,1977$.

19. CAMARA, G.M.S.; GODOY, O.P.; MARCOS FILHO, J.; D'ARCE,M. A.B.R. - Soja - Produção, pré-processamento e transformação agroindustrial. São Paulo, Fundação de Estudos Agrários Luiz de Queiroz, 1982. p. 53-99.

20. COCKS, L.V. \& REDE, C. van - Laboratory handbook for oil and fat analysts. London, Academic Press, 1966. p.3359 .

21. COENEN, J.W.E. - Fractionnement et interestērification des corps gras dans la perspective du marché mondial des matières premières et des produits finis. II. Interestērification. Rev. Fr. Corps Gras, Paris, $21(7)$ : 403-13, 1974 .

22. COENEN, J.W.E. - Modification of oils and fats. In: MORTON, I. ed. \& RHODES, D.N.,ed. - The contribution of chemistry to food supplies. London, Butterworths, 1974. p.15-54.

23. COENEN, J.W.E. - Hydrogenation of edible oils. J.Am. Oil Chem.Soc., Chicago, 53(6):382-9, 1976. 
24. COLEMAN, M.H. - The structural investigation of natural fats. Adv. Lipid Res., 1:1-64, 1963.

25. COMISSÃO NACIONAL DE NORMAS E PADRÕES PARA ALIMENTOS Resolução no 22/77. Diārio Oficial da União, 07 set. 1977, p. 11807-10.

26. CORnEliUS, J.A. - Palm oil and palm kernel oil. Prog. Chem. Fats Other Lipids, Oxford, 15(1):5-27, 1977.

27. DASGUPtA, J.; ADHIKARI, S.; CHAKRABARTY, M.M.; BHATTACHA RYYA, D. - Glyceride composition in interesterified fats. Fette, Seifen, Anstrichm., Hamburg, 84(3):1114,1982 .

28. DUTERTRE, R. - Méthodes analytiques applicables au contrô le de l'estérification et de l'interestérification. Rev. Fr. Corps Gras, Paris, 23(10):547-56, 1976.

29. ERICKSON, D.R. - Soybean oil: update on number one. J.Am. Oil Chem. Soc., Chicago, 60(2):303A-8A, 1983.

30. FARMACOPÉIA brasileira. 3.ed. São Paulo, Organização Andrei, 1977. p. 981.

31. FATS, oils production on the rise. J.Am. Oil Chem.Soc., Chicago, 61(8):1298-1314, 1984 .

32. FAUR, L. - L'interestérification. Applications dans le domaine alimentaire. Rev. Fr. Corps Gras, Paris, 24(2): $85-91,1977$.

33. GANDER, K.F. - Margarine oils, shortenings, and vanaspati. J. Am. Oil Chem. Soc., Chicago, 53 (6):417-20,1976. 
34. GIOIELLI, L.A.; BARUFFALDI, R.; SCHUCH, R. - Avaliação da velocidade de esterificação de ácidos graxos com glicerol. Bol. Soc. Bras. Ciênc. Tecnol. Aliment., Cam pinas, $17(2): 147-58,1983$.

35. GIOIELLI, L.A.; BARUFFALDI, R.; SCHUCH, R. - Distribuiição de ácidos graxos em relação ao glicerol durante o pro cesso de esterificação. Rev. Farm. Bioquím. Univ. São Paulo, $20(1): 44-50,1984$.

36. GIOIELLI, L.A.; BARUfFALDI, R.; SCHUCH, R.; OTAKI, E. Caracterização de margarinas brasileiras. Bol. Soc. Bras. Ciênc. Tecnol. Aliment., Campinas, 17(4):369-79, 1983 .

37. GREENWELL, B.A. - Chilling and crystallization of shortenings and margarines. J. Am. Oil Chem. Soc., Chicago, $\underline{58}(3): 206-7,1981$.

38. HAIGHTON, A.J. - Blending, chilling, and tempering of mar garines and shortenings. J.Am. Oil Chem. Soc., Chica go, $\underline{53}(6): 397-9,1976$.

39. hARTMAN, L. \& ESTEVES, W. - Tecnologia de óleos e gorduras vegetais. In: FUNDAÇÃO TROPICAL DE PESQUISAS E TECNOLOGIA - Tecnologia agro-industrial. São Paulo, 1982 , p. 1-10.

40. HARTMAN, L. \& LAGO, R.C.A. - Rapid preparation of fatty acid methyl esters from lipids. Lab. Pract., London, 22:475-6, 494, 1973 . 
41. HILDITCH, T.P. \& WILLIAMS, P.N. - The chemical constitution of natural fats. 4.ed. London, Chapman \& Hall, 1964. p. 341 .

42. HUStedt, H.H. - Interesterification of edible oils. J. Am. Oil Chem. Soc., Chicago, 53(6):390-2, 1976.

43. INSTITUTO ADOLFO LUTZ - Normas analiticas do Instituto Adolfo Lutz. 2.ed. São Paulo, 1976. v.1, p. 188-9.

44. InStituto ADOLFO LUTz - Normas analiticas do Instituto Adolfo Lutz. 2. ed. São Paulo, 1976. v.1, p. 189-90. 45. JACOSBERG, B. \& HO, O.C. - Studies in palm oil crystallization. J. Am. Oil Chem. Soc., Chicago, 53(10):609-17, 1976.

46. KREULEN, H.P. - Fractionation and winterization of edible fats and oils. J.Am. Oil Chem. Soc., Chicago, 53(6): 393-6, 1976.

47. KUKSIS, A. - Newer developments in determination of structure of glycerides and phosphoglycerides. Prog. Chem. Fats Other Lipids, Oxford, 12:1-163, 1972.

48. LANGSTRAAT, A. - Characteristics and composition of vegetable oil-bearing materials. J.Am. Oil Chem. Soc., Chicago, $\underline{53}(6): 241-7,1976$.

49. LASZLO, H.; MASSA, M.H.L. de M.; PEREIRA, D.A. - Ocorrência de ácidos trans em produtos gordurosos comerciais brasileiros. Bol. Téc. Div. Tecnol. Agric. Aliment., Rio de Janeiro, $\underline{3}: 255-64,1970$. 
50. LAU, F.Y.; HAMMOND, E.G.; ROSS, P.F. - Effect of randomization on the oxidation of corn oil. J. Am. Oil. Chem. Soc., Chicago, 59(10):407-11, 1982.

51. LEFEBVRE, J. - Finished product formulation. J.Am. Oil Chem. Soc., Chicago, 60(2):247A-52A, 1983.

52. LEFEBVRE, J. - Formulation et gestion de la qualité en margarinerie. Rev. Fr. Corps Gras, Paris, 30(2):59-65, 1983.

53. LILLARD, D.A. - Effect of processing on chemical and nutritional changes in food lipids. J. Food Prot., Ames, $\underline{46}(1): 61-7,1983$.

54. LIST, G.R.; EMKEN, E.A.; KWOLEK, W.F.; SIMPSON, T.D.; DUTTON, H.J. - "Zero trans" margarines: preparation, structure, and properties of interesterified soybean oil-soy trisaturate blends. J. Am. Oil Chem. Soc., Chicago, 54 (10):408-13, 1977 .

55. LO, Y.C. \& HANDEL, A.P. - Physical and chemical properties of randomly interesterified blends of soybean oil and tallow for use as margarine oils. J.Am. Oil Chem.Soc., Chicago, $60(4): 815-8,1983$.

56. LORUSSO, S.; PASCUCCI, E.; FEDELI, E. - Il processo

interesterificazione delle sostanze grasse: aspetti economici, tecnici ed analitici. Riv.Ital. Sostanze Grasse, Milan, 61(3):139-43, 1984 .

57. MACLELlan, M. - Palm oil. J. Am. Oil Chem. Soc., Chicago, $\underline{60}(2): 320 \mathrm{~A}-5 \mathrm{~A}, 1983$. 
58. MACRAE, A.R. - Lipase-catalyzed interesterification

oils and fats. J. Am. Oil Chem. Soc., Chicago, 60(2): $243 \mathrm{~A}-6 \mathrm{~A}, 1983$.

59. MANI, V.V.S. \& LAKSHMINARAYANA, G. - Pancreatic hydroly sis of four seed fats and calculation of the glyceride compositions using a computer. Fette, Seifen, Anstrichm., Hamburg, $\underline{72}(6): 434-8,1970$.

60. MARGARINE output rises. J. Am. Oil Chem. Soc., Chicago, 61 111$): 1672,1984$.

61.MASSIELO, F.J. - Changing trends in consumer margarines. J. Am. Oil Chem. Soc., Chicago, 55(2):262-5, 1978.

62. MASSON, L. - Relative nutritional value of various dietary fats and oils. J.Am. Oil Chem. Soc., Chicago, 58(3): $249-55,1981$.

63. MATTIL, K.F. - Hydrogenation. In: SWEERN, D., ed. - Bayley's industrial oil and fat products. 3.ed. New York, Interscience, 1964. p. 793-896.

64. MATTSON, F.H. \& VOLPENHEIN, R.A. - The use of pancreatic lipase for determining the distribution of fatty acids in partial and complete glycerides. J. Lipid Res., New York, 2 $(1): 58-62,1961$.

65. MORDRET, F. \& HELME, J.P. - Les lipides. Composition et structure glycéridique. Ann. Nutr. Aliment, Paris, $\underline{29}(4): 1-47,1975$. 
66. NAZIR, D.J.; MOORECROFT, B.J.; MISHKEL, M.A. - Fatty acid composition of margarines. Am. J. Clin. Nutr., Bethesda, 29 (4):331-9, 1976.

67. OPFER, W.B. - Margarine production - a review of modern manufacturing processes. Chem. Ind., London, (18): $681-7,1978$.

68. POSORSKE, L.H. - Industrial-scale application of enzymes to the fats and oil industry. J.Am. Oil Chem. Soc., Chicago, 61(11):1758-60, 1984 .

69. RAGHUVEER, K.G. \& HAMmOND, E.G. - The influence of glyce ride structure on the rate of autoxidation. J. Am. Oil Chem. Soc., Chicago, $\underline{44}(4): 239-43,1967$.

70. RATTRAY, J.B.M. - Biotechnology and the fats and oils industry: an overview. J.Am. Oil Chem. Soc., Chicago, $61(11): 1701-12,1984$.

71. ROCHA, A.V. da \& RANGEL, P.M. - Oleaginosas no Brasil Estudo econômico. In: SIMPOSIO ANUAL DA ACIESP, 6\%, São Paulo, 1982. Anais. São Paulo, Academia de Ciên cias do Estado de São Paulo, 1982. p. 1-17.

72. ROSSELL, J.B. - Phase diagrams of triglyceride systems. Adv. Lipid Res., New York, ㅌ:353-408, 1967.

73. ROSSELL, J.B. - Interactions of triglycerides and of fats containing them. Chem. Ind., London, (9):832-5, 1973.

74. ROSSELL, J.B. - Aceites y grasas comestibles para usos especificos. Alimentaria, Madrid, 152:29-40, 1984. 
75. ROSSELL, J.B.; KING, B.; DOWNES, M.J. - Detection of adulteration. J.Am. Oil Chem. Soc., Chicago, 60 (2): $285 A-91 A, 1983$.

76. ROSSELL, J.B.; RUSSELL, J.; CHIDLEy, J.E. - Glyceride analysis of commercial fats by lipase hydrolysis. J. Am. Oil Chem. Soc., Chicago, 55(12):902-3, 1978.

77. SCHUCH, R.; BARUFFALDI, R.; GIOIELLI, L.A. - Fatty acid composition of brazilian plants. I. Stizolobium aterrimum Piper \& Tracy and Lucuma caimito Roem. seed oils. J. Am. Oil Chem. Soc., Chicago, $61(7)$ : $1207-8,1984$.

78. SEHER, A. - Hydrogenation and transesterification. In: PAOLETTI, R., ed., JACINI, G.,ed., PORCELLATI, R., ed.Lipids: Technology. New York, Raven Press, 1976. v.2, p. 527-33.

79. SOFT \& Lite, a novidade da SANBRA nas prateleiras. Atual. SANBRA, São Paulo, 82:24-5, 1984.

80. SREENIVASAN, B. - Interesterification of fats. J. Am. Oil Chem. Soc., Chicago, 55(11):796-805, 1978.

81. STIRTON, A.J. - Fat splitting, esterification, and interesterification. In: SWERN, D.,ed. - Bailey's industrial oil and fat products. 3.ed. New York, Interscience, 1964. p. 931-72.

82. SZPIZ, R.R. \& NETTO, H.C.M. - Contribuição ao estudo do óleo de babaçu. Bol. Téc. cent. Tecnol. Agríc. Aliment., Rio de Janeiro, 13:7-15, 1978. 
83. SZPIZ, R.R.; PEREIRA, D.A.; LAGO, R.C.A. - Comparação en tre óleos de três palmáceas brasileiras. Bol. Téc. Cent. Tecnol. Agric. Aliment., Rio de Janeiro, 14: $33-46,1980$.

84. TAN, B.K. \& HAMILTON, R.J. - Glyceride analysis of palm oil after solvent fractionation. J. Am. Oil

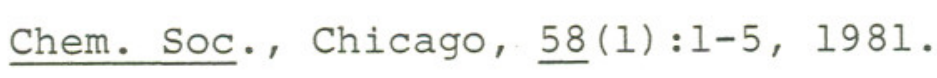

85. TANGO, J.S.; LACAZ, P.A.A.; SANTOS, L.C. dOs; TURATti,J. M.; SILVA, M.T.C.; FIGUEIREDO, I.B. de; MANTOVANI,D. M.B.; CAMPOS, S.D.S. de - Caracteristicas físicas e químicas do óleo de dendê. Bol. Inst. Tecnol. Aliment., Campinas, 18(4):509-42, 1981.

86. VANDERWAL, R.J. - Triglyceride structure. Adv. Lipid

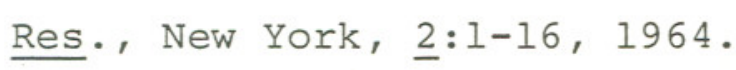

87. VASQUEZ LADRON, R. \& CASTRO RAMOS, R. de - Importancia del estudio de los diagramas de fases de los glicéridos para conocer las propiedades de las mezclas de grasas. Grasas Aceites, Seville, 23(2):132-8,1972.

88. WADA, S. \& KOIZUMI, C. - Influence of the position of insaturated fatty acid esterified glycerol on the oxi dation rate of triglyceride. J. Am. Oil Chem. Soc.' Chicago, 60 (6):1105-9, 1983.

89. WEIHRAUCH, J.L.; BRIGNOLI, C.A.; REEVES III, J.B.; IVERSON, J.L. - Fatty acid composition of margarines, pro cessed fats, and oils. Food Technol., Chicago, $31(2)$ : 80-85, 91, 1977 . 
90. WIEDERMANN, L.H. - Margarine oil formulation and control. J. Am. Oil Chem. Soc., Chicago, $4 \underline{5(9)}$ :515A, 520A-2A, $560 \mathrm{~A}, 1968$.

91. WIEDERMANN, L.H. - Margarine and margarine oil, formula tion and control. J. Am. Oil Chem. Soc., Chicago, 55(11): 823-9, 1978 .

92. WIEDERMANN, L.H. - Changes in commercial fat and oil products by the year 2000. J. Am. Oil Chem. Soc., Chicago, 60(2):400A-4A, 1983.

93. WILIIAMS, K.A. - Oils, fats and fatty foods. 4.ed. London, Churchill, 1966. p. 75-171.

94. WORLD fat and oil supplies will continue to expand during the 1982/83 marketing year. J. Am. Oil Chem.Soc., Chicago, 60 (1):61A-4A, 1983.

95. YARON, A.; TURZNYSKI, B.; SHMULINZON, C.; LETAN, A. Evaluation of transesterified hardened and liquid soybean oils as raw materials for margarine oils. Fette, Seifen, Anstrichm., Hamburg, 75(9):533-6,1973.

96. YOUNG, F.V.K. - Palm kernel and cocount oils: analytical characteristics, process technology and uses. J. Am. Oil Chem. Soc., Chicago, 60(2):326A-31A, 1983. 